\title{
TÉCNICAS DE CULTIVO E MANEJO DA ROSEIRA EM SISTEMAS DE CULTIVO SEM SOLO
}

\section{ERNESTO JOSÉ RESENDE RODRIGUES}

Engenheiro Agrônomo

Orientador: Prof. Dr. KEIGO MINAMI Co Orientador: Pesq. Dr. ENRICO FARINA

Tese apresentada à Escola Superior de Agricultura "Luiz de Queiroz", Universidade de São Paulo, para obtenção do título de Doutor em Agronomia, Área de Concentração: Fitotecnia.

\section{PIRACICABA}

Estado de São Paulo - Brasil

Abril - 1999 
Dados Internacionais de Catalogação na Publicação (CIP) DIVISĀo DE BIBLIOTECA E DOCUMENTAÇĀO - Campus "Luiz de Queiroz"/USP

Rodrigues, Ernesto José Resende

Técnicas de cultivo e manejo da roseira em sistemas de cultivo sem solo / Ernesto José Resende Rodrigues. - - Piracicaba, 1999.

84 p. : il.

Tese (doutorado) - - Escola Superior de Agricultura Luiz de Queiroz, 1999.

Bibliografia.

1. Balanço hidrico 2. Cobertura plástica 3. Enraizamento 4. Enxertia 5. Estaca 6. Hidroponia 7. Rosa 8. Sistema de cultivo 9. Soluçāo nutritiva I. Título

CDD 635.933372

4 Permitala a copia total ou parcial deste documeato, desde que citada a fonte 0 Autor" 
Aos meus pais Nolviro Rodrigues Rosa

e Onésia de Resende Rodrigues, aos

meus Avôs Antônio Resende e

Ana Pereira de Resende, e

Aos meus irmãos

e cunhados,

\section{OFEREÇO}

A minha esposa Vilma Aparecida Santos

Rodrigues e a minha filha

Sara Rodrigues 


\section{AGRADECIMENTOS}

O autor agradece a todos que direta ou indiretamente contribuiram para a realização deste trabalho, em especial:

Ao Prof. Dr. Keigo Minami pela orientação, incentivo, apoio e confiança apresentada.

Ao Pesq. Dr. Enrico Farina, do Istituto Sperimentale per la Floricoltura di Sanremo, pela preciosa e segura orientação, amizade, compreensão e convivência.

Ao Pesq. Dr. Antonio Fernando C. Tombolato, do Instituto Agronômico de Campinas, pela sua indicação e apoio para a realização do Doutorado "Sanduíche".

Ao Centro de Ensino e Desenvolvimento Agrário de Florestal - UFV, pela oportunidade concedida.

Ao Departamento de Horticultura da ESALQ, Professores, Secretárias, Funcionários e amigos, pelo apoio e incentivo.

Ao Istituto Sperimentale per la Floricoltura di Sanremo, pela oportunidade concedida, apoio e suporte para a realização dos trabalhos práticos da tese.

À Coordenação de Aperfeiçoamento de pessoal de Nível Superior (CAPES), pelo suporte financeiro.

À Assessoria de Assuntos Internacionais da Universidade Federal de Viçosa, pelo apoio institucional prestado durante a realização do curso. 


\section{SUMÁRIO}

Página

RESUMO viii

SUMMURY. $x$

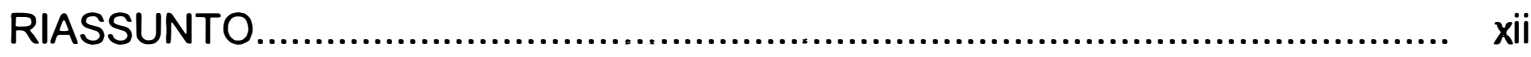

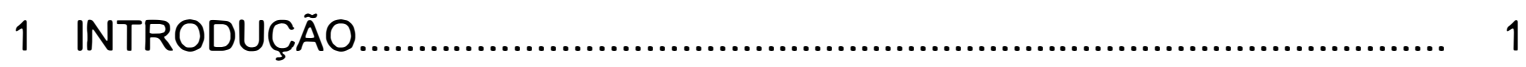

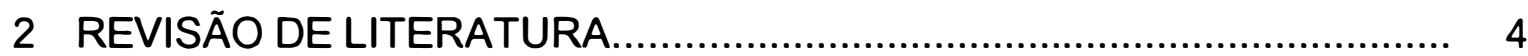

3 CULTIVO HIDROPÔNICO FECHADO DA ROSEIRA COM RECIRCULO PROLONGADO DA SOLUÇÃO NUTRITIVA E COM EMPREGO DE BAIXA TECNOLOGIA: PARAMETROS DE USO, SUPORTE INFORMATICO E RESPOSTA AGRONÔMICA....................................... 16

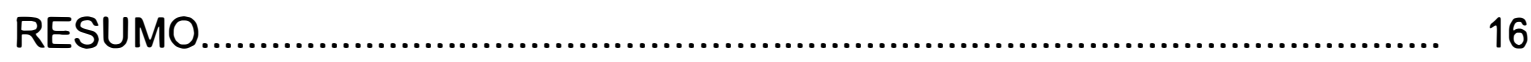

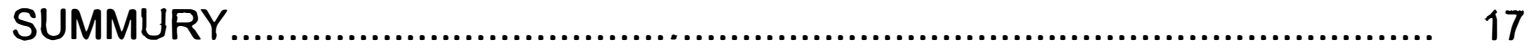

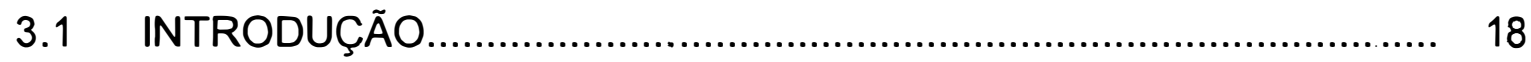

3.2 MATERIAL E MÉTODOS.............................................................. 20

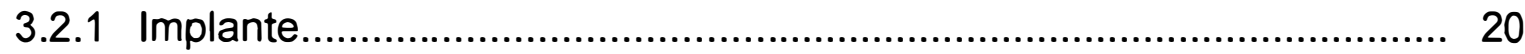

3.2.2 Substrato, material vegetal e forma de condução................................ 22

3.2.3 Parâmetros para uso deste sistema................................................ 24

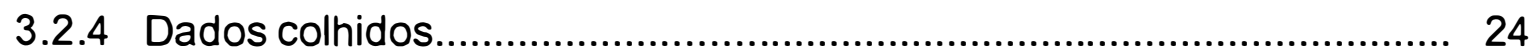

3.2.5 Avaliação do $\mathrm{pH}$ e da condutividade elétrica..................................... 25

3.3 RESULTADOS.......................................................................... 25

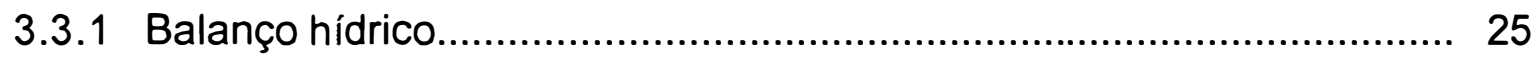

3.3.2 Balanço dos elementos fertilizantes............................................... 26

3.3.3 Produção de drenado instantâneo e em reciclagem e relação entre características do drenado instantâneo e em reciclo. 
3.3.4 Correção do drenado exaurido e composição da solução nutritiva....... 30

3.3.5 Produtividade e qualidade da produção........................................... 30

3.4 DISCUSSÃO.............................................................................. 32

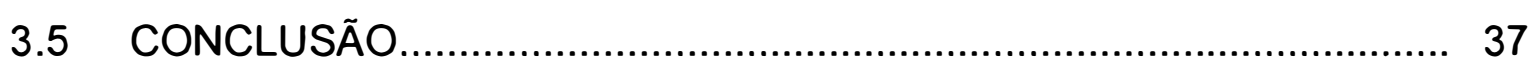

4 AVALIAÇÃO AGRONÔMICA DE ROSEIRAS PROPAGADAS POR ENXERTIA OU ENRAIZAMENTO DE ESTACAS EM CULTIVO

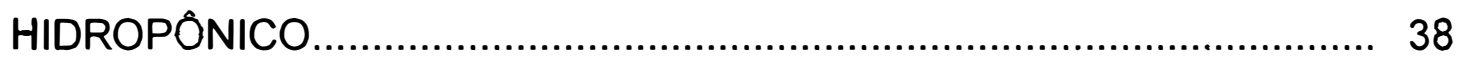

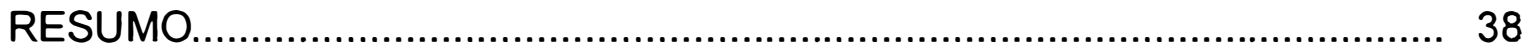

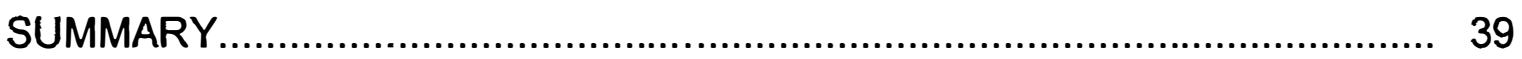

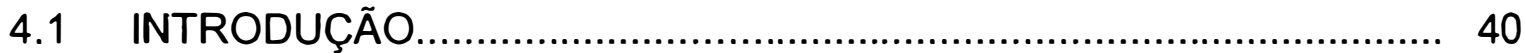

4.2 MATERIAIS E MÉTODOS ............................................................. 41

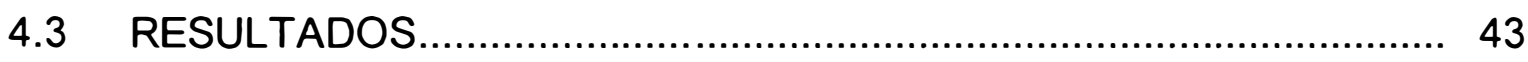

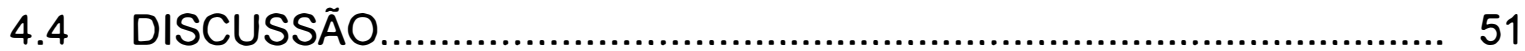

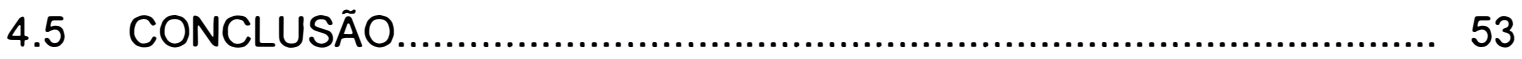

5 COBERTURA DO SUBSTRATO COM FILME PLÁSTICO EM CULTIVO SEM SOLO DA ROSEIRA ............................................................. 54

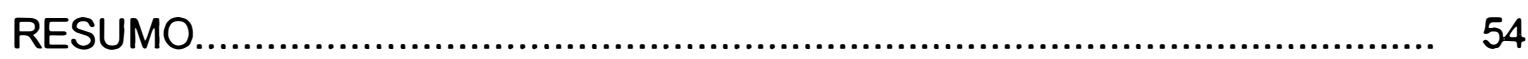

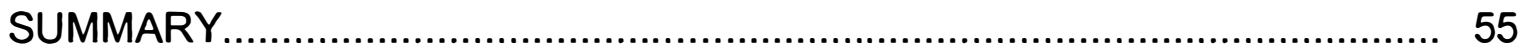

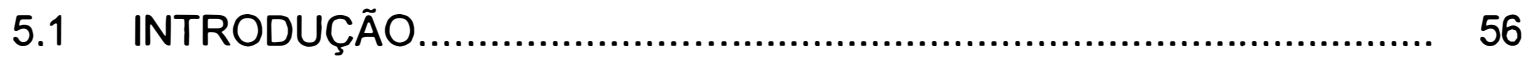

5.2 MATERIAL E MÉTODOS ........................................................... 57

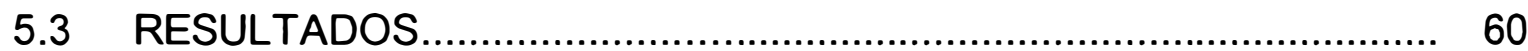

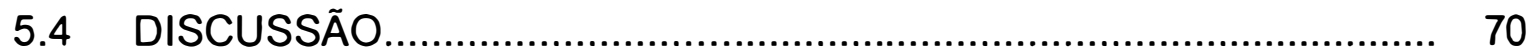

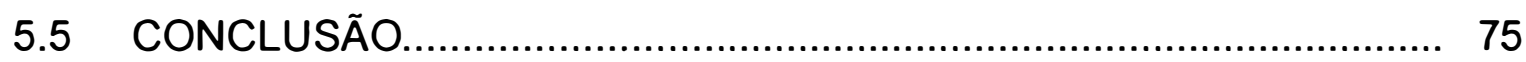

REFERÊNCIAS BIBLIOGRÁFICAS ........................................................ 76 


\title{
TÉCNICAS DE CULTIVO E MANEJO DA ROSEIRA EM SISTEMAS DE CULTIVO SEM SOLO
}

\author{
Autor: ERNESTO JOSÉ RESENDE RODRIGUES \\ Orientador: Prof. Dr. KEIGO MINAMI \\ Co Orientador: Pesq. Dr. Enrico Fariana
}

\section{RESUMO}

Foram conduzidos três experimentos sobre o cultivo sem solo da roseira. O primeiro ensaio teve como objetivo avaliar um sistema simples, para manejo dos elementos nutritivos, em sistema hidropônico fechado, e com baixo emprego de capital, compatível com propriedades de pequeno e médio porte. $O$ sistema baseia-se no emprego de uma bomba e duas caixas em terrenos de natural declividade, uma posicionada na parte mais baixa do terreno, de onde a solução nutritiva é bombeada e distribuída nos interventos de fertirrigação. Nesta pesquisa, são relatados dados de 18 meses de cultivo da roseira sem solo a ciclo fechado contínuo, parâmetros de uso do sistema, metodologias usadas, suporte de cálculo, dados do balanço hídrico/nutricional e produtividade.

No segundo ensaio foi avaliado o efeito agronômico, sobre a roseira, do uso de roseiras propagados por enxertia e propagadas por enraizamento de 
estaca, em sistema hidropônico de cultivo com substrato. Os resultados evidenciaram aumento na produção para as flores, de classe I e também para toda a produção comercial em favor das plantas enxertadas. Foram também verificados, para as plantas enxertas, aumentos da matéria fresca exportada sob forma de flores e também na matéria fresca total (flores + descarte de flores + material de poda. Após a poda de rebaixamento das plantas, feita no verão, foi verificada uma menor formação de mergulhões ou ramos de renovação, nas plantas do cv Sari oriundas de estacas enraizadas.

Foi montado um terceiro ensaio, para avaliar o efeito da cobertura do substrato, com lona plástica, sobre o balanço hídrico/nutricional e sobre o crescimento e produtividade na cultura da roseira. Como resultado do uso da cobertura do substrato, foi verificada redução do consumo hídrico e menor salinização dos substratos. O uso da cobertura do substrato permitiu uma melhoria de qualidade de flores e também ganho em produtividade, com menor consumo hídrico, resultando em maior eficiência de uso da água. A umidade no ambiente das raízes manteve-se mais estável, principalmente na superfície do substrato, comprovando o uso da cobertura do substrato como mais uma técnica para o controle da umidade e da salinidade do substrato, com redução da quantidade de drenagem e da quantidade de água e de fertilizantes administrados, com redução dos custos de produção e benefícios para o meio ambiente. 


\title{
CULTIVATION METHODS AND MANAGEMENT TECNICAL ON ROSE SOILLESS CULTURE SYSTEMS
}

\author{
Author: ERNESTO JOSÉ RESENDE RODRIGUES \\ Adviser: Prof. Dr. KEIGO MINAMI \\ Co adviser: Pesq. Dr. Enrico Farina
}

\section{SUMMARY}

In that work, it was carried out three research on the behaviour of cut rose plants produced in soilless culture. The first, the aim was to check a simple equipment suitable at the management of nutrition in a closed system compatibible with the low imputs of the small floricultural farms. Non frequent chemical analysis of nutrient levels in the drainage solution and a subsequent regeneration are proposed as a substitute of sensors for continuous adjustment of $\mathrm{pH}$ and concentration. The method was tested in a system with two tanks and one pump. One tank placed in higher position was intended for storage of exhausted nutritive solution (E.C.> $4000 \mathrm{mmS} / \mathrm{cm}$ ) and regeneration after chemical analysis. The second tank in a lower position is intended for receiving the drain after distribution to the substrate; such drain mixed with fresh nutritive solution when necessary was available for the next distribution. In case of storage of the exhausted drainage in the upper tank, a fresh nutritive solution was supplied in the lower tank and recirculated. E.C. was monitored daily in the lower tank. 
The second experiment, was investigated the effect of propagation method (rooting of cuttings or grafting on $R$. indica roostock) on growth, flower yield and flower quality of the rose cvs Anna and Sari, in soilless culture with free drainage. The plants were grown in greenhouse on raised banches filled with mixture of sand:peat $(4: 1 \mathrm{v} / \mathrm{v})$. The composition of the fertilizing solution was the same used in commercial productions. Fertigation volume was determined by volume and EC of the drainage. The Expected Leaching Fraction was 0.1 . In eighteen months of harvesting an increase of yield of flowers of class I $(I>50 \mathrm{~cm})$ was determined in the case of the grafted plants (from 17.33 to 27.95 flowers/plants for cv Anna and from 14.8 to 21.6 flowers/plants for cv Sara). Higher yield of commercial flowers qualit was obtained from grafted plants. Higher fresh matter of cut flower and of the total harvest stem + dischard material from pruning was reached by grafted plants. Higher length of flower stem was obtained from the grafted plants of the cv Anna and Sari in the case of flowers belonging to class $\|(1<50 \mathrm{~cm})$, but only for cv Anna in the case of the flowers of class I. The plants of the cr Sari propagated by cut rooting showed poor development of primary shoot (pseudo-suckers) after cut-back in july. On the whole grafted plants (minigreffe) gave higher yield and higher flower quality showing higher growth rate (fresh weight of material harvested).

The thirth experiment, was evaluated the effect of plants of rose cvs Anna and Sari grown on close soilless systems with and without mulching of black polyethylene. The plants were grown in greenhouse on raised benches filled with sand:peat $(4: 1 \mathrm{v} / \mathrm{v})$. The fertirrigation was carried out following method developed in Stituto Sperimentale per la Floricoltura di Sanremo. There was reduction in the water consumption of 35 and $16 \%$ corresponding respectively to cvs Anna and Sari with mulching. The heigher number of irrigation to reduction of the electrical conductivity level of substrate was evidenced when unmulched. The results showed significtive differences about flowers production and quality of mulched systems. Heigher efficient in the use of water caused low evaporation, and the lower electrical conductivity in the substrate. 


\title{
METODI DI ALLEVAMENTO E TECNICHE DI CONDUZIONE IN ROSA FUORI SUOLO
}

\author{
Autore: ERNESTO JOSÉ RESENDE RODRIGUES \\ Tutore: Professore Dr. KEIGO MINAMI \\ Co-tutore: Ricercatore Dr. Enrico Farina
}

\section{RIASSUNTO}

In questo lavoro, sono state condotte tre sperimentazione sulla coltivazione fuori suolo della rosa recisa. La prima, con lo scopo di trovare un sistema di conduzione semplice, a basso costo di investimento, compatibile com la realtà economica delle aziende di piccole o medie dimennsioni. II sistema è stato composto di due vasche in terreno di naturale pendenza, una inferiore dalla quale la soluzione nutritiva viene pompata e distribuita negli interventi di fertirrigazione. In questa vasca si raccolgono i drenati che vengono recircolati. Quando il volume risulta eccessivamente ridotto per effetto del consumo, si aggiunge soluzione nutritiva fresca che si miscela al dranato stesso. II ricircolo continua fino a che la soluzione nutritiva non viene giudicata più idonea sulla base dei valori di $\mathrm{pH}$ e salinità. In tal caso la soluzione. tolta dal sistema è 'parcheggiata' nella vasca superiore per l'analise chimica e successiva 
riequilibratura. La soluzione rigenerata viene poi riutilizzata secondo i criteri già citati. In questo contributo vengono fornite, in relazione a 18 mesi di coltivazione di rosa a ricircolo continuo, informazioni relative ai parametri d'uso del siltema, alle metodologie utilizzate, ai supporti di calcolo, ai dati relativi al bilancio idriconutrizionale e alla resa agronomica.

La seconda esperimentazione è stato fatto una valutazione agronomica comparata di piante di rosa propagate per radicazione di talea o innestate su $R$. indica su bancale sopraelevato riempito con sabbia: torba $=4: 1 \mathrm{v} / \mathrm{v}$, e drenato a perdere. Le fertirrigazioni sono state fatte con una soluzione completa cori macro e micro elementi. I risultati mettono in evidenza per i fiori di Classe I $(1>50 \mathrm{~cm})$ e della Classe commerciale aumenti del numero di fiori/planta sulla $\mathrm{cv}$. Sari e Anna a favore delle piante innestate. Sono state verificati per le piante innestate anche aumenti nella materia fresca asportata sotto forma di fiori nonché nella materia fresca totale (fiori + scarti di raccolta + legno di potatura). L'effetto positivo dell'innesto è stato verificato anche sulla lunghezza degli steli fiorali delle Classe I e II, con eccezione della Classe I della cv. Sari. Una minor formazione dei "maschi" di rinnovo è stata verificata per le piante da radicazione di talea della cv. Sari dopo un taglio estivo di riabbassamento della pianta.

$\mathrm{Nel}$ terzo esperimento, sono stata condutta una prova sperimentale con lo scopo di valutare l'effetto della pacciamatura sul bilancio idrico/nutrizionale e sulla crescita e produttività di una coltura di rosa. La pacciamatura è stata eseguita mediante film plastico nero di spessore $0,18 \mathrm{~mm}$. La forma di conduzione è stata la stessa del secondo sperimento. Come risultati della pacciamatura sono stati verificati riduzione nel consumo idrico pari a $35 \mathrm{e}$ $16 \%$ rispettivamente per le cv Anna e Sari. Con la pacciamatura è stato verificato anche mantenimento di un maggior livello di umidità nel substrato, contenimento dell'incremento della salinità nel substrato stesso e nei drenati con riduzione nei numeri di interventi con acqua per la correzione della salinità, riduzione nel consumo di fertilizzanti. Quando viene utilizzata la pacciamatura si 
determina un incremento nella produzione di sostanza fresca e di fiori, nonchè della qualità degli stessi. Conseguentemente aumenta l'efficienza nell'uso d'acqua. Dalla sperimentazione vengono comprovati numerosi effetti positivi della pacciamatura nel sistema fuori suolo con possibilità di benefici a livello dei costi di produzione e delle rese agronomiche. 


\section{INTRODUÇÃO}

O cultivo sem solo é uma técnica relativamente nova, que pode ser utilizada tanto nas grandes empresas agrícolas, quanto nas pequenas e médias. Se utilizada devidamente, é possível obter inúmeras vantagens, em comparação com o cultivo tradicional no solo, como o cultivo em locais, onde anteriormente não era possivel faze-lo, por exemplo, regiões desérticas ou com problemas de doenças de solo. $O$ progresso técnico está ligado diretamente aos conhecimentos de biologia das plantas, com a descoberta dos elementos essenciais, juntamente com o uso de estufas apropriadas, da climatização, controle da luz, e somada a isto, a hidrocultura. Todo esses recursos no conjunto são fundamentais para a melhoria da produtividade das culturas, com ganhos na qualidade e na quantidade. Os cultivos sem solo possibilitam também redução da mão-de-obra empregada pela possibilidade de automação de muitas operações. Um outro aspecto importante, que é levado em consideração principalmente nos países mais desenvolvidos, é a melhoria das condições do trabalho no campo agrícola, significando ganhos em termos de status social.

Os fatores de crescimento são fornecidos à planta, tanto na sua parte aérea quanto nas raízes, sendo que ao solo compete fornecê-los às raízes. 0 controle das condições do ar atmosférico exigidas pelas plantas em condições de cultivo tradicional sobre o solo e em hidroponia, é praticamente o mesmo; a grande diferença entre os dois tipos de cultivo relaciona-se à maior possibilidade de controle das condições fornecidas pelo solo. 
A hidroponia representa uma alternativa atraente, visto que, por meio de uma solução nutritiva, eliminam-se as dificuldades que impedem a manutenção do equilíbrio entre os diversos fatores de crescimento fornecidos pelo solo. Assim, utilizam-se de substratos com o meio de cultura inerte, como areia, perlita, lã de rocha, etc., substratos que atuam como armazenadores de água, nutrientes e ar e dão sustentação às plantas e, assim, facilitam que se mantenha o sistema em equilíbrio e sob controle. Portanto, possibilitam que 0 cultivo permaneça livre de problemas que normalmente afligem a agricultura convencional.

Vários sistemas de cultivos podem ser usados para a produção de rosas, desde a hidroponia, com lâminas de solução de várias espessuras, até o sistema de cultivo em substrato. Entretanto, são utilizados para o cultivo da roseira principalmente os sistemas com substratos sobre canaletas, em vasos e sobre a lã de rocha. Sistemas de cultivo sem solo que representam hoje uma técnica já consolidada nos países mais adiantados da Europa, onde já existem protocolos de cultivo à disposição de produtores, assim como estão em desenvolvimento alguns estudos para definições específicas do cultivo.

A adoção do sistema fechado requer a adoção de determinados investimentos que na maioria dos casos são elevados e incompatíveis com os pequenos e médios produtores. Esta situação é agravada pela carência de assistência técnica para tal condução, juntamente com a baixa confiabilidade dos produtores sobre a sua própria capacidade de condução do sistema fechado.

Com a utilização na hidroponia de substratos artificiais com propriedades físico / químicas como $\mathrm{pH}$, porosidade, retenção de água, etc., mais apropriadas para as culturas, resta hoje a dúvida sobre a utilização ou não de porta-enxertos como mediadores do substrato com a planta, para manter o ritmo de crescimento e a vitalidade das plantas, uma vez que a lógica de permitir uma longevidade maior das plantas já não é mais significativa para uma visão de desfrute intensivo das plantas, característico do cultivo sem solo. Uma 
outra questão a ser discutida, ao nível de cultivo sem solo, é o efeito da proteção do substrato com filme plástico sobre os substratos de cultivo e seus reflexos sobre o manejo do sistema e sobre as culturas, aspectos bastante estudados para o cultivo sobre solo natural e consagrado seu uso ao nível prático.

Dentro desta temática, foram conduzidos alguns ensaios com os seguintes objetivos gerais:

a) Avaliar o efeito agronômico, sobre a roseira, do uso de roseiras propagadas por enxertia e propagadas por enraizamento de estacas em sistema hidropônico de cultivo com substrato.

b) Avaliar o efeito da cobertura do substrato com lona plástica sobre 0 balanço hídrico/ nutricional e sobre o crescimento e produtividade na cultura da roseira.

c) Avaliar e fornecer os parâmetros e metodologias para utilização de um sistema de cultivo hidropônico com baixo emprego de tecnologias e de baixo custo e que permita reciclagem contínua da solução nutritiva, para a cultura da roseira. 


\section{REVISÃO BIBLIOGRÁFICA}

O primeiro exemplo de cultivo sem solo foi dado pelos povos astecas no México. Esta população não possuía terrenos cultiváveis, e montou um sistema bastante engenhoso para utilizar um lago existente em seu território. Foi construída uma jangada de bambu e sobre elas era colocada terra fértil retirada do fundo do lago. Sobre cada jangada eram cultivados vegetais diversos. As plantas emitiam raízes que se dirigiam para a água do lago. Para a venda de alguns produtos, as jangadas eram levadas até os mercados. Esse sistema foi usado até o final do século XIX (Vincenzoni, 1988).

As formas mais científicas de Hidrocultura iniciaram-se no século XVII. Em 1650, já se pensava que a matéria seca das plantas se formava da água. De acordo com Schubert (1981), Van Helmont pegou um grande barril e o preencheu com 200 libras $(90.72 \mathrm{Kg})$ de terra previamente seca em forno. Instalou, neste recipiente, uma estaca de salgueiro que recebeu durante 5 anos apenas água de chuva. Então tomou, novamente, o peso da terra do recipiente e observou que a diferença do peso inicial foi de 2 onças (62,5 gramas), enquanto o peso da planta tinha aumentado de $74 \mathrm{~kg}$. Concluiu, então, que a água é que fornecia os elementos necessários para o crescimento das plantas.

Sucessivamente, em 1699, Woodward formulou uma nova hipótese de que fosse a terra e não água a fornecer os elementos da matéria seca dos vegetais e, para provar isto, imaginou uma nova experiência (Mengel \& Kirkby, 1987). Em recipientes do mesmo tamanho, instalou plantas de menta em diferentes tipos de água: de chuva, de rio, de enxurrada e esgoto diluído. Observou que onde a quantidade de material sólido era maior, a produtividade 
da menta foi melhor. Concluiu, então, que não era da água que as plantas se nutriam, mas, sim do material sólido do solo. Com esse ensaio, refutou as considerações de Van Helmont.

A cultura sem solo foi retomada em 1758 por Durhamel Du Monceau. Ele fez germinar algumas sementes sobre uma espuma úmida e, quando elas emitiram as primeiras raizes, ele fixou as plantas na boca de garrafas, de modo que as raizes ficassem mergulhadas no líquido nela contida. Alguns recipientes continham água pura e outros uma solução aquosa de sais. Constatou um bom crescimento das plantas cultivadas com a solução que continha os sais e, portanto, deduziu que as plantas absorvem água mais os sais nela contidos (Vincenzoni, 1988).

Diversos pesquisadores de todo mundo estudaram os princípios desta técnica, mas a maior difusão da hidrocultura se deu com as bases da Química Orgânica Moderna, com as contribuições de Saussure, em 1804, com suas cuidadosas investigações sobre a constituição das plantas e sobre a absorção dos elementos minerais pelas raizes e de Justus von Liebig que introduziu a "lei do mínimo". Até que Sachs e Knop, em 1860 e 1865, respectivamente lançaram as primeiras receitas de solução nutritiva, em que Sachs declara que, com os seus experimentos, provou ser possivel desenvolver normalmente plantas terrestres em água, desde que sejam adicionados os nutrientes, assim como os substratos sólidos não seriam absolutamente necessários para o desenvolvimento das plantas (Steiner, 1985). Graças aos seus trabalhos, outros pesquisadores puderam determinar a concentração ótima da solução, o equilibrio mais favorável entre o diversos elementos e a necessidade das plantas com relação aos microelementos.

O primeiro a demonstrar a possibilidade de cultivo ao nivel prático, por meio desta técnica foi Gericke (1940), que publicou os resultados de seus trabalhos. Ele considerou que, se fosse possivel criar plantas em lugares onde a terra comum e o esterco não pudessem ser utilizados, ou em locais onde a jardinagem comum não fosse possivel, algo de grande e real valor teria sido 
conquistado para a humanidade. Ele cultivou tomates com grande sucesso, até atingir a altura de cerca de $8 \mathrm{~m}$. Ele batizou esta nova técnica de hidroponia e prosseguiu criando uma grande variedade de outras plantas como flores, cereais, tubérculos e frutas. A partir daí, o emprego da hidroponia espalhou-se rapidamente pelos Estados Unidos e Europa.

A etapa sucessiva no desenvolvimento desta técnica foi devida a Withrow \& Biebel (1943), que introduziram na cultura sobre areia a subirrigação, sistema que posteriormente foi aperfeiçoado com a utilização de outros tipos de substratos, como uso de cascalhos e outros tipos de rochas vulcânicas e materiais sintéticos.

Nos anos 50, na Holanda, surge o IWOSC, atualmente ISOSC (International Society for Soilless Culture), que reagrupa os estudiosos de cultura sem solo e promove a cada quadriênio um congresso sobre a matéria, de modo a acelerar a utilização prática a partir dos conhecimentos gerando intercâmbio de experiências e da coordenação dos programas de pesquisa.

As bases para os cálculos das soluções nutritivas foram apresentadas durante o VI Congresso do Instituto Internacional da Potassa em Florença, Itália em 1968, por Steiner e posteriormente republicadas pelo mesmo autor, em 1984. Nesta artigo, vêm demonstradas as relações reciprocas entre cations os $\mathrm{K}^{+}, \mathrm{Ca}^{++}$, e $\mathrm{Mg}^{++}$e entre os ânions, $\mathrm{NO}_{3}^{-}, \mathrm{H}_{2} \mathrm{PO}_{4}^{-}$e $\mathrm{SO}_{4}^{-}$para a solução universal de Steiner. Também vem demostrado como calcular diferentes receitas desta solução para a concentração e pH que se desejar, porque, de acordo com seu trabalho, somente as relações mútuas entre os ânions e as relações mútuas entre cations é que são universais, sendo possível obter diferentes receitas de soluções, a partir de diferentes escolhas de pressão osmóticas e de pH (Steiner, 1984), soluções que se adequam a diversas culturas.

Uma importante diferença entre cultivo hidropônico e a produção no solo consiste na grande capacidade tampão existente no solo e que é muito restrita nos sistemas hidropônicos. Portanto, tal fator influencia na composição 
da solução de nutrientes, pela absorção de água ou de nutriente, variações que ocorrem muito mais facilmente nos sistemas hidropônicos do que sobre o solo. Com o aumento do uso do cultivo sem solo, muitos problemas de alteração da composição das soluções e de controle e de monitoração dos elementos tornaram-se relevantes. Alt (1980), trabalhando com as culturas de cravo e rosa sobre os substratos cascalho e argila expandida respectivamente, verificou a necessidade de ajuste do $\mathrm{pH}$ pelo menos duas vezes por semana, e uma maior variação do nitrogênio e do potássio na solução nutritiva, elementos que se concentravam com o desenvolver das cultura. Isto acontecia para as formulações de soluções nutritivas recomendadas por Cooper, em 1975, e Steiner, em 1968, aumentos que foram bastante correlacionados com a variação da condutividade elétrica da solução.

O ajuste da solução nutritiva compreende a monitoração do nível de água, da concentração dos nutrientes e do valor de $\mathrm{pH}$. Durante o período de cultura, os sais podem acumular-se quando o consumo da água pelas plantas for superior ao de nutrientes ou por perdas de água por evaporação, causando danos as raízes, quando este nível se torna crítico (Noordegraaf, 1994).

Vários fatores podem influenciar a composição dos nutrientes na solução, como o tipo de substrato usado, o tipo de recipiente ou vasos utilizados, a qualidade da água, assim como a própria poluição. O ideal, entretanto segundo Arnon (1944), seria obter uma solução nutritiva mais adequada, que pudesse sustentar um bom desenvolvimento das plantas e conseguisse manter constante a concentração dos elementos durante 0 desenvolvimento das plantas, de maneira tal que os trabalhos executados para o controle do sistema sejam reduzidos.

Os niveis dos nutrientes na solução nutritiva, recirculante ou não, podem ser mantidos pela adição de soluções suplementares, nas quais as proporções entre estes sejam iguais ao seu influxo médio na cultura (Nielsen, 1984), ou, pela troca de solução em função da taxa de crescimento e volume de solução colocado à disposição da planta, variação da concentração e do pH. 
O manejo da fertirrigação, em cultivo hidropônico, ao nível empresarial, pode ser efetuado por meio de cálculos, desde que se tenha a correlação microclimática com a cinética de absorção dos nutrientes e consumo de água, manejo que poderá ser utilizado se fizer uso de um microcomputador, para auxiliar nos cálculos. Pela análise química do percolado e dados microclimáticos, de 5 anos, foi possível manter o controle da fertirrigação em cravos e Chamaelaucium, e manter uma taxa de percolação próxima de $15 \%$, seguindo uma rotina de cálculos, via softwares específicos (Farina, 1996).

A melhor relação de nutrientes para o crescimento e produção da roseira sobre o substrato turfa, foi obtida com a seguinte proporção iônica (expressa como meq\% do total de nutrientes catiônicos e do total de nutrientres aniônicos): 64 N, 18 S, 18 P, 38 K, 26 Ca e 36 Mg, com uma dose ótima de 510 meq/ planta e a relação de ânions/cátions igual a 1.3, como sendo a composição que mostrou resultados mais satisfatórios (Gabriel \& Meneve, 1973).

A composição dos fertilizantes recomendados em 1992 e 1993 pela IKC (Informatie en Kennis Centrum Akkeren Tuinbouw), para a cultura da roseira em cultivo hidropônico (sistema fechado), foi analisado por Bloemnard e Moolenbroek (1995) e muitos ajustes foram feitos, por terem verificado que as concentrações de $\mathrm{K}$ e de $\mathrm{Ca}$, tornaram-se altas, as de amônia e de $\mathrm{Mg}$ tornaram-se baixas, em cultivo de dois anos consecutivos. Num segundo experimento, foi verificado que a quantidade de água absorvida pela cultura chegou a $772 \mathrm{~mm} / \mathrm{ano}$. A necessidade de nutrientes para suprir a cultura, em kg/ha/ano, foi de 906 N, 263 P, 1117 K, 204 Mg, 668 Ca, e 332 S. A perda (em kg/ha/ano) por drenagem foi de 265 N, 53 P, 429 K, 77 Mg, 299 Ca e 148 S. Assim, o fornecimento dos elementos minerais não estava balanceado com a extração da planta, ou seja, com um aproveitamento de $19 \%$ N, $50 \%$ P, $22 \%$ $\mathrm{Mg}, 35 \% \mathrm{Ca}$ e $50 \%$ de $\mathrm{S}$; recomendando que sejam feitos mais estudos a respeito deste assunto. 
A alta condutividade elétrica (CE) da solução de nutrientes, para a produção de tomates, tem resultado em frutos de melhor qualidade, (Sonneveld \& Welles, 1988). Entretanto, a alta CE para a cultura da rosa afetou negativamente a espessura, o comprimento e a firmeza das hastes florais, com redução também da vida pós-colheita (De Kreij \& Van Den Berg, 1990). No verão, a CE superior a $1400 \mathrm{mmS} / \mathrm{cm}$ afetou fortemente o plantio, com redução dos parâmetros analisados; já no período de inverno, a CE menor que 1400 $\mathrm{mmS} / \mathrm{cm}$ também foi prejudicial.

Segundo Urban et al. (1995a), os fatores culturais são menos importantes do que os fatores pós-colheitas para manter a vida em vaso, e os niveis de umidade relativa e de $\mathrm{CE}$ da solução nutritiva não favorecem a abertura e nem a vida pós-colheita da rosa, embora exista uma forte variação sobre a transpiração e a absorção no decorrer das estações do ano. Existe um aumento na transpiração e absorção de água do verão para o outono, seguida de uma redução na primavera.

Niveis altos de CE tendem a causar redução na condutividade estomatal e da fotossintese, afetando, consequentemente, a produção e alongamento das células, envolvendo, inclusive, a qualidade das plantas. $O$ fechamento parcial dos estômatos está ligado, mais precisamente, com os repentinos e elevados aumentos na salinidade no ambiente de raizes. Estes aumentos ocorrem quando a quantidade de suprimento de nutrientes é maior que a demanda da planta, provocando perdas de nutrientes e água por lixiviação dos substratos, que irão poluir a superfície do solo e também o lençol d'água subterrâneo. Para contornar estes problemas, deveria ser feito um suprimento da quantidade de água e de nutrientes o mais próximo possivel das necessidades das plantas, reduzindo as lavagens no ambiente de raízes com redução das perdas e, ainda, possibilitaria a reciclagem da solução por um período maior ou permanentemente (Urban et al., 1995b).

O nitrogênio pode ser administrado na forma de ions de nitrato ou ions de amônio. Diferentes efeitos fisiológicos, no ambiente das raízes, podem ser 
desencadeados, variando a relação entre estes íns na solução. Um excesso de íns amônio pode resultar em deficiência de $\mathrm{K}, \mathrm{Ca}$, e $\mathrm{Mg}$, baixa relação cátions/ânions, inibição da fotossintese e pode conduzir $\circ \mathrm{pH}$ do substrato a valores excessivamente baixos para as plantas. Por outro lado, a presença destes ânions na solução de nutrientes, em baixas taxas, pode aumentar a produção. Em condições de temperaturas mais amenas, as plantas podem absorver mais eficientemente $\mathrm{NH}_{4}{ }^{+}$, quando as raízes apresentam maiores reservas de açúcares; caso contrário, nos períodos mais quentes, é preferivel a forma nítrica, quando as reservas são menores e sua presença seria fitotóxica (Ganmore-Neumann \& Kafkafi, 1983). A variação do pH da solução é variável com os certos tipos de substratos. Nos processos de nitrificação ou oxidação biológica do ín amônio para a forma nítrica, ela ocorre pela ação de bactérias dos gêneros Nitrosomonas e Nitrobacter, que não desenvolvem em substratos orgânicos (Taiz e Zeiger, 1991).

A absorção de nitrogênio, em relação à irradiação e os estágios de desenvolvimento de produção da roseira, cv. Royalty, foi estudada utilizando um sistema de hidroponia com recirculação de nutrientes. A taxa de absorção do nitrogênio seguiu um padrão cíclico relacionado ao desenvolvimento das brotações e colheitas de flores. A taxa de absorção mudou quatro a cinco vezes durante um simples ciclo de crescimento das brotações (i.e. 29 - $146 \mathrm{mg} \mathrm{N}$ / planta/ dia), com uma média de absorção no verão de $60-70 \mathrm{mgN} / \mathrm{dia}$ e no inverno de $30 \mathrm{mg} \mathrm{N} /$ dia. Após a colheita das flores, a taxa de absorção de $\mathrm{N}$ se reduziu para dar início ao desenvolvimento das novas hastes florais. A menor taxa de absorção de $\mathrm{N}$ ocorreu quando a taxa de alongamento das brotações era máxima, e a maior taxa de absorção ocorreu quando as hastes florais adquiriam a maturidade comercial. A irradiação não alterou a periodicidade do ciclo de absorção de N, mas afetou a sua demanda média diária (Cabrera et al., 1995a).

Suprindo com fertilizante marcado $\operatorname{com}{ }^{15} \mathrm{~N}$, nos diferentes estágios do ciclo do florescimento da roseira, cv Royalty, foi estudado para verificar o 
momento da absorção do $\mathrm{N}$ e a dinâmica total deste no interior da planta. Durante o período de rápido alongamento das brotações, o $\mathrm{N}$ absorvido da solução de nutriente supriu $16-36 \%$ do $\mathrm{N}$ da haste floral. O resto, que representa a maior parte do $\mathrm{N}$ contido na haste floral em crescimento, foi oriundo do $\mathrm{N}$ armazenado em outros órgãos, particularmente do caule e das folhas. A absorção de $\mathrm{N}$ foi aumentada após o ciclo de florescimento, e este $\mathrm{N}$ armazenado foi suficiente para suprir a demanda de crescimento das hastes floriferas e reabastecer o suprimento das folhas e dos tecidos lenhosos. Estes órgãos continuam armazenando $\mathrm{N}$ até se tornarem viáveis para o reinício das brotações (Cabrera, et al., 1995b).

Os micronutrientes são mantidos, independentemente da adição dos macronutrientes. Isto ocorre porque a absorção destes elementos não é afetada grandemente pelas concentrações dos macronutrientes. Além do mais, o $\mathrm{B} \mathrm{e}$ especialmente $\circ \mathrm{Mg}$ podem facilmente alcançar níveis tóxicos, níveis que podem variar com os cultivares, afetando sensivelmente 0 rendimento (Sonnevelt, 1989). O ferro deve ser adicionado na forma quelada.

Das várias formas do ferro quelado, o Fe-EDDHA (ethylenediamine di o-hydrocyphenyl-acetic acid) foi a mais estável em termos de manter o conteúdo de ferro solúvel em solução recirculante, seguida Fe-DTPA (diethylenetriamine pentaacetic acid) e o Fe-EDTA (ethylenediamine tetraacetic acid) como a menos estável. A solubilidade que interfere na absorção deste elemento pela planta. Os conteúdos de ferro solúvel na solução com Fe-DTPA foram menores a valores de pH 5,5. O Fe-EDDHA e o Fe-EDTA, não tiveram grande alteração em sua estabilidade com a variação do pH (Fisher, 1984). Ao nível prático, o Fe-DTPA é o mais usado, e em alguns casos específicos de utlilização do pH de 6.5 , são recomendados o Fe-EDDHA.

Problemas associados a recirculação de nutrientes, em regiões semiáridas como as de Israel, para o desenvolvimentos da cultura da roseira foram apontados por Raviv et al. (1995). Estes problemas incluem a alta salinidade da água de irrigação; a alta evapotranspiração local acarretando rápido aumento 
da salinidade da solução drenada; a diferença iônica entre a água irrigada e a água drenada e o risco de disseminação de doenças de solo. Entretanto, a produção e a qualidade da cultura não foi afetada quando foi feita a recirculação, e o consumo de água e de fertilizante foram reduzidos em $25 \%$, e o aumento da salinidade foi menor que o esperado.

As condições climáticas podem interferir no metabolismo das plantas. Assim diferenças no déficit de umidade entre a folha e 0 ar da casa de vegetação afetaram grandemente a transpiração da roseira (cv Frisco). Estas diferenças são causadas particularmente pelas diferenças da temperatura mínima da água do sistema e a temperatura do ar da estufa. A transpiração no cv. Frisco apresentou correlação com o déficit de umidade e com a radiação global incidente, e afetou também a produção de outros quatro cultivares (Graaf, 1995).

Duchein et al.(1995) estudaram a eficiência do uso da água e consumo de nutrientes da roseira, cultivada em casa de vegetação sobre lã de rocha e verificaram que a radiação solar e a água foram utilizados com maior eficiência pela cultura, durante o inverno, quando comparado com os demais períodos do ano. A eficiência da água foi quase três vezes superior no inverno do que no verão $(0,8$ contra 0,3 flores/L). As justificativas seriam: a temperatura do ar e a umidade dentro da casa de vegetação, tal como a temperatura do substrato, estariam na faixa ótima, pois a eficiência do uso da radiação é geralmente superior em baixas a moderadas condições de luz. Quanto a taxa de absorção de nutrientes foi linear para a absorção de água até aproximadamente 0,4 Lplanta dia. Acima deste valor, a absorção de nutrientes se reduziu significativamente (exceto para $\circ \mathrm{P}$ ), pois altas taxas de absorção de água correspondem a altos niveis de radiação, portanto, as altas temperaturas do substrato afetam negativamente a absorção de nutriente pelas raízes. De acordo com o mesmo autor, estes resultados mostram a importância do controle climático em locais de climas tropicais durante os periodos mais quentes. Pensa-se em um sistema de resfriamento, como o fog, que é capaz de reduzir 
tanto a temperatura do ar como pressão de vapor, permitindo maior eficiência da radiação e também taxas superiores de fotossíntese. Aquele autor concluiu que o resfriamento do substrato pode ser benéfico por permitir a manutenção de altas taxas de absorção de nutrientes e evitar o excesso de drenagem ou o uso sistemático de lavagens do substrato para evitar salinização do mesmo. Um outro fator importante é acompanhar a radiação solar e a temperatura do substrato para ajustar o nível de fertilizantes na solução de nutrientes.

Quanto ao sistema de condução das plantas de rosa em sistemas de cultivo sem solo, não existe ainda um consenso e nem uma experiência sonclusiva. Muitos produtores continuam com os mesmos sistemas que usavam para o cultivo em terra, outros estão tentando mudar este sistema, com uma condução baixa da planta combinada com a curvatura dos ramos.

O sistema de condução de plantas de rosa conhecido como "poda japonesa" ou em "coroa" vem sendo bastante difundido na França e Itália, para o cultivo sem solo (Morisot, 1997). Neste sistema, as estruturas das plantas são mantidas muito baixas $(<25 \mathrm{~cm})$. Uma parte vegetativa muito desenvolvida constituída de ramos curvados é deixada, chamada de "Pulmão da planta". As podas sobre esta parte da planta são bastante limitadas. Algumas flores formadas deste pulmão são colhidas, em períodos de maior demanda do comércio, e nos demais são deixadas na planta. Esta técnica favorece o desenvolvimento de hastes longas em detrimento das demais. Entretanto, este sistema não serve para todas os cultivares. Os cultivares: Elegance, Feria, First Red, Grand Gala, Leonidas, Noblesse, Pareo, Prophyta, Ravel, RoyalRed, Shara, Sari, Soleada, Sonia, Texas, Top Secret, Versilia, Vision, etc. tiveram resultados positivos; já nos cultivares Anna, Pailine, Tennessee, Vivaldi etc, as plantas não apresentaram vigor e ramificaram pouco.

Três sistemas de condução de plantas de rosas foram estudados, na Holanda, por Kool (1996). No primeiro tratamento, tido como controle, foram curvados todos os ramos na sexta semana do plantio, e os ramos formados a partir da base das plantas até a altura de $30 \mathrm{~cm}$ eram continuamente removidos, 
com exceção daqueles oriundos da parte mais basal (mergulhões). As colheitas foram iniciadas exatamente sobre estes mergulhões, na quarta gema a partir da base, contendo pelo menos 5 folíolos. Nos ramos de ordem superior, foram feitas as colheitas sobre a segunda folha com 5 folíolos, sistema de poda e colheita normalmente utilizado na Holanda. Um segundo tratamento foi igual ao primeiro, com a variação de que neste foram deixados se desenvolverem somente dois ramos por planta. Um terceiro tratamento foi, deixando-se desenvolver somente um ramo por planta, associado à densidade duplicada de plantas para 24 plantas $/ \mathrm{m}^{2}$ de canteiro (espaçamento de $0.25 \times 0.17 \mathrm{~m}$ ). A formação de ramos basais nos dois primeiros sistemas mostrou que a competição entre ramos basais é maior que a competição entre plantas no início da produção e que durante os anos subsequentes não houve diferença nem entre plantas e nem entre ramos basais. A maior densidade de plantas aumentou o número de flores colhidas e reduziu o peso individual das flores.

Os tipos de implantes para o cultivo sem solo da roseira foram discutidos durante o congresso de hidrocultura, realizado em Sanremo em 1996 (Belliard, 1996). O primeiro tipo de implante é o cultivo em vasos que variam de 14 a $20 \mathrm{~L}$, preenchidos com substratos, dispondo de 2-3 plantas/vaso. Este sistema é indicado para regiões onde a topografia é mais acentuada pela facilidade de distribuição no terreno. Neste sistema, vem colocado um dreno no fundo do vaso para recolher o excesso de irrigação. O segundo tipo é a cultura em canais; é o sistema mais utilizado na Itália e França. Para adotar este sistema, é necessário ter uma caída relativamente homogênea do terreno. Inicialmente, foram adotados canais de $30 \times 30 \mathrm{~cm}$ de dimensões e comprimentos variáveis; hoje estão sendo usadas canaletas com dimensões menores, de $25 \times 25 \mathrm{~cm}$. Um terceiro tipo é o cultivo sobre a lã de rocha, predominante no norte da Europa (Holanda e Bélgica). Para este tipo de condução há necessidade de um sistema de fertirrigação bastante sofisticado para o controle da salinidade, e apresenta, ainda, a inconveniência de que a lã de rocha não pode ser reutilizada, e fica difícil descartar esse material. Um 
quarto tipo é o cultivo em sacos preenchidos com perlitas ou substratos orgânicos.

Os substratos mais utilizados para a cultura sem solo na Europa são: a pedra pomes de $3-8 \mathrm{~mm}$, a perlita de $3-12 \mathrm{~mm}$, fragmentos da rocha vulcânica pozzolana de 2-8mm, como substratos orgânicos são usados a turfa e a fibra de coco (Belliard, 1996). Vários outros substratos podem ser testados para as nossas condições de Brasil como a argila expandida que foi testada com sucesso para o cultivo sem solo do crisântemo (Barbosa, 1996), desde que este substrato seja 0 mais inerte possível quimicamente, e apresente uma granulometria não muito grossa (com tendência de pouca retenção de água), nem muito fina (com perigo de asfixia para as raízes). É importante também, levar em consideração o preço, a facilidade de operar este material, a sua disponibilidade e sua resistência ou estabilidade no tempo, assim como a possibilidade de reutilização. 


\section{CULTIVO HIDROPÔNICO FECHADO DA ROSEIRA COM RECÍRCULO PROLONGADO DA SOLUÇÃO NUTRITIVA}

\section{RESUMO}

Os experimentos sobre cultivo sem solo a ciclo fechado da roseira foram conduzidos no 'Istituto Sperimentale per la Floricoltura di Sanremo'. O objetivo foi encontrar um sistema simples com baixo emprego de capital, compatível com propriedades de pequeno e médio porte. O sistema se baseia no emprego de duas caixas, em terrenos de natural declive, uma posicionada na parte mais baixa do terreno, de onde a solução nutritiva é bombeada e distribuída nos interventos de fertirrigação. Nesta caixa, são também recolhidos os drenados que posteriormente irão recircular. Quando o volume torna excessivamente reduzido, por efeito do consumo, coloca-se solução nutritiva nova, que se mistura ao drenado remanescente. A solução permanece em reciclo até ser considerada ruim para o reciclo (a solução é considerada exaurida quando a CE supera o teto máximo estipulado para a roseira que foi de $4000 \mathrm{mmS} / \mathrm{cm}$ ). A partir deste momento, a solução é retirada de circulação e armazenada na caixa superior, desta é retirada uma amostra, para as análises químicas, e sucessivamente reequilibrada, para retornar ao sistema, como solução nova. No caso, para remoção da solução exaurida da caixa posicionada na parte inferior do conjunto, o sistema continua em funcionamento, com a administração de solução nova. A CE do drenado, em recirculação, da caixa inferior é monitorado diariamente. Nesta pesquisa, são relatados dados de 18 meses de cultivo da roseira sem solo a ciclo fechado contínuo, parâmetros de uso do sistema, metodologias usadas, suporte de cálculo, dados do balanço hídrico/nutricional e produtividade.

Palavras-chave: Rosa, cultivo hidropônico, sistema fechado 


\section{PROLONGED RECYCLING IN CLOSED GROWING SYSTEM FOR ROSE}

\section{SUMMARY}

An experiment on rose cultivation in closed soilless growing system was carried out from October 1996 until May 1998. The aim was to check a simple equipment suitable at the management of nutrition in a closed system compatibible with the low resources of the small floricultural farms. Non frequent chemical analysis of nutrient levels in the drainage solution and a subsequent regeneration are proposed as a substitute of sensors for continuous adjustment of $\mathrm{pH}$ and solution concentration. The method was tested in a system provided with two tanks and one pump. One tank placed in higher position was intended for storage of exhausted nutritive solution (E.C.> $4000 \mathrm{mmS} / \mathrm{cm}$ ) and regeneration after chemical analysis. The second tank in a lower position is intended for receiving the drain after distribution to the substrate; such drain mixed with fresh nutritive solution when necessary will be available for the next distribution. In case of storage of the exhausted drainage in the upper tank, a fresh nutritive solution will be supplied in the lower tank and recirculated. E.C. is monitored daily in the lower tank.

in this paper data related to 18 months of rose growth in soilless culture with continued ricirculation, are reported. Good productive results were observed. A noteworthy reduction in water consumption and a high level (90$95 \%)$ of nutrients utilization were achieved. The methods proved itself useful for cost reduction and for environmental respect, used for improving the efficiency of the use of water and fertilizer, qualification and produtivity roses.

Key words: Rose, soiless closed systens 


\subsection{INTRODUÇÃO}

A cultura da rosa sem solo está ainda em fase de expansão, em vista das pesquisas para comprovação dos efetivos elementos de interesse que ela apresenta sobre o plano das tecnologias de produção e de rendimentos. $\mathrm{Na}$ maior parte dos casos, são utilizados substratos como pedra pomes ou agriperlita e eventualmente misturados com a turfa. A quase totalidade dos implantes funciona a ciclo aberto, com perda do percolado. Em poucos locais ocorrem caso em que se faz uma efetiva reutilização do excesso de fertirrigação percolada, nem mesmo para a recirculagem por reduzida duração ou para a fertilização de outras culturas praticadas sobre solo natural.

Os altos percentuais de drenagem utilizados, a freqüência dos interventos de irrigação no decorrer da jornada, associada à relativa capacidade de retenção hídrica dos substratos, determinam significativa emissão de resíduos químicos sobre o solo. Uma estimativa feita na França por pesquisadores do INRA ressaltam perdas de $300 \mathrm{~L} / \mathrm{m}^{2}$, por 9 meses de cultura de tomate, o que corresponde a 7-8 toneladas de fertilizantes por hectare. A estimativa feita pela equipe técnica da Chambre d'Agriculture del Var relataram perdas de $500 \mathrm{~L} / \mathrm{m}^{2} / a n o$ nos sistemas abertos com dispersão de 10 toneladas/ha/ano de fertilizantes, dos quais uma tonelada seria de $\mathrm{N}$.

Esta situação torna-se supostamente mais agravante em áreas produtivas, onde a preparação profissional específica do produtor e o nível de assistência técnica no setor da hidroponia é ainda mais deficiente, como tem acontecido em algumas zonas italianas e aqui no Brasil. $O$ que na verdade ocorre é que o meio mais fácil para evitar situações de risco com salinidade sobre as culturas é aumentar a quantidade de drenagem. Além dos evidentes problemas de impacto ambiental, calcula-se que os gastos em fertilizantes e água podem alcançar mais de $1 \mathrm{real} / \mathrm{m}^{3} / \mathrm{ano}$, do qual uma elevada quota, avaliada em mais de 0.8 reais é desperdiçada, porque é jogada sobre o solo. 
A solução mais óbvia e radical para tais problemas, além da utilização de confiáveis métodos de controle da efetiva exigência hídrica da planta, é a adoção do ciclo fechado. Entretanto, mesmo as empresas agrícolas que já se encontram com implantação compatível com este tipo de solução, nenhuma delas adotaram efetivamente o sistema fechado. Os motivos que têm determinado tais comportamentos são diversos, e entre estes pode-se enumerar a baixa confiabilidade dos produtores sobre a sua própria capacidade de conduzir o sistema fechado e a existência de alguns problemas fitopatológicos de real importância para determinadas espécies quando cultivadas neste sistema. Junto a isto deve-se acrescentar a problemática da carência de assistência técnica disponível para tal condução e, sem esquecer as políticas comerciais de algumas empresas que fornecem equipamentos, sistemas, tecnologias, assistência, e que privilegiam o ciclo aberto. Em determinados casos, ressaltam problemas ligados ao custo das tecnologias propostas para os sistemas a reciclo, que para as reais circunstâncias não seriam compatíveis com os níveis de investimento suportáveis para os pequenos e médios agricultores.

Com base nesta situação, e também ao fato de que no futuro próximo será inevitável a adoção de sistemas fechados, foi conduzida, junto ao "Istituto Sperimentale per la Floricoltura di Sanremo", uma pesquisa sobre o cultivo sem solo com reciclagem da solução nutritiva para a cultura da rosa. Tais atividades são originadas, consequentemente, de uma avaliação preliminar do uso de sistema de reciclagem com baixo emprego de tecnologia. Os resultados relativos a tais avaliações preliminares executadas sobre plantas de Chamaelaucium (Farina et al, 1997a). Um dos objetivos, relacionado ao sistema foi a substituição do uso de sensores, para a monitoragem 'em linha', dos níveis dos elementos na solução nutritiva com uma simples analise química de laboratório. Neste trabalho, são fornecidos, para 18 meses de cultivo hidropônico da roseira em reciclagem contínua, os parâmetros de uso do sistema, as metodologias de utilização, discussão sobre a questão do 
dimensionamento de alguns elementos para a implantação deste sistema e dados relativos ao balanço hídrico/nutricional e produtividade agronômica.

\subsection{MATERIAL E MÉTODOS}

\subsubsection{Implante}

O experimento foi conduzido no "Istituto Sperimentale per la Floricoltura di Sanremo", Itália. O conjunto constituia-se de duas caixas (uma superior e uma inferior sobre um terreno com declividade natural e uma bomba. A cada distribuição do fertilizante o drenado era recolhido mediante um apropriado sistema hidráulico de recuperação na caixa inferior; de lá eram redistribuídos nos interventos de fertirrigações sucessivos. Diariamente era executado o monitoramento da salinidade e do $\mathrm{pH}$. Quando o volume de solução recirculante resultava em excessiva redução pelo efeito do consumo(1/5 do volume máximo $=1 / 5$ do volume da caixa para reciclo), é acrescentada solução nutritiva nova que era misturada ao drenado (Figura $1 \mathrm{e}$ 2).

A irrigação, controlada por programador, ocorria através de bicos de irrigação com jato de $180^{\circ}$, inseridos sobre um tubo de adução dispostos sobre a superfície do substratos e em posição próxima a uma das paredes da canaleta. As plantas foram transplantadas a uma distância de $5 \mathrm{~cm}$ da parede oposta àquela do tubo de irrigação. Uma pequena aba de polipropileno na forma de 'L' serviu para cobrir uma parte da superfície do substrato, formando uma câmara entre as bordas da superfície da canaleta e a base das plantas, de tal modo que a irrigação das plantas fosse feita dentro desta câmara e permitisse a oxigenação da solução nutritiva e também lavar, por completo, o volume de substrato a disposição das plantas, sem jogar a solução nutritiva fora desta canaleta. 


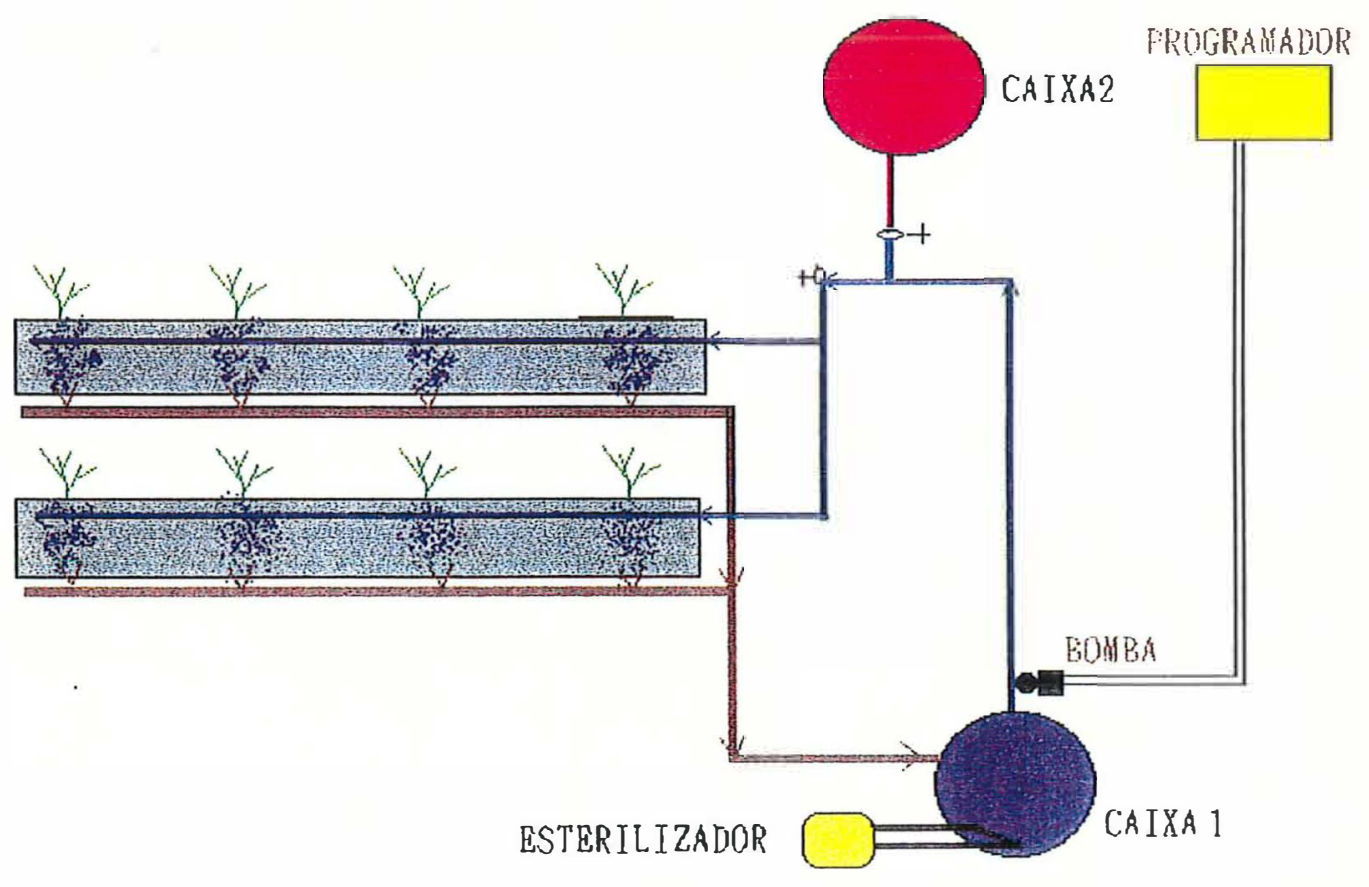

Figura 1 - Esquema utilizado na implantação do sistema a ciclo fechado

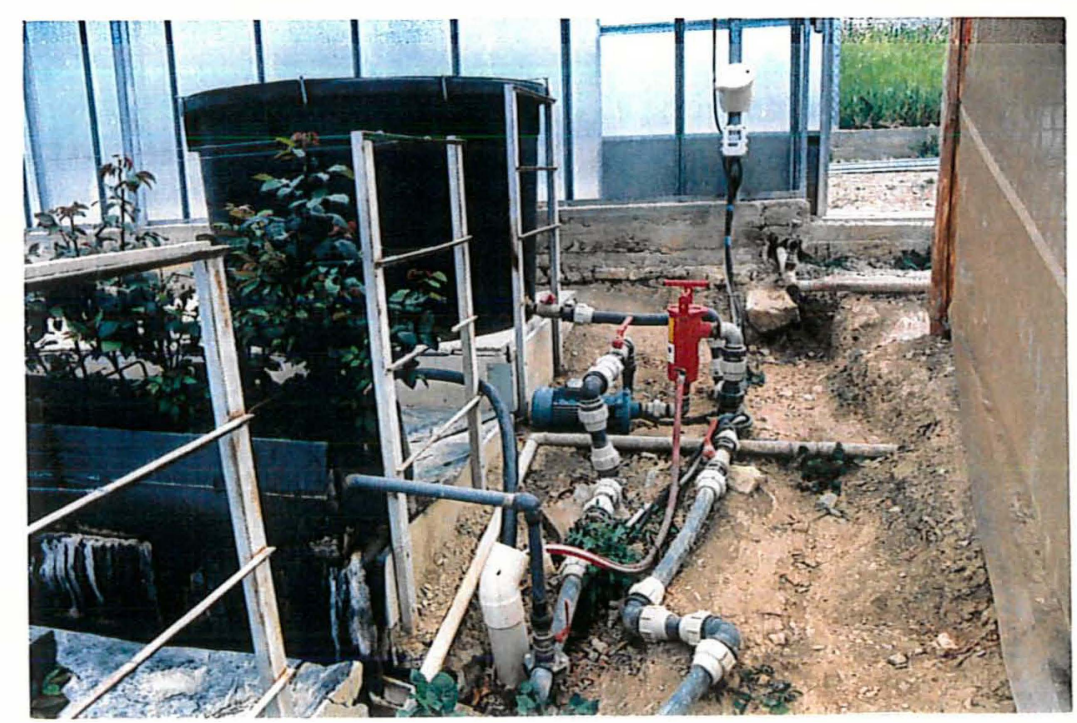

Figura 2 - Sistema de fertirrigação e armazenamento de solução exaurida 
O drenado era considerado bom para a reciclagem até quando, para o volume de drenado maior ou igual a $1 / 5$ daquele da caixa inferior, não alcançasse o teto máximo de salinidade. No caso de ultrapassar este teto máximo de salinidade, o drenado "exaurido" era transferido para a caixa superior e retirado da reciclagem, enquanto na caixa inferior era colocada solução nutritiva nova que era utilizada para a reciclagem. $O$ drenado exaurido era submetido a alguns ciclos de esterilização mediante lâmpada de UV e corrigido $\circ \mathrm{pH}$ a 6 para as sucessivas determinações químicas-analíticas. De posse desses dados analíticos era feito o cálculo para retornar aos valores do nível inicial da solução exaurida. Tais cálculos levam em consideração os valores de $\mathrm{N}, \mathrm{P}, \mathrm{K}, \mathrm{Ca}, \mathrm{Mg}$, e $\mathrm{Fe}$, e a utilização de um software projetado justamente para este fim, que executa os cálculos de reequilibratura. Após a correção química dos elementos minerais e o controle do $\mathrm{pH}$ final a valores de 5.8-6.0, a solução da caixa superior pode retornar ao sistema para ser reutilizada.

\subsubsection{Substrato, material vegetal e forma de condução}

O sistema foi conduzido em canaletas de polipropileno contendo pedra pomes de granulometria mista de 3 a $12 \mathrm{~mm}$, calibre normalmente utilizado na Riviera das Flores (Sanremo) para o cultivo sem solo. Foram cultivadas plantas de rosa microenxertadas da cv Anna sobre o porta-enxerto $R$. indica. O volume de substrato à disposição foi de cerca $14 \mathrm{l} /$ planta. As plantas foram dispostas em fila única distanciadas de $23 \mathrm{~cm}$ ( $d=10.7$ plantas $/ \mathrm{m}^{2}$ cultivado), com livre crescimento de outubro de 1996 até o primeira colheita, executada em dezembro de 1996. A colheita foi feita com cortes sobre o ramo que continha a flor, ou seja, com condução dos ramos a subir, com exceção de um rebaixamento a ramos de segunda ordem em julho de 1997 e uma poda de revigoramento na metade de fevereiro de 1997. O experimento foi conduzido sobre estufa de vidro sem aclimatação térmica ou luminosa, a exceção de uma 
caiação (branqueamento dos vidros com calda de cal) para redução do excesso de radiação no período de junho/agosto 1997.

Foi utilizada inicialmente uma solução nutritiva de composição semelhante àquela utilizada por Brun, de condutividade elétrica igual a 2100 $\mathrm{mmS} / \mathrm{cm}$, com a concentração reduzida a $2 / 3$ no período de verão junho/setembro (Tabelas 1 e 1a). Para preparar a solução nutritiva, foram usados fertilizantes de uso cotidiano e água de distribuição municipal com teor inicial de $100-150 \mathrm{mg} / \mathrm{L}$ de Ca e condutividade igual a $300-500 \mathrm{mmS} / \mathrm{cm}$, usada após descalcificação através resina de troca iônica. Os micronutrientes foram administrados com solução nutritiva de concentração em $\mathrm{mg} / \mathrm{L}$ de $\mathrm{Mn} 0.17, \mathrm{Cu}$ 0.17 , b 0.03 , Zn 0.03 , Mo 0.03 . O Fe foi distribuído alternando, na solução irrigada, o uso da forma quelada (Sequestrene) com aquela ionica livre (sulfato ferroso).

Tabela 1. Composição da solução nutritiva de outubro de 1996 a outubro de 1997

\begin{tabular}{lcccccccccc}
\hline Concentração & $\begin{array}{c}\mathrm{N}^{-\mathrm{NO}_{3}} \\
(\mathrm{mg} /)\end{array}$ & $\begin{array}{c}\mathrm{N}-\mathrm{NH}_{4} \\
(\mathrm{mg} /)\end{array}$ & $\begin{array}{c}\mathrm{P} \\
(\mathrm{mg} /)\end{array}$ & $\begin{array}{c}\mathrm{K} \\
(\mathrm{mg} /)\end{array}$ & $\begin{array}{c}\mathrm{Ca} \\
(\mathrm{mg} /)\end{array}$ & $\begin{array}{c}\mathrm{Mg} \\
(\mathrm{mg} /)\end{array}$ & $\begin{array}{c}\mathrm{Fe} \\
(\mathrm{mg} /)\end{array}$ & Microel. & $\mathrm{pH}$ & $\begin{array}{c}\mathrm{E} . \mathrm{C} \\
\mathrm{mmS} / \mathrm{cm}\end{array}$ \\
\hline Normal & 151 & 23 & 41 & 220 & 96 & 33 & 0.7 & Compl. & 6.0 & 2100 \\
Reduzida & 101 & 15 & 27 & 146 & 64 & 22 & 0.4 & Compl. & 6.0 & 1400 \\
\hline
\end{tabular}

Tabela 1a. Composição da solução nutritiva de novembro de 1997 ao final da prova

\begin{tabular}{lcccccccccc}
\hline Concentração & $\begin{array}{c}\mathrm{N}^{\mathrm{NO}} \mathrm{N}_{3} \\
(\mathrm{mg} /)\end{array}$ & $\begin{array}{c}\mathrm{N}^{\mathrm{NH}} 4 \\
(\mathrm{mg} /)\end{array}$ & $\begin{array}{c}\mathrm{P} \\
(\mathrm{mg} / \mathrm{l})\end{array}$ & $\begin{array}{c}\mathrm{K} \\
(\mathrm{mg} /)\end{array}$ & $\begin{array}{c}\mathrm{Ca} \\
(\mathrm{mg} /)\end{array}$ & $\begin{array}{c}\mathrm{Mg} \\
(\mathrm{mg} /)\end{array}$ & $\begin{array}{c}\mathrm{Fe} \\
(\mathrm{mg} /)\end{array}$ & Microel. & $\mathrm{pH}$ & $\begin{array}{c}\mathrm{E} . \mathrm{C} \\
\mathrm{mmS} / \mathrm{cm}\end{array}$ \\
\hline Normal & 164 & 19 & 18 & 192 & 110 & 19 & 0.7 & Compl. & 6.0 & 2100 \\
Reduzida & 109 & 13 & 12 & 128 & 73 & 13 & 0.4 & Compl. & 6.0 & 1400 \\
\hline
\end{tabular}




\subsubsection{Parâmetros para uso deste sistema}

Foram previstos três interventos de irrigação ao dia: às $8.30 / 12.30 /$ 17.20 horas, reduzidos a dois interventos durante o período de inverno: às 8.30 e 16.30 horas. $O$ volume irrigado em cada aplicação foi igual a 0.45 L/plantas, com um drenado médio compreendido entre os 70 e $80 \%$.

O teto máximo de salinidade adotado para estabelecer o drenado como bom para recircular foi baseado em uma experiência feita anteriormente com a cultura do Chamaelaucium e rosa (Farina et al, 1997a). O valor foi fixado em $4000 \mathrm{mmS} / \mathrm{cm}$, obviamente para volume de drenado maior ou o máximo igual a $1 / 5$ daquele da caixa inferior de reciclagem.

\subsubsection{Dados colhidos}

Foram coletados dados do ritmo de consumo e do volume da solução nutritiva presente no sistema como um todo, e foram adotados os volumes das soluções nutritivas novas colocadas no sistema como parâmetros. Na solução drenada em reciclagem foram analisadas diariamente $\mathrm{opH}$ e salinidade. Para as soluções exauridas, além do $\mathrm{pH}$ e salinidade, foram executadas as determinações químicas. Para as análises foi utilizado o sistema "Spectroquant Merck", um espectrofotometro SQ118 e os respectivos kits analíticos. Para a analise do Mg foi utilizado o sistema "Aquaquant Merk", com prévia concentração da amostra do drenado trâmite evaporador de rotação.

Sobre as plantas foram coletadas dados de colheita de flores e em seguida, feita a classificação segundo critérios comerciais utilizados para o cultivar em questão, para os quais são previstas 5 categorias de qualidade para o mercado de Sanremo: $40-50 \mathrm{~cm}, 50-60 \mathrm{~cm}, 60-70 \mathrm{~cm}, 70-80 \mathrm{~cm}$ e $>80$ $\mathrm{cm}$. Para os principais fluxos de produção foram coletados amostras de peso e comprimento das flores para cada categoria comercial. 


\subsubsection{Avaliação do pH e da condutividade elétrica}

Para a caracterização da evolução do $\mathrm{pH}$ e da salinidade, tanto do drenado instantâneo (colhido na saída do substrato contendo a cultura) e quanto do drenado em reciclo (amostras colhidas na caixa inferior onde é armazenada a solução em reciclo), foram coletadas amostras seguindo os turnos de irrigação e segundo a redução da solução estoque em reciclo (evapotranspiração + consumo pelas plantas + perdas no sistema). Foi utilizado duas soluções nutritivas idênticas em concentração (Tabela 1), mas com a relação entre o nitrogênio amoniacal e nítrico diferentes:

a) solução com N-NH4 : N-NO3 $=1: 8$

b) solução com $\mathrm{N}-\mathrm{NH} 4: \mathrm{N}-\mathrm{NO} 3=1: 3$, solução derivada da reiquilibratura da solução exaurida.

O período de condução deste ensaio foi de março a abril de 1998.

\subsection{RESULTADOS}

Os resultados correspondem aos 20 meses de cultivo em reciclagem. Durante este período não foi retirado do sistema nenhum drenado, a não ser temporariamente, com o objetivo de reequilibrar a solução ao setup inicial e permitir sua reutilização.

\subsubsection{Balanço hídrico}

Os resultados obtidos indicam um consumo de cerca 64.000 litros de água para os 566 dias de cultivo de 406 plantas, correspondendo a 0.28 L/planta/dia. O consumo mínimo foi igual a $0.09 \mathrm{~L} /$ planta/dia no período de inverno, que corresponde à primeira quinzena de janeiro de 1998. Para agosto, que corresponde ao verão, foi o período de máximo consumo, alcançando 0.6 L/planta/dia (Figura 3). Para se entender melhor estes dados de consumo 
mínimo absoluto, recorda-se que em janeiro as temperaturas são baixas, que ao nível de solo chegaram próximas de zero e que não foi dado nenhum tipo de suplementação térmica às plantas.

\subsubsection{Balanço dos elementos fertilizantes}

O balanço nutricional após 566 dias está na Tabela 2. Os consumos médios diários por planta para cada elemento são: $39 \mathrm{mg}$ de $\mathrm{N}, 7.4 \mathrm{mg}$ de $P$, $46 \mathrm{mg}$ de $\mathrm{K}, 22 \mathrm{mg}$ de $\mathrm{Ca}$ e $7 \mathrm{mg}$ de $\mathrm{Mg}$. A relação entre os elementos consumados é $\mathrm{N}: \mathrm{P}: \mathrm{K}: \mathrm{Ca}: \mathrm{Mg}=1: 0.19: 1.18: 0.57: 0.17$ semelhantes àqueles utilizadas para a composição da solução nutritiva (1: $0.23: 1.26: 0.55: 0.19)$. 0 percentual de utilização dos elementos fertilizantes colocados foi notavelmente alta.

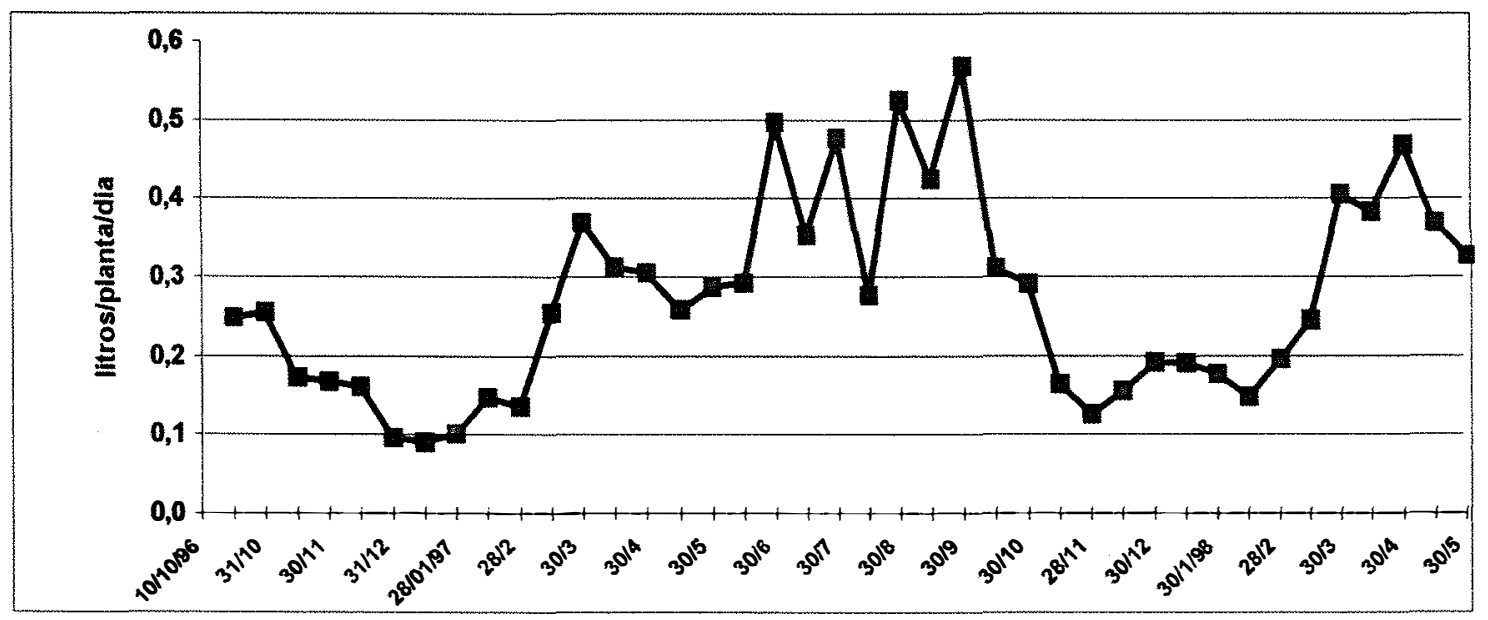

Figura 3 - Consumo hídrico médio por planta de rosa em sistema de cultivo sem solo 
Tabela 2. Balanço do fornecimento de fertilizantes para as 406 plantas de rosa em cultivo sem solo em reciclo em 566 dias

\begin{tabular}{lrrrrrr}
\hline & $\mathrm{N}$ & $\mathrm{P}$ & \multicolumn{1}{c}{$\mathrm{K}$} & $\mathrm{Ca}$ & \multicolumn{1}{c}{$\mathrm{Mg}$} & $\mathrm{Fe}$ \\
\hline Adicionados ao sistema $(\mathrm{g})$ & 9195 & 1720 & 10772 & 5555 & 1565 & 31,2 \\
Restante no sistema $(\mathrm{g})$ & 202 & 14 & 212 & 464 & 31 & 6,7 \\
Consumido (g) & 8992 & 1706 & 10561 & 5092 & 1534 & 24,5 \\
Consumido/planta/dia (mg) & 39 & 7,4 & 46,0 & 22,2 & 6,7 & 0,11 \\
Relação entre elementos & 1,00 & 0,19 & 1,17 & 0,57 & 0,17 & \\
\hline Água Consum.(ப/planta/dia) & \multicolumn{7}{c}{0,28 Litros } \\
\hline
\end{tabular}

\subsubsection{Produção de drenado instantâneo e em reciclagem e relação entre características do drenado instantâneo e em reciclo}

No decorrer dos 18 meses, foram produzidos 4400 litros de drenado exaurido. Tais quantidades correspondem a uma produção média de 0.019 L/planta/dia. Foi obtido ritmo de produção máxima no período junho/agosto 1997 (0.024 Lplanta/dia) e ritmo de produção mínimo no período novembro de 1997 / março de 1998 (0.007 L/planta/dia). O percentual de drenagem variou entre os valores máximos de $80 \%$ no período de outubro de 1996/ maio de 1997 e o valor mínimo de $68 \%$ no período de abril / maio de 1998 (Tabela 3). De posse desses dados da efetiva quantidade de drenagem, pode-se presumir que em cada aplicação de irrigação se tenha obtido uma boa homogeneização da solução nutritiva no ambiente radicular das plantas, se comparado a solução recirculante irrigada.

Tabela 3. Parâmetros de fertirrigação e volume de drenado em cada período da prova

\begin{tabular}{ccccc}
\hline Período & Aplicação/dia & Consumo/dia (L) & Irrigação/dia (L) & Drenagem (\%) \\
\hline $10 / 10 / 96-20 / 05 / 97$ & 2 & 0,20 & 0,99 & 80 \\
$20 / 05 / 97-11 / 11 / 97$ & 3 & 0,37 & 1,48 & 75 \\
$11 / 11 / 97-10 / 04 / 98$ & 2 & 0,22 & 0,99 & 78 \\
$10 / 04 / 98-30 / 05 / 98$ & 3 & 0,47 & 1,48 & 68 \\
\hline
\end{tabular}


No experimento conduzido para analisar 0 andamento do $\mathrm{pH}$ e salinidade nos drenados, no teste onde foi feito uso da solução nova com condutividade elétrica de $2100 \mathrm{mmS} / \mathrm{cm}$ e $\mathrm{N}-\mathrm{NH} 4: \mathrm{N}-\mathrm{NO} 3=1: 8$. Esta solução, ao passar pelo substrato, deu origem a um drenado instantâneo com condutibilidade de $3000 \mathrm{mmS} / \mathrm{cm}$ que, ao ser misturado com a solução na caixa inferior, deu origem a um drenado com condutividade um pouco superior àquela da solução irrigada. Com o suceder dos interventos de fertirrigação, a salinidade do drenado instantâneo e do drenado na caixa tenderam a nivelarse, aumentando contemporaneamente para valores de condutividade sempre superior à inicial. O teto da salinidade de $4000 \mathrm{mmS} / \mathrm{cm}$ foi superado nesta série de avaliações, quando a solução em reciclo foi reduzida a cerca de $1 / 3$ do volume inicial. $\mathrm{O}$ andamento do $\mathrm{pH}$, ao contrário, foi menos indicativo, entretanto, é importante evidenciar que se manteve entre 6.3 e 6.8 com o progredir da reciclagem ,e mesmo, com o aumento da concentração do drenado (Figura 4). Entretanto quando foi utilizada solução regenerada, cuja relação entre nitrogênio $\mathrm{N}-\mathrm{NH}_{4}: \mathrm{N}-\mathrm{NO}_{3}$ era de $1: 3, \circ \mathrm{pH}$ reduzia de 6.5 para $3.2 \mathrm{na}$ solução recirculante, enquanto o drenado instantâneo apresentava sempre valores do $\mathrm{pH}$ em torno de 3.2 (Figura 5).

Retornando à condução normal do sistema, onde a solução nutritiva fresca se mistura a solução drenada já presente, no total da experimentação, o drenado foi considerado exaurido 9 vezes em períodos de cerca 65 dias entre eles, com exceção de um período de utilização da solução nutritiva mais longo, entre novembro de 1997 e março de 1998. Cada vez que a condutibilidade do drenado atingia um nível superior a $4000 \mathrm{mmS} / \mathrm{cm}$, este era considerado exaurido, e neste momento, o pH correspondente era bastante ácido estando entre os niveis de 4.8 - 5.2. Apesar disto, os valores de $\mathrm{pH}$ analisados durante $\mathrm{O}$ funcionamento do sistema estavam sempre na faixa de $5.8-6.2$, valores considerados bons para a condução neste tipo de cultivo. 


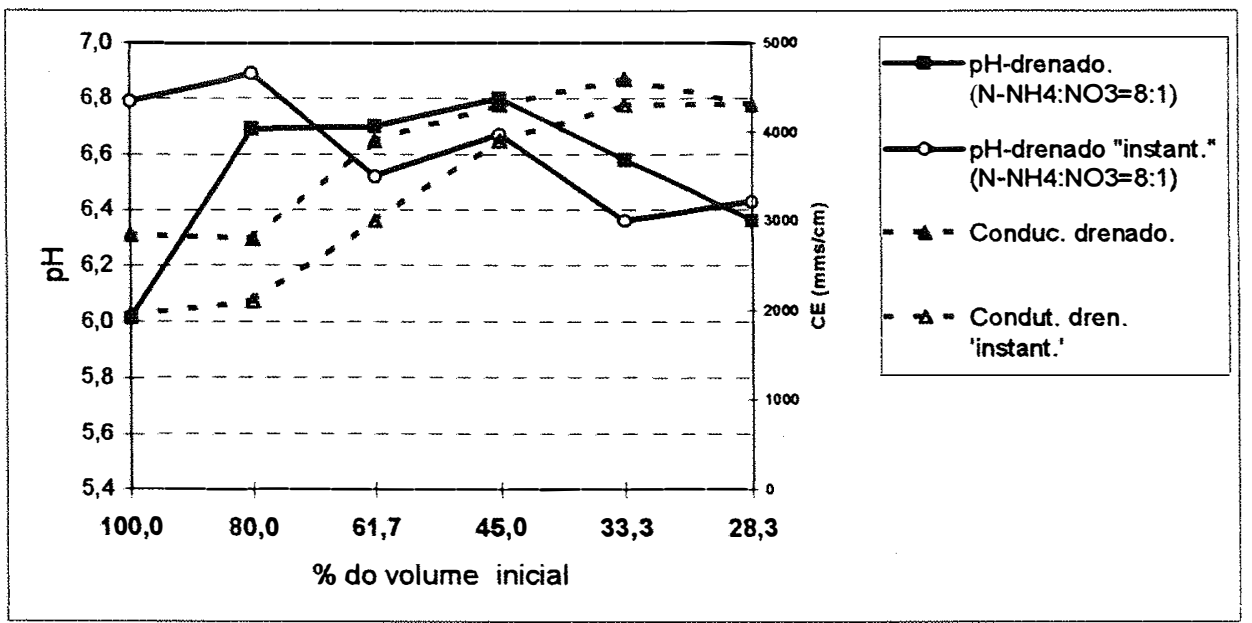

Figura 4 - Andamento da condutividade e do pH do drenado instantâneo e em reciclo com solução nutritiva inicialmente com relação nitrogênio amoniacal e nítrico 1:8

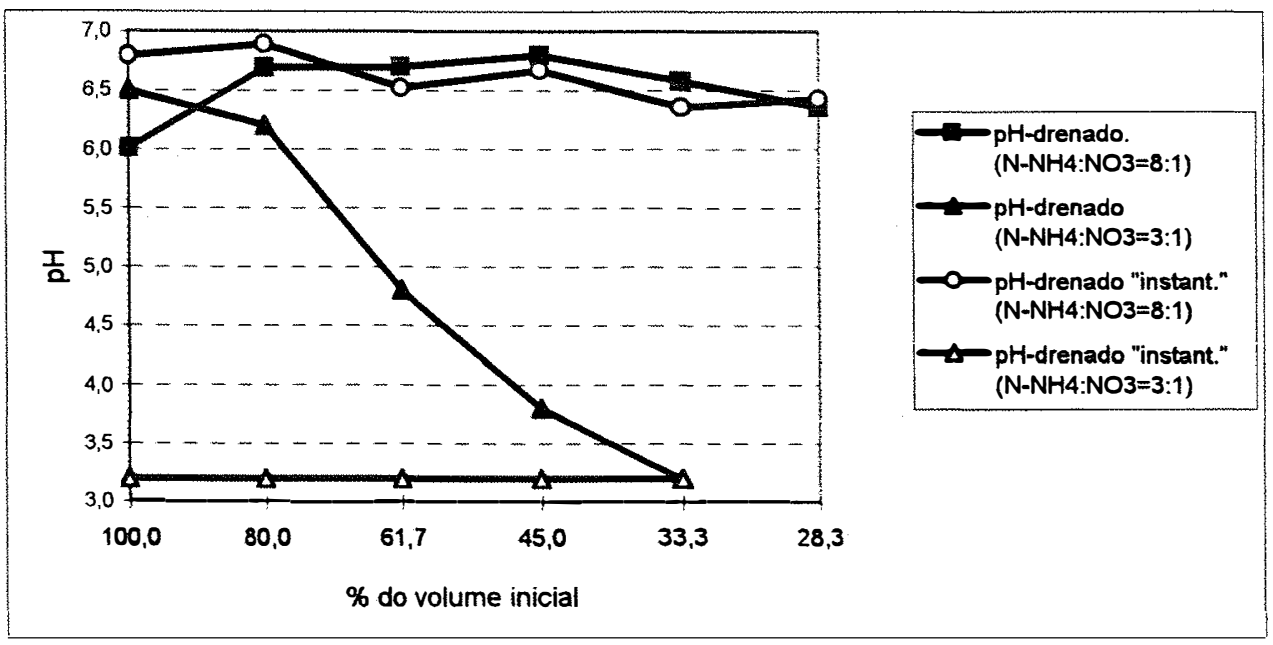

Figura 5 - Andamento do pH do drenado instantâneo e em reciclo com diferente relação entre nitrogênio na forma amoniacal e nítrica 


\subsubsection{Correção do drenado exaurido e composição da solução nutritiva}

A correção dos elementos nutritivos da solução drenada foi feita com água e adubos minerais, após uma série de cálculos executados via específico software FERSAN 46, software projetado pelo Dr. Enrico Farina do "Istituto Sperimentale per la Floricoltura di Sanremo". O programa toma como base os parâmetros nutricionais do elemento do drenado mais desbalanceado em relação aos níveis ótimos de $\mathrm{N}, \mathrm{P}, \mathrm{K}, \mathrm{Ca}, \mathrm{Fe}$ e salinidade. Ao final dos cálculos, somente os níveis de $\mathrm{N}, \mathrm{P}, \mathrm{K}, \mathrm{Ca}$, Fe eram retornados aos níveis ótimos; os demais elementos, mesmo que ausentes analiticamente, não eram reequilibrados, retornando aos devidos niveis por ocasião da adição da solução nova ao sistema. Finalmente, $\mathrm{opH}$ da solução reequilibrada era levado a 6 mediante a adição de solução de ácido nítrico diluída.

\subsubsection{Produtividade e qualidade da produção}

O rendimento total analisado foi de 26.5 flores / planta, para o período de 18 meses de condução da roseira sem solo que correspondeu a 15 meses de colheita. A classificação das flores colhidas nas suas respectivas classes comerciais caracterizadas por diferença de comprimento de hastes florais estão na Tabela 4. É importante ressaltar que não foi feita aclimatação da casa de vegetação no período, e que as plantas entram em dormência no período de inverno e também que o sistema de condução das plantas usado foi o sistema tradicional. Atualmente, estão usando o sistema de condução japonês ou em coroa, que permite um favorecimento da produção somente de hastes longas em detrimento das demais (Morisot, 1997), sistema já bastante usado na França e cujo uso na Itália está aumentando. 
Tabela 4. Produção de rosas nos dezoito meses de colheita nas diferentes classes comerciais em comprimento $(\mathrm{cm})$

\begin{tabular}{|c|c|c|c|c|c|c|c|}
\hline $\begin{array}{c}\text { Classe } \\
\text { comercial }\end{array}$ & $<40 \mathrm{~cm}$ & $40-50 \mathrm{~cm}$ & $50-60 \mathrm{~cm}$ & $60-70 \mathrm{~cm}$ & $70-80 \mathrm{~cm}$ & $>80 \mathrm{~cm}$ & Total \\
\hline Rosas/planta & 8.89 & 8.08 & 5.55 & 2.33 & 0.53 & 0.12 & 26.50 \\
\hline
\end{tabular}

Uma atribuição de qualidade sobre base objetiva de parâmetros biométricos foi calculada a partir do peso por unidade de comprimento, em cada fluxo de produção (Tabela 5). Destes dados é possível verificar que as hastes florais desenvolvidas logo após o período de repouso invernal, período que corresponde ao primeiro fluxo de produção, apresentam uma espessura maior em decorrência da poda de inverno ou poda de rejuvenescimento, sendo também o período em que se concentra também a maior produção de flores (Figura 6 e 7).

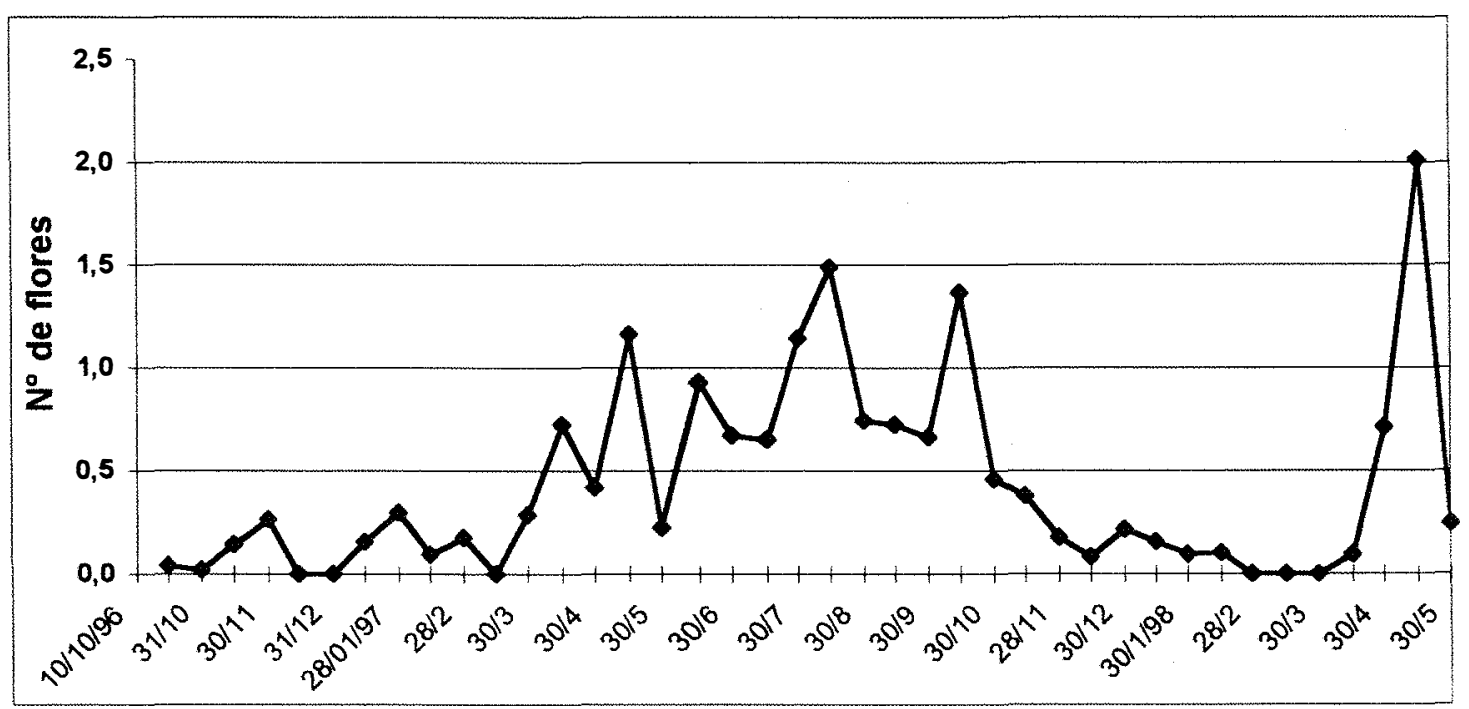

Figura 6 - Distribuição da produção comercial de flores $(>40 \mathrm{~cm})$ 
Tabela 5. Peso por unidade de comprimento de hastes dentro de cada classe comercial

\begin{tabular}{ccccccc}
\hline & \multicolumn{7}{c}{ classe comercial } \\
\hline Data & $<40$ & $40-50$ & $50-60$ & $60-70$ & $70-80$ & $>80$ \\
$08 / 04 / 97$ & não determ. & 1,10 & 1,26 & 1,23 & 1,47 & 1,58 \\
$30 / 06 / 97$ & não determ. & 0,59 & 0,58 & 0,77 & 0,83 & - \\
$30 / 09 / 97$ & não determ. & 0,53 & 0,51 & 0,65 & - & - \\
$07 / 05 / 98$ & não determ. & 0,94 & 1,12 & 1,18 & 1,21 & 1,2 \\
\hline
\end{tabular}

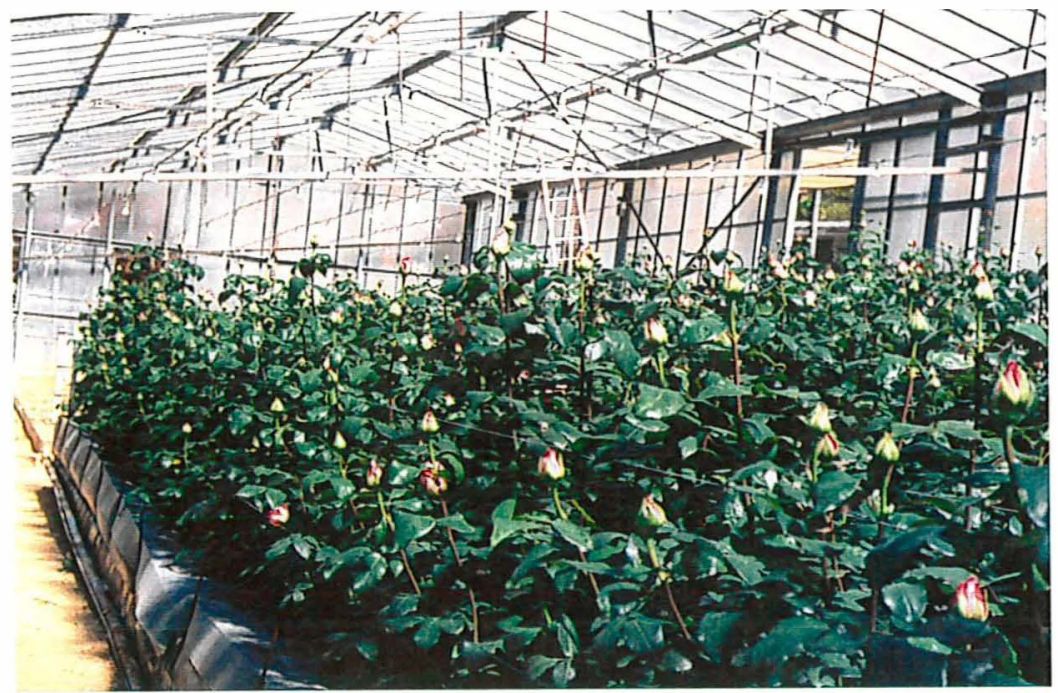

Figura 7 - Visão geral das roseiras no período de produção

\subsection{DISCUSSÃO}

O consumo médio de água obtido no decorrer do experimento $(0.28$ L/planta/dia) foi muito inferior àquele obtido no decorrer de uma experiência feita anteriormente no mesmo sistema para o cultivo sem solo do Chamaelacium (Farina et al, 1997a). Realmente, neste caso relatado, o consumo foi igual a $0.95 \mathrm{~L} /$ planta/dia, média obtida de 10 meses entre outubro e 
julho. Esta diferença de consumo hídrico assim evidente pode ser em decorrência, pelo menos em parte, do efeito da cobertura do substrato usada no ensaio para proteção do substrato e redução da perda de água. É interessante ressaltar-la, mesmo porque no caso da rosa que apresenta crescimento e área foliar muito superior ao do Chamaelaucium obteve-se um consumo médio muito menor. Por outro lado, estes dados sobre o uso de cobertura do substrato em cultura sem solo, já evidenciados por Farina et al., 1997(b), é que levaram a este tipo de condução, por apresentar uma redução no consumo de água de até $30 \%$ e ainda maior produção. No caso deste ensaio, o baixo consumo de água se presume que seja por uma baixa intensidade de evaporação de água e um baixo conteúdo e reduzido aumento da salinidade da solução do substrato, fato importante na condução do sistema, principalmente quando se pensa neste tipo de cultivo em áreas tropicais ou com altas temperaturas e baixa umidade relativa.

O consumo de água ressaltado correspondente a 64.000 litros é muito inferior àqueles obtidos para um cultivo normal sobre terra, estimados em $100 \mathrm{a}$ $130 \mathrm{~m}^{3}$, em base aos turnos de rega e aos volumes de irrigação previstos e que normalmente são aumentados por conta dos próprios produtores ou por condições climáticas mais rigorosas (assistência técnica local).

Em relação ao consumo dos elementos nutritivos, os percentuais de utilização dos macro-elementos, N, P, K, Ca e Mg se encontram entre 91 a 99.2 $\%$; já o $\mathrm{Fe}$ apresentou um baixo aproveitamento em relação àquele que se administrou nas soluções, caso já previsto, uma vez que o $\mathrm{Fe}$ torna-se não disponivel às plantas após determinado período, mesmo que presente na solução é, assim, colocado em quantidades superiores àquelas exigidas pelas plantas, principalmente em casos de ciclo fechado (Tabela 6 ). No caso de se decidir por descartar o drenado remanescente no sistema após os 18 meses de reciclagem, seria jogada no ambiente ou utilizado como adubo em culturas em solo normal, após previa diluição, somente uma pequena quantidade de elementos, muito inferior àquela estimada por Guerin et al (1995), que foi igual 
a $50 \%$. Menor ainda se comparadas as perdas estimadas aos níveis experimentais para o cultivo a ciclo aberto nos experimentos feitos por Jeannequin e Fabre (1993), os quais indicam dispersão superior a $65 \%$ de $\mathrm{N}$ (forma nítrica), a $45 \%$ para o $\mathrm{P}$, a $58 \%$ para o $\mathrm{K}$, a $56 \%$ para o Ca e superior a $80 \%$ para o $\mathrm{Mg}$.

Tabela 6. Balanço do fornecimento dos fertilizantes após 566 dias de reciclo da solução nutritiva

\begin{tabular}{lcccccc}
\hline & $\mathrm{N}$ & $\mathrm{P}$ & $\mathrm{K}$ & $\mathrm{Ca}$ & $\mathrm{Mg}$ & $\mathrm{Fe}$ \\
\hline Colocado $(\mathrm{g})$ & 9195 & 1720 & 10772 & 5555 & 1565 & 31,2 \\
Não utilizado $(\mathrm{g})$ & 202 & 14 & 212 & 464 & 31 & 6,7 \\
\% de utilização & 97.8 & 99.2 & 98.0 & 91.7 & 98.0 & 78.5 \\
\hline
\end{tabular}

A utilização do ciclo fechado segundo a metodologia descrita, permitiu, portanto, uma grande economia de fertilizantes, acima de tudo em relação ao seu desperdício quando este é jogado no meio ambiente, com benefícios do tipo econômico (menor despesa com adubos) e benefícios ao nível ambiental.

Em relação ao aumento da acidez verificada durante as análises de controle do $\mathrm{pH}$ e condutividade elétrica, a partir das soluções nutritivas regeneradas, é necessário considerar que a quantidade de $\mathrm{N}-\mathrm{NH}_{4}$ é um dos principais fatores de controle do $\mathrm{pH}$ de uma solução em reciclagem. Willmsen(1984), trabalhando com alface, considerou que, para manter um pH entre 4 e 5 , seria necessário cerca de $10 \%$ de $\mathrm{N}$ amoniacal e de $90 \%$ de $\mathrm{N}$ nítrico. $\mathrm{O} \mathrm{pH}$, portanto, depende grandemente do nível de $\mathrm{N}$ amoniacal. Por outro lado, o $\mathrm{N}-\mathrm{NH}_{4}$ pode ser oxidado a $\mathrm{N}-\mathrm{No}_{3}$ em passagens sucessivas pela ação de bactérias, principalmente as dos gêneros Nitrosomonas e Nitrobacter que 0 transforma através das reações metabólicas e produzem $\circ$ ion $\mathrm{H}^{+}$. Portanto, é de se considerar que, a partir das soluções nutritivas obtidas dos drenados exauridos regenerados por meio da adição de sais de amônio, se possam obter drenados com elevada acidez, como efetivamente verificados 
neste ensaio, problema que ao nível prático surgem com freqüência, uma vez que, por falta de sais específicos, torna-se difícil regenerar a solução sem a adição de amônio para reequilibrar a solução.

Com relação ao aumento da acidez avaliada na solução circulante no momento que se apresentava com elevada concentração, justamente após vários ciclos com reposição com soluções frescas, não pode ser correlacionada com a elevada quantidade de íon a mônio, uma vez que as análises químicas do drenado exaurido evidenciam ausencia deste ín no momento de ser retirado de circulação. Deste modo, é necessário considerar que a solução nutritiva é um sistema químico extremamente complexo para se fazer uma análise unitária dos fatores que interagem e governam o sistema, sabendo-se que ela é composta de múltiplos subsistemas que apresentam unidades de equilibrio químicos diferentes, quanto à sua solubilidade e capacidade tamponante, mas que interagem entre elas. Poderia ser interessante considerar principalmente dentro dessas propriedades destes subsistemas, aquelas do fosfato biácido que é uma realidade conhecida dentro deste sistema. Para isto, se tiver uma solução de um sal de fosfato biácido, por exemplo, a concentração de cerca $0.1 \mathrm{M}$ (cerca $12 \mathrm{~g} / \mathrm{L}$ ), $\circ \mathrm{pH}$ vai a valores de 4-5, enquanto a diluição de tal solução leva $\circ \mathrm{pH}$ a 7 , ou seja ao $\mathrm{pH}$ semelhante ao da água. Isto pode confirmar o aumento da concentração de íons $\mathrm{H}^{+}$e da salinidade verificada no decorrer do experimento.

Um outro aspecto importante deste método é possibilitar o controle, por meio de análises químicas, de um eventual e desequilíbrio de alguns elementos no drenado exaurido e, portanto, de adequar a real quantidade dos elementos nutritivos à exigência da espécie em cultivo. Por exemplo, nesta pesquisa, o $\mathrm{P}$ administrado pelo primeiro setup (Tabela 1 ) foi excessivamente alto para o reciclagem; uma vez que não era absorvido pela cultura, este vinha acumulado na solução do drenado, e assim permitiu que fosse feito o ajuste, mudando-se a formulação para uma outra que continha menor concentração deste elemento. 
Com os dados desta pesquisa, na qual o consumo de água foi de 0.28 L/planta/dia, o percolado correspondeu a uma produção de drenado exaurido igual a $0.019 \mathrm{~L}$ planta dia. $\mathrm{O}$ drenado exaurido foi analisado e sucessivamente regenerado 9 vezes em 18 meses. Para um cultivo que não seja ao nível experimental, é possivel manejar o drenado exaurido de tal forma que não sejam necessárias análises e regenerações freqüentes. Para isso, bastaria que se armazenasse em uma caixa diversos drenados inadequados ao reciclo e depois seriam submetidos a uma única análise para a sua sucessiva regeneração. Neste caso, o acúmulo progressivo dos drenados em uma caixa de estocagem permitiria diminuir o custo das análises químicas, que variariam segundo o tipo de laboratório no qual seriam encaminhados, sejam públicos, privados, consorciados, ou na própria empresa. Particularmente, o momento em que deve ser efetuada as análises químicas seria sugerido pelo próprio valor econômico do drenado exaurido acumulado e o valor de custo da análise, fato que talvez não seja ainda a realidade, porque não se tem uma legislação rigorosa que proíba o descarte de resíduos químico sobre o solo.

A título de exemplo, pode-se estimar o seguinte cálculo: a partir do valor médio do drenado exaurido obtido no decorrer do experimento, indicou o valor de 2.76 reais $/ \mathrm{m}^{3}$ como base e conômica das análises. Portanto, uma caixa de estocagem de $10 \mathrm{~m}^{3}$ conteria um drenado no valor de 27 reais, ou seja, valor que corresponderia ao custo da análise química junto a um laboratório público. $\mathrm{O}$ volume de $10 \mathrm{~m}^{3}$ de drenados exaustos é alcançado, ao ritmo de 0.019 I/planta/dia, após 526.313 plantas cultivadas /dia (valores que correspondem por exemplo a 526 dias para 1000 plantas em cultivo, ou a 53 dias para 10.000 plantas e assim por diante). Mas, no caso de se estocar o drenado, deve-se levar em consideração que seria necessária a utilização de uma outra caixa para executar os sucessivos reequilibrios ou usar uma caixa de estocagem com volume maior que o total do drenado de tal forma que possibilite sua reequilibratura após as análises. 


\subsection{CONCLUSÃO}

Ao final de 18 meses de cultivo fechado, não foi descartado nenhum drenado do sistema, mas deve-se ressaltar que para ser efetuado este tipo de manejo com longa duração dependeria, acima de tudo, da qualidade da água, porque alguns sais não utilizados pelas plantas, mesmo que não sejam tóxicos, tendem com o tempo a acumular e tornar cada vez mais difícil a regeneração da solução com os elementos nutritivos aos valores do setup e ainda manter os valores da condutibilidade elétrica dentro dos valores toleráveis as plantas. Os ganhos positivos são dirigidos principalmente para a redução dos custos de produção pela utilização em níveis quantitativos dos elementos nutritivos, e também com respeito à preservação do meio ambiente, sem descarte de produtos químicos poluentes. O método proposto compreende a escolha de algumas técnicas, recentemente introduzidas como 0 uso de cobertura protetora "mulching" para a obtenção destes resultados citados. Parte importante deste método é a utilização de computadores, com software específicos, na agilização dos cálculos para a regeneração do drenado a partir das análises, ao nível de pesquisa e principalmente de propriedades agrícolas.

O sistema proposto é superior ao do sistema aberto, mesmo que seja necessário descartar o drenado exaurido após determinado período. 


\section{PRODUÇÃO DE ROSEIRAS PROPAGADAS POR ENXERTIA OU ESTAQUIA EM CULTIVO HIDROPÓNICO}

\section{RESUMO}

Plantas dos cv Sari e Anna propagados por enraizamento de estacas ou enxertadas sobre $R$. indica foram cultivadas em sistema hidropônico aberto, utilizando a mistura areia:turfa $(4: 1 \mathrm{v} / \mathrm{v})$ como substrato. As fertirrigações foram feitas com uma solução completa de macro e micro nutrientes. Os resultados evidenciam aumento na produção para as flores de I classe de 17.33 para 27.95 flores/planta sobre os cultivares Anna e de 14.08 para 21.6 flores/planta sobre o cv Sari a favor das plantas enxertadas. Resultados semelhantes em favor das plantas enxertadas, foram obtidos na produção comercial de flores. Foram verificados, para as plantas enxertas também aumentos da matéria fresca exportada sob forma de flores e também na matéria fresca total (flores + descarte de flores + material de poda). $O$ efeito positivo da enxertia foi verificado também sobre o comprimento das hastes florais da classe 1 e II, com exceção da classe I da cv Sari. Após a poda de rebaixamento das plantas, feita no verão, foi verificado uma menor formação de mergulhões ou ramos de renovação, nas plantas da cv Sari oriundas de estacas enraizadas.

Palavras-chave: Rosa, propagação, hidroponia, estaquia, enxertia, 


\section{PRODUCTION OF ROSE PLANTS HIDROPONICS PROPAGATED BY CUTTINGS OR GRAFTING}

\section{SUMMARY}

The effect of propagation method (rooting of cuttings or grafting on $R$. indica roostock) on growth, flower yield and flower quality of the rose cvs Anna and Sari was investigated in soilless culture with free drainage. The plants were grown in greenhouse on raised banches filled with mixture of sand:peat $(4: 1 \mathrm{v} / \mathrm{v})$. The composition of the fertilizing solution was the same used in commercial productions. Fertigation volume was determined by volume and EC of the drainage. The Expected Leaching Frection was 0.1. In eighteen months of harvesting an increase of yield of flowers of class 1 ( $1>50 \mathrm{~cm})$ was determined in the case of the grafted plants (from 17.33 to 27.95 flowers/plants for cv Anna and from 14.8 to 21.6 flowers/plants for cv Sara). Higher yield of commercial flowers qualit was obtained from grafted plants. Higher fresh matter of cut flower and of the total harvest stem + discard material from pruning was reached by grafted plants. Higher length of flower stem was obtained from the grafted plants of the cv Anna and Sari in the case of flowers belonging to class $\|(1<50 \mathrm{~cm})$, but only for cv Anna in the case of the flowers of class I. The plants of the cv Sari propagated by cut rooting showed poor development of primary shoot (pseudosuckers) after cut-back in july. On the whole grafted plants (minigreffe) gave higher yield and higher flower quality showing higher growth rate (fresh weight of material harvested).

Key words: Rose, propagation method, cuttings, soilless culture 


\subsection{INTRODUÇÃO}

O cultivo sem solo da roseira representa hoje uma técnica de condução já consolidada nos países mais adiantados da Europa, onde já existem protocolos à disposição dos produtores ou estão em desenvolvimento das definiçōes específicas para sua utilização. Pode ser discutido ainda se a utilização de plantas enxertadas deve ser considerada uma opção preferencial. No cultivo sem solo, existem aspectos agronômicos e fisiológicos a serem considerados, bem como as característicos de tal técnica. Um destes aspectos é a particular condição em que se explora o sistema radicular. Tais condições derivam das propriedades físico/químicas do substrato como $\mathrm{pH}$, porosidade etc., das condições de manejo as quais o mesmo substrato é colocado sobre as bases especificas do sistema e do protocolo de gestão da nutrição (composição da solução nutritiva, concentração de oxigênio, temperatura, etc.). Com certeza, um bom substrato para cultivo sem solo deve possuir um conjunto de características particularmente boas para garantir um elevado ritmo de crescimento, em geral melhor do que a maior parte dos substratos naturais. Portanto, a relação de mediador com o terreno, freqüentemente atribuída ao porta-enxerto, sobre a qual normalmente são feitas as escolhas dos portaenxertos, resultaria menos importante. Também a função de garantir maior vitalidade e permitir maior longevidade das plantas assume menor significado na ótica de um desfrute intensivo das plantas, típico do sistema sem solo. É natural, portanto, que se pergunte se a escolha de plantas enxertadas, que são mais caras em relação às plantas propagadas por enraizamento de estacas, seja ainda considerada oportuna para o cultivo sem solo em substratos artificiais.

Com o objetivo de obter alguns elementos que possam contribuir para esclarecer esta dúvida, uma avaliação agronômica comparando plantas propagadas por enraizamento de estacas e plantas enxertadas foi inserido dentro do programa do trabalho de rosas em cultura hidropônica. 


\subsection{MATERIAIS E MÉTODOS}

Os experimentos foram conduzidos junto ao 'Istituto Sperimentale per la Floricoltura di Sanremo', na Itália. Roseiras dos cvs Sari e Anna, obtidas por enraizamento de estacas e por microenxertias (minigreffe), usando como portaenxerto a $R$. indica, foram cultivadas em regime hidropônico em arquibancadas suspensas.

Como substrato, foi adotada uma mistura composta inicialmente de areia:turfa $=4: 1 \mathrm{v} / \mathrm{v}$, substrato que foi utilizado outras vezes por diferentes espécies, com baixa interação química com os elementos fertilizantes das soluções nutritivas e suficiente quanto à porosidade para esta cultura, capacidade de retenção hídrica e boa como suporte físico para as plantas. Este substrato permitiu fertirrigações a cada 3 dias, sem riscos para a cultura.

O transplante foi feito no inicio de Novembro de 1995 distribuindo as plantas em fila única. A densidade final na superfície cultivada resultou em 6,1 plantas $/ \mathrm{m}^{2}$. Para evitar competição entre as variedades ou materiais diferentemente propagados, dotados de diferente ritmos de crescimento, cada variedade, dentro cada variação de propagação, foi transplantada até completar a superfície de duas arquibancadas, escolhidas ao acaso dentro da estufa. Sobre cada arquibancada foram colocadas 7 parcelas, cada uma contendo 6 plantas, sendo utilizadas apenas as 5 centrais como parcelas experimentais para coleta de dados de crescimento e produção. Portanto, foram previstas 10 repetições para cada combinação dos niveis dos fatores experimentais, cv $\mathbf{X}$ unidade de propagação. As plantas foram deixadas em livre crescimento, a temperatura mínima hibernal de $10^{\circ} \mathrm{C}$, até abril de 1996 , fazendo somente a retiradas dos botões florais formados.

As fertirrigações foram feitas com uma solução completa de macro e micro nutrientes obtida via adubos minerais usuais, como nitrato de amônio, 
fosfato monoamônio, nitrato de cálcio e nitrato de magnésio. A relação entre elementos nutritivos está relatada na tabela 1 . O Fe foi distribuído alternado-se na solução irrigada, sob a forma de quelada (Sequestrene) e a forma iônica livre (sulfato ferroso).

Tabela 1. Composição da solução nutritiva

\begin{tabular}{ccccccc}
\hline \multicolumn{7}{c}{ Concentração $(\mathrm{mg} / \mathrm{l})$} \\
\hline $\mathrm{N}-\mathrm{NO}_{3}$ & $\mathrm{~N}-\mathrm{NH}_{4}$ & $\mathrm{P}$ & $\mathrm{K}$ & $\mathrm{Ca}$ & $\mathrm{Mg}$ & $\mathrm{pH}$ \\
169 & 20 & 40 & 210 & 125 & 23 & $5.5-6$ \\
\hline $\mathrm{Zn}$ & $\mathrm{Mn}$ & $\mathrm{Cu}$ & $\mathrm{Mo}$ & $\mathrm{Bo}$ & $\mathrm{Fe}$ & Cond. (mS/cm) \\
0.03 & 0.17 & 0.17 & 0.03 & 0.03 & 0.6 & 2.1 \\
\hline
\end{tabular}

Foi utilizado um sistema hidropônico aberto com drenagem a perder. Para acompanhar e fazer o controle do estado hídrico das culturas, foi usado o método proposto por Farina (1996), que se baseia essencialmente no controle da percolação efetiva das fertirrigações efetuadas. Para o monitoramento do sistema, foi montada, dentro das arquibancadas, uma caixa de $70 \times 70 \times 17 \mathrm{~cm}$ de material plástico, o qual era preenchido com os mesmo substrato e continha plantas em cultivo idêntico ao restante da arquibancada. As caixas continham um leve declive para o centro e um furo central, com o objetivo de canalizar o excesso de irrigação a um recipiente coletor ali disposto. $O$ confronto entre 0 volume drenado real e aquele teórico permite calcular o volume a ser irrigado na fertirrigação sucessiva. O percentual de drenado teórico foi fixado em $10 \%$ do volume de solução fertirrigante administrada; o intervalo entre as fertirrigações foi fixado em dois por semana. 
No inverno 1996/97 foi mantido um regime térmico mínimo do ar de $12^{\circ} \mathrm{C}$. Foi adotado o sistema de colheita contínua, ou seja, sem programação de colheitas e sem períodos de repouso hibernal. O corte da haste floral foi feito no ramo do botão, com exceção nos períodos de rebaixamento, a ramos de ordem inferior àqueles floridos, sempre que foi julgado necessário, seguindo uma avaliação de vigor dos ramos floridos, ou nos períodos de rebaixamento a ramos de segunda ordem, de inverno e nos períodos de repouso e de baixa produção do verão.

Uma avaliação da formação de gemas de renovação (mergulhões) foi feita no final de setembro de 1996. Do mês de abril de 1996 até final de junho 1998, foram analisados dados de produção de flores e de matéria fresca. As flores foram divididas em classes caracterizadas por diferença de comprimento $e$ hastes: Classe I $(>50 \mathrm{~cm})$, classe II $(30-50 \mathrm{~cm})$, classe II $(<30 \mathrm{~cm})$.

Os dados foram submetidos à análise de variância e sucessivamente ao teste de confronto de médias ( Teste de Tukey. $\mathrm{P}=0.05$ ).

\subsection{RESULTADOS}

Os dados foram analisados separadamente para cada cultivar. Os dados de colheita de abril de 1996 a julho de 1998 (26 meses de colheitas continua) estão na tabela 2, e evidenciam um aumento significativo no número de flores pertencentes à classe I, em favor das plantas enxertadas, tanto sobre a cv Anna (de 17.33 para 27.95 flores/planta) quanto sobre a cv Sari (de 14.08 para 21.6 flores/planta). Nenhuma diferença significativa em relação à forma de propagação foi constatada para a produção da classe II cv Sari, mas, para a cV Anna, houve uma redução da produção de flores dentro desta categoria. Entretanto, analisando-se a produção comercial relativa, soma das duas produções na classe I e classe II, verifica-se, no caso da cv Anna, aumentos de $15.6 \%$ e de $17.6 \%$ para a cv Sari, conforme expresso na tabela 2 . 
Tabela 2. Produtividade média (número de flores/planta) de 27 meses de colheita dentro das devesas classes

\begin{tabular}{lcccccc}
\hline & \multicolumn{2}{c}{ Classe I } & \multicolumn{2}{c}{ Classe II } & \multicolumn{2}{c}{ comercial } \\
\hline \multirow{4}{*}{ Anna } & Sari & Anna & Sari & Anna & Sari \\
Enxertadas & $27.95 \mathrm{a}$ & $21.60 \mathrm{a}$ & $12.97 \mathrm{a}$ & $34.97 \mathrm{a}$ & $40.92 \mathrm{a}$ & $56.61 \mathrm{a}$ \\
Estacas & $17.33 \mathrm{~b}$ & $14.08 \mathrm{~b}$ & $18.09 \mathrm{~b}$ & $34.07 \mathrm{a}$ & $35.46 \mathrm{~b}$ & $48.15 \mathrm{~b}$
\end{tabular}

As médias nas colunas seguidas da mesma letra não diferem significativamente entre si (teste de Tukey, $p=0.05$ )

Da análise da produção de matéria fresca vegetal, confirma-se claramente o efeito positivo do porta-enxerto, já verificado ao nível de rendimento de número de flores. Verifica-se, no caso das plantas enxertadas, um substancial aumento da massa de matéria exportada na forma de flores (de 1309.7 para 1545.5 e de 1230.5 para $1774.5 \mathrm{~g} /$ planta respectivamente, para o cv Anna e Sari). Análogo aspecto pode ser encontrado, analisando-se a massa total de matéria fresca exportada, que corresponde à massa das flores menos aquelas flores de descarte e a parte podada por efeito de limpeza ou para revigoramento das plantas (tabela 3 ).

Tabela 3. Peso médio da matéria fresca das flores colhidas e da substância fresca total exportada das plantas de rosa propagadas por estacas ou microenxertia.

\begin{tabular}{lcccc}
\hline & \multicolumn{2}{c}{ Matéria fresca de flores $(\mathrm{g})$} & \multicolumn{2}{c}{ Matéria fresca total $(\mathrm{g})$} \\
\hline & Anna & Sari & Anna & Sari \\
Enxertadas & $1545.48 \mathrm{a}$ & $1774.53 \mathrm{a}$ & $1712.97 \mathrm{a}$ & $1992.96 \mathrm{a}$ \\
Estacas & $1309.73 \mathrm{~b}$ & $1230.53 \mathrm{~b}$ & $1442.25 \mathrm{~b}$ & $1443.15 \mathrm{~b}$ \\
\hline
\end{tabular}

As médias nas colunas seguidas da mesma letra não diferem significativamente entre si (teste de Tukey, $p=0.05$ ) 
Com respeito ao comprimento médio das flores colhidas, foi verificado, para o cv Anna, aumento de 57.8 para $60.7 \mathrm{~cm}$ na classe I e de 42.1 para 43.9 cm na classe II para o material propagado via microenxertia. Para o cv Sari, um aumento no comprimento significativo ao nível estatístico foi verificado em favor das plantas enxertadas, somente no caso da classe II (de 40.0 para $41.2 \mathrm{~cm}$ ). Os dados relativos a estes parâmetros biométricos não são apenas de significado fisiológico, mas também de importância prática, porque correlacionam às classes de qualidade comercial, resultados que estão representados na tabela 4.

Tabela 4. Comprimento médio das flores dentro de cada classe comercial (cm)

\begin{tabular}{lcccc}
\hline & \multicolumn{2}{c}{ Comprimento(classe I) } & \multicolumn{2}{c}{ Comprimento(classe II) } \\
\hline \multirow{3}{*}{ Enxertadas } & Anna & Sari & Anna & Sari \\
Estacas & $60.71 \mathrm{a}$ & $54.54 \mathrm{a}$ & $43.93 \mathrm{a}$ & $41.22 \mathrm{a}$ \\
& $57.87 \mathrm{~b}$ & $53.54 \mathrm{a}$ & $42.11 \mathrm{~b}$ & $40.03 \mathrm{~b}$
\end{tabular}

As médias nas colunas seguidas da mesma letra não diferem significativamente entre si (teste de Tukey, $p=0.05$ )

Com relação à distribuição da produção no tempo, figuras 1 e 2, é possível verificar o andamento da floração (produção da classe I), demonstrando ser um processo análogo para as plantas enxertadas ou plantas propagadas por enraizamento de estaca, exceto com relação à maior produtividade para o primeiro tipo de propagação. As duas variedades seguem o mesmo padrão de floração, dentro dos tratamentos previstos, mas são diferenciadas entre elas. Com relação ao cv Sari (figura 2), é importante notar, em particular, na primeira fase de produção, uma forte diferença em favor das plantas enxertadas, aspecto relacionado seguramente a um maior vigor expresso destas plantas. A diferença relativa se acentua, na verdade, no andamento da produção das flores de 
qualidade comercial (figura 3). Já para o cv Anna, esta diferença não foi evidenciada, como mostra a figura 4. A hipótese do maior vigor das plantas enxertadas do cv Sari pode ser reforçada com os resultados relativos à presença de ramos de renovação no fim de setembro de 1996, após a poda de rebaixamento feita em julho, assim como pela maior espessura de hastes dada pela relação do peso por $\mathrm{cm}$, demostrado para o cv Sari, figura 5 e 6 . Na tabela 5 , vem expressa a quantidade destes ramos mais robustos e vigorosos, que se originam na base da planta (mergulhões) e que são utilizados em geral para reconstituir a estrutura produtiva da planta, condição ilustrada pela figura 7 e 8 .

Tabela 5. Formação de ramos basais de renovação após a poda de julho de 1996 ( ramos/planta média \pm err. Std)

\begin{tabular}{lll}
\hline & cv Anna & cv Sari \\
\hline Enxertadas & $0.18 \pm 0.043$ & $0.14 \pm 0.046$ \\
Estacas & $0.21 \pm 0.043$ & $0.03 \pm 0.016$ \\
\hline
\end{tabular}

É possivel verificar facilmente que, entre as quatro combinações $c v x$ método de propagação, foram exatamente as plantas da cv Sari propagadas por enraizamento de estaca as que apresentaram resultados claramente inferiores. 


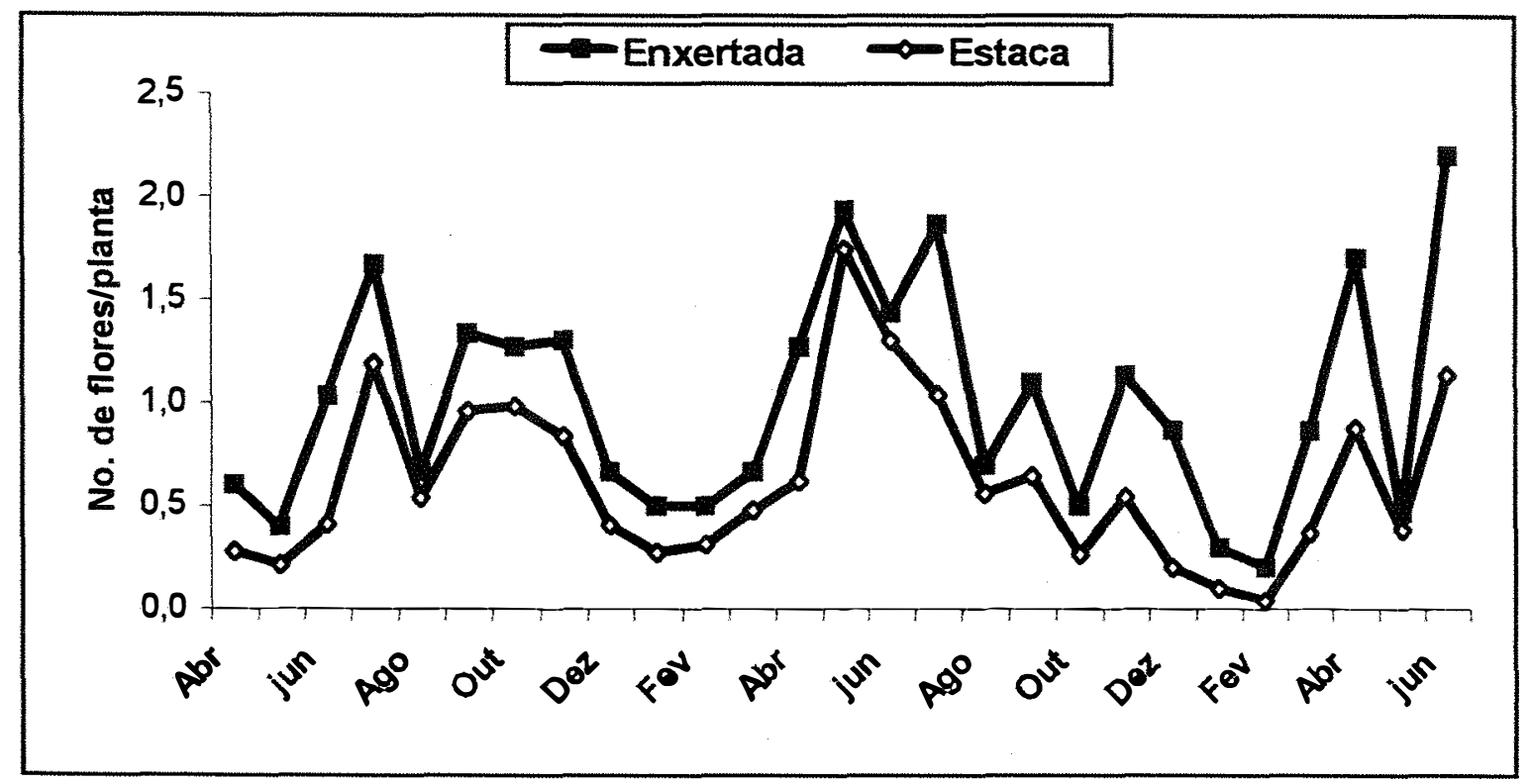

Figura 1 - Distribuição da produção de flores de I classe no tempo - cv Anna

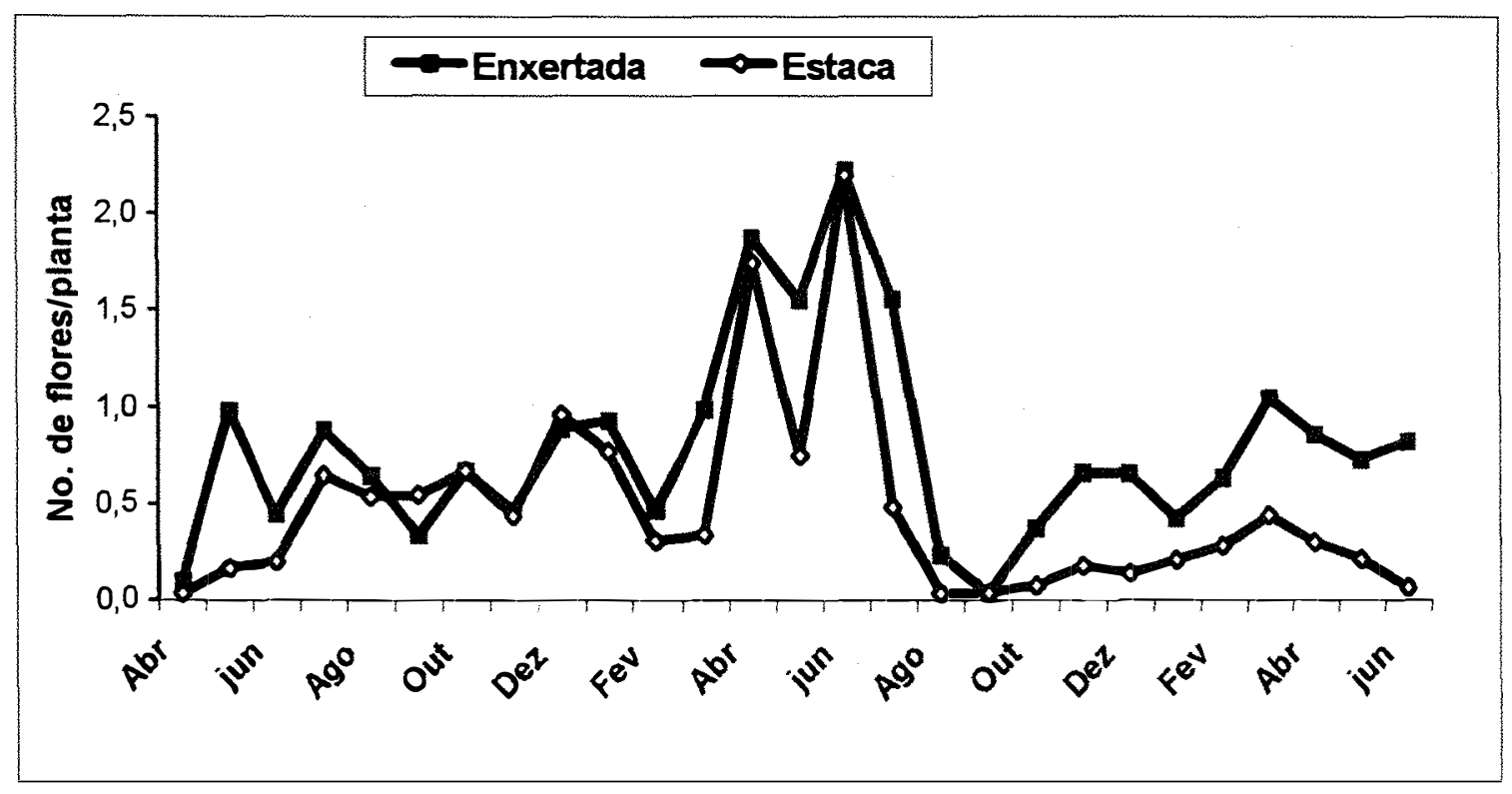

Figura 2 - Distribuição da produção de flores de I classe no tempo - cv Sari 


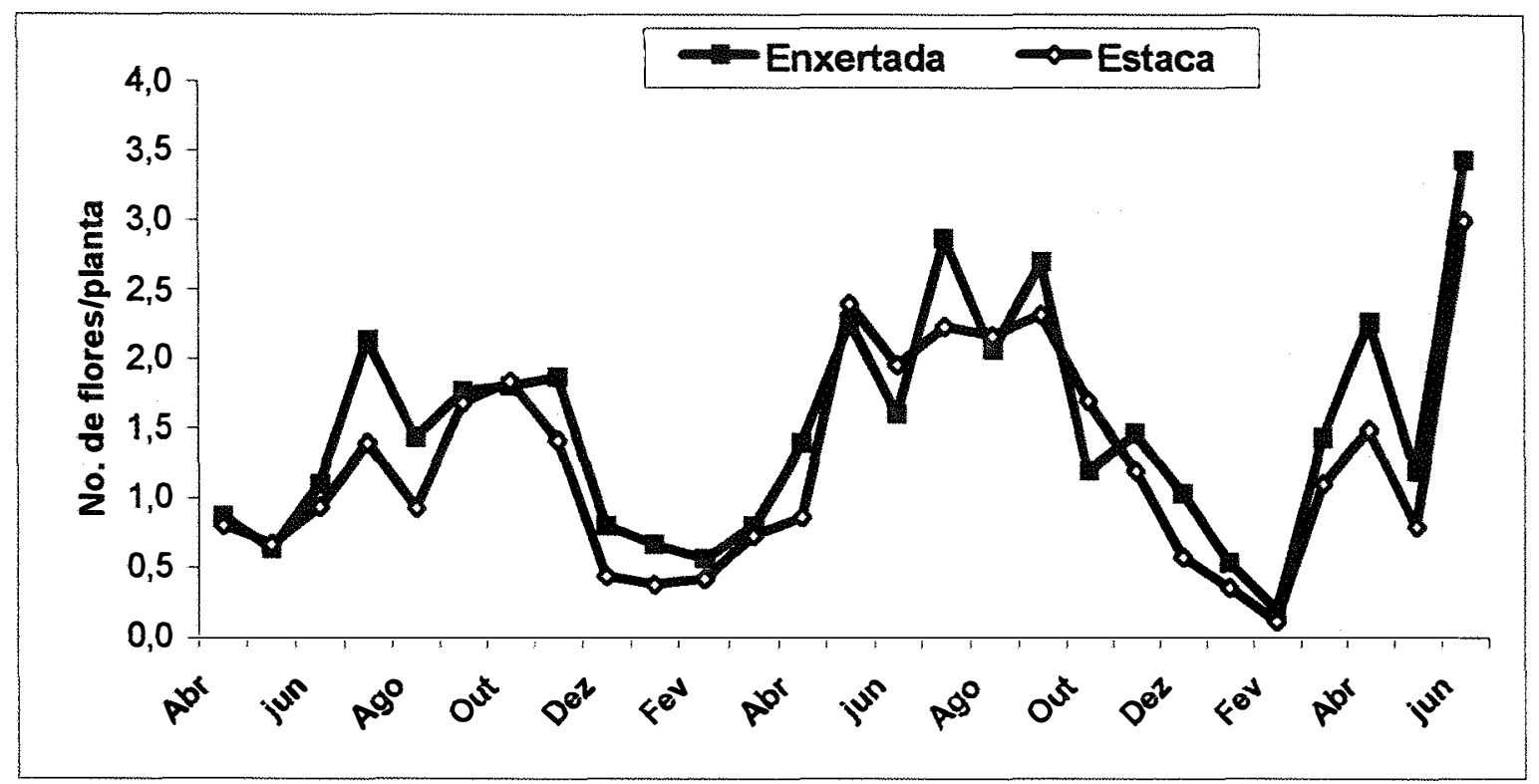

Figura 3 - Distribuição da produção de flores comerciais no tempo - cv Anna

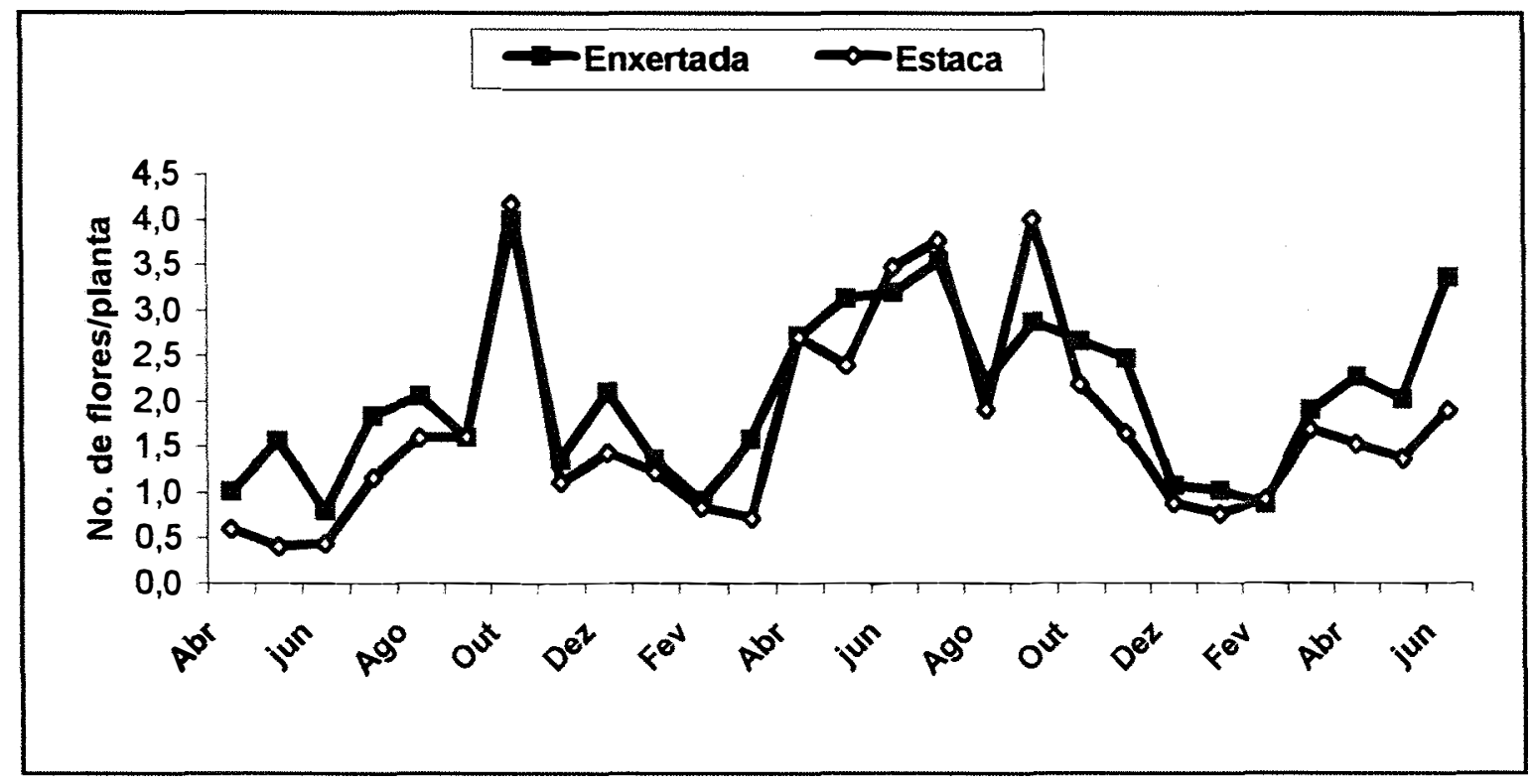

Figura 4 - Distribuição da produção de flores comerciais no tempo - cv Sari 


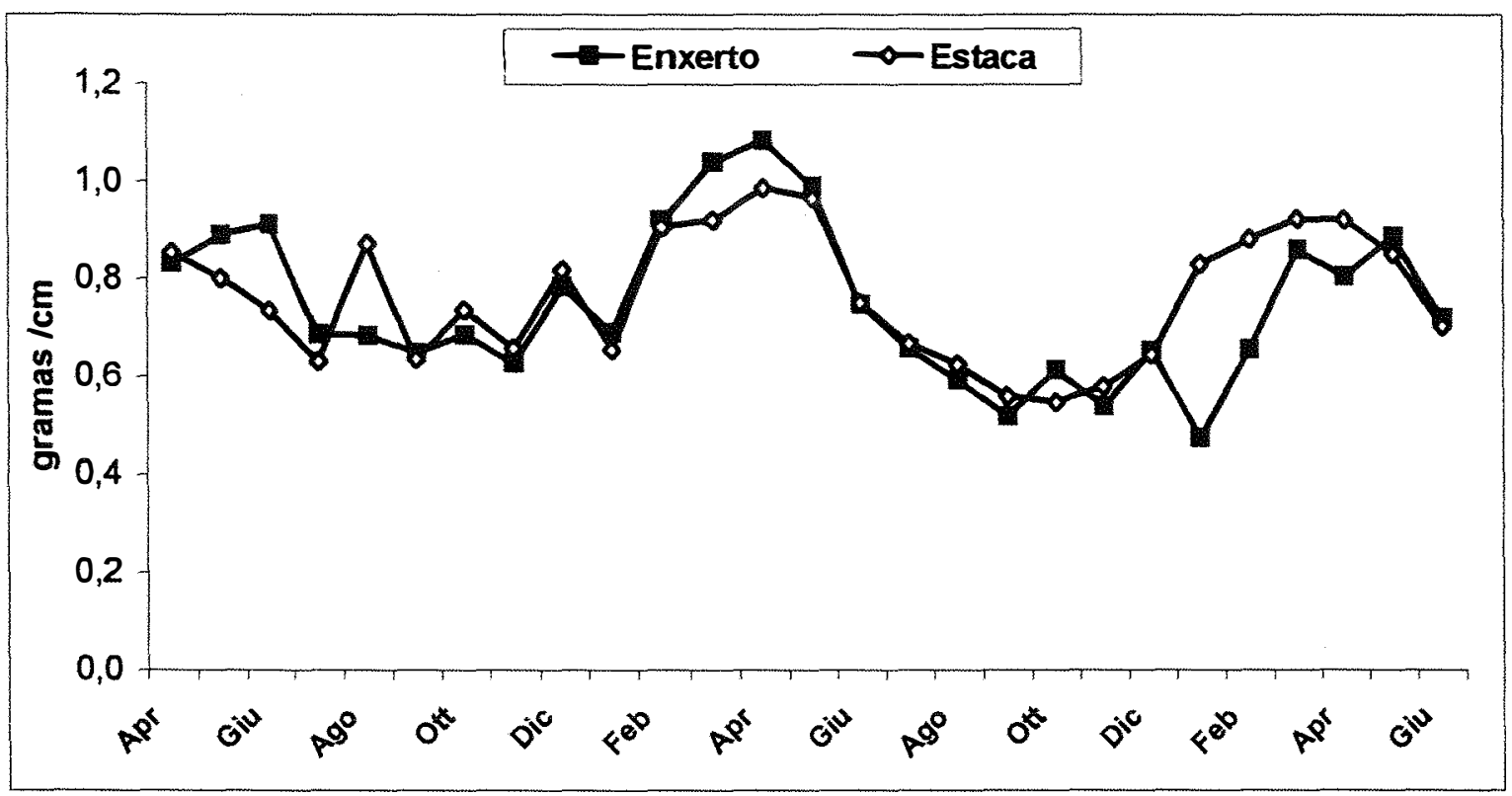

Figura 5 - Distribuição do peso médio por centímetro de haste de rosa colhida no tempo - cv Anna

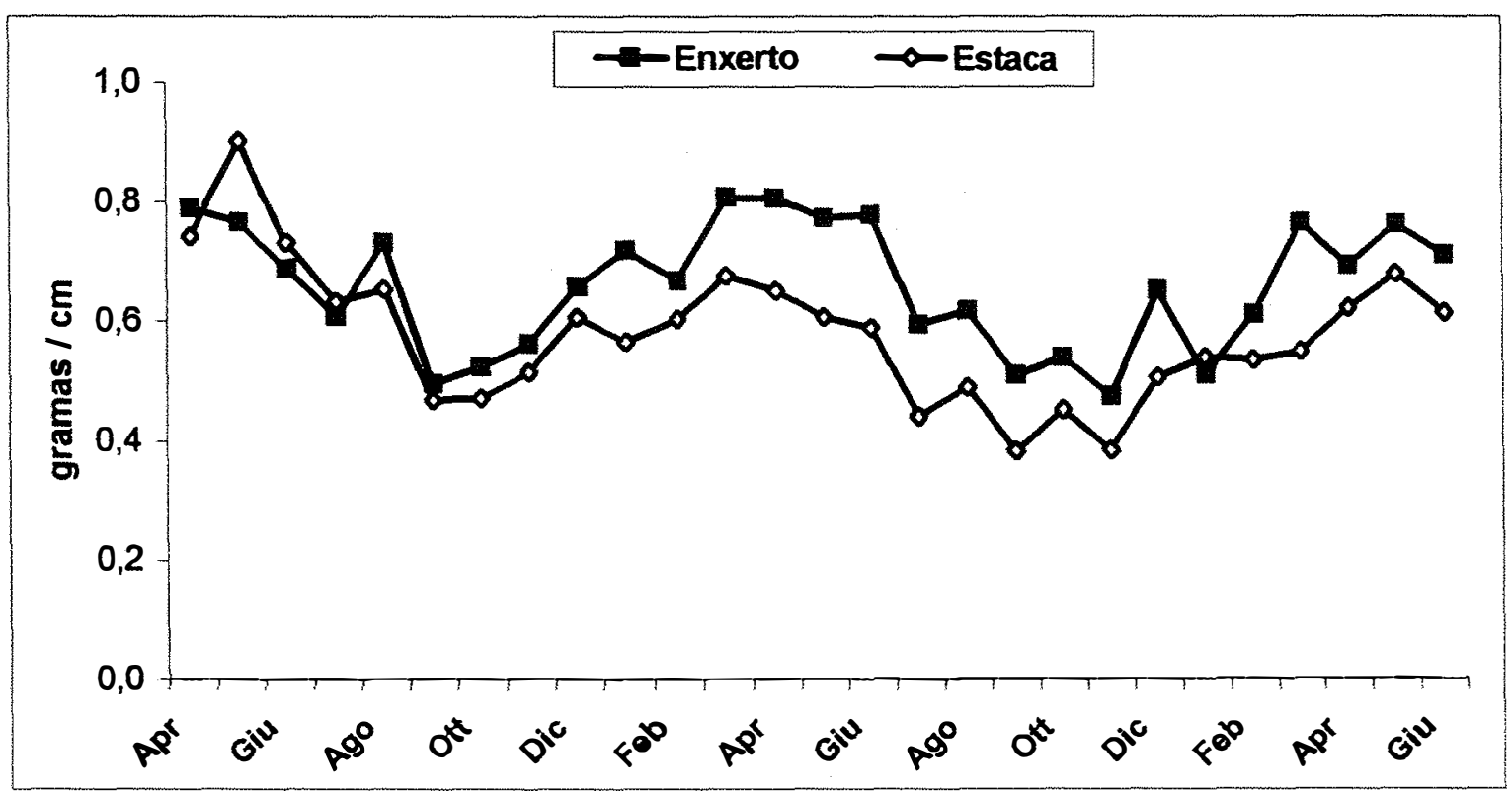

Figura 6 - Distribuição do peso médio por centímetro de haste de rosa colhida no tempo - cv - Sari 


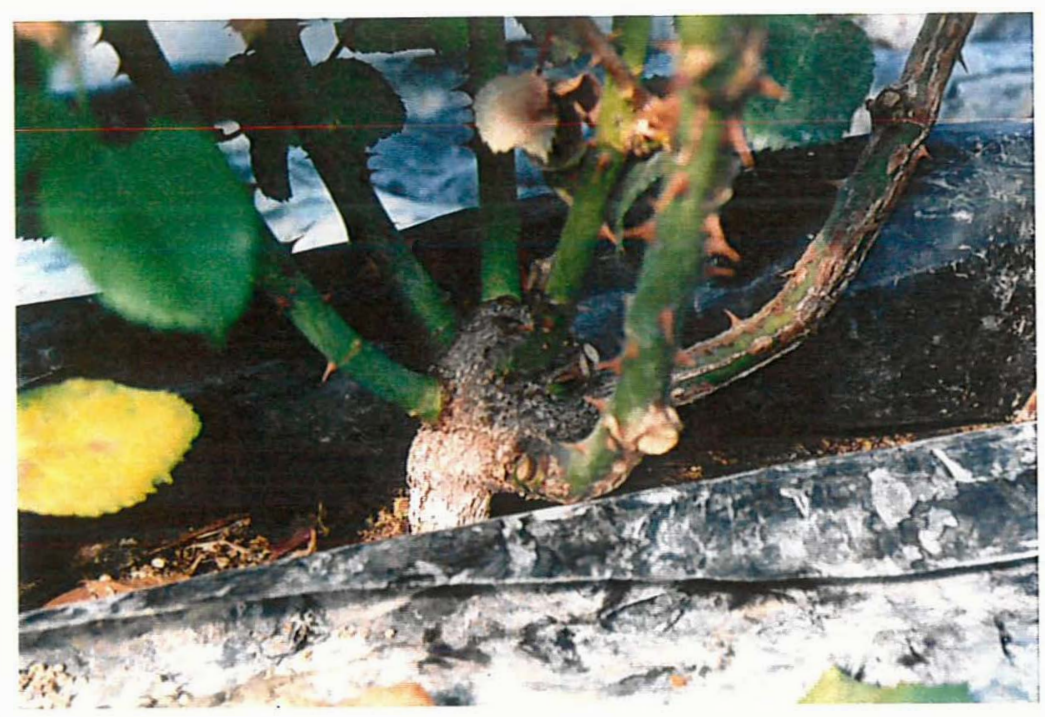

Figura 7 - Roseira da cv Sari propagada por enxertia

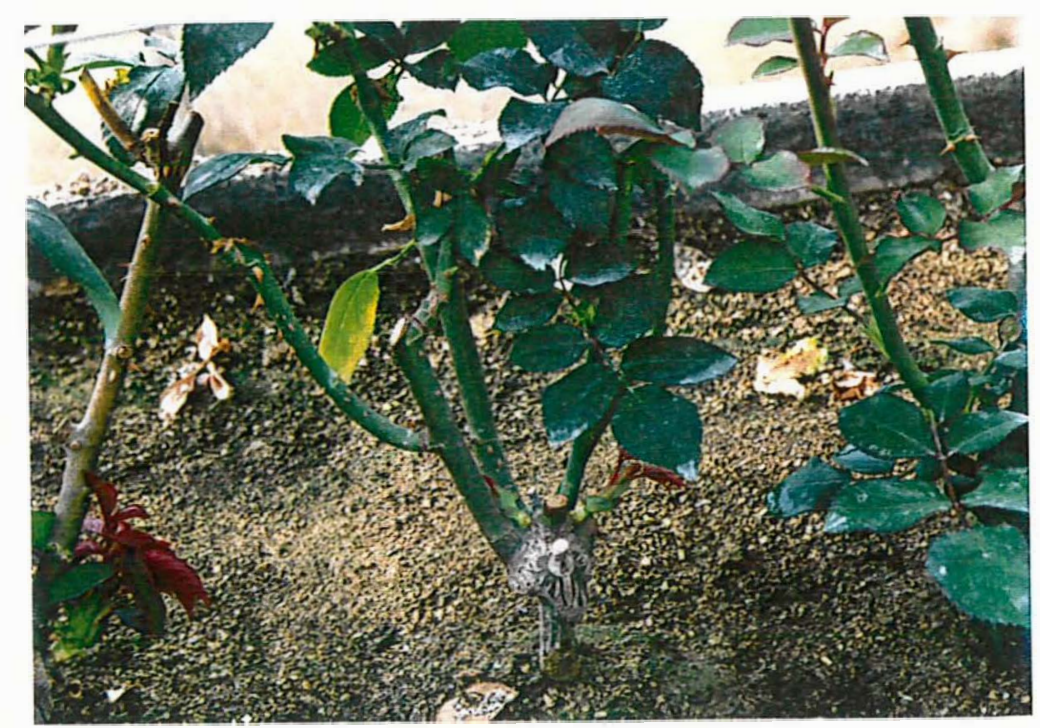

Figura 8 - Roseira da cv Sari propagada por estaquia 


\subsection{DISCUSSÃO}

O uso de plantas propagadas por enxertia é, ultimamente, uma prática comum no cultivo tradicional da rosa. No solo, naturalmente tem-se maior risco de ataques de patógenos ao sistema radicular, além das condições de nutrição não serem sempre as ideais para a cultura. Esta técnica de propagação vem sendo usada para obter rendimentos superiores e dar maior longevidade produtiva às plantas. No cultivo sem solo, o benefício do enxerto poderia ser devido a uma maior tolerância às variações da salinidade no substrato, que é variável com relação à suscetibilidade do cultivar. Neste sentido, Singh(1984) verificou que a recuperação, o crescimento e o desenvolvimento das gemas foram reduzidos com a utilização de determinados porta-enxertos, principalmente quando o nivel de salinidade da solução drenada foi maior ou igual a $4000 \mathrm{mmS} / \mathrm{cm}$. De acordo com a metodologia adotada, é oportuno e importante recordar que a modalidade de condução da nutrição adotada prevê um aumento do volume de irrigação ou mesmo somente de água nas condições em que a salinidade da solução drenada for maior ou igual a $4000 \mathrm{mmS} / \mathrm{cm}$ (Farina, 1996). Deste modo, pode-se afirmar também, baseando-se no controle da salinidade do drenado, que foi evitado, na fase de condução, o surgimento de situações de elevada salinidade no substrato. Portanto, não é admissivel supor que os benefícios obtidos da utilização de plantas enxertadas sejam apenas pela maior tolerância à salinidade, sendo necessário procurar diferentes razões para eventual melhora da performance das plantas. Com isto, recorda-se como elementos de grande importância, os dados relativos sobre o número dos novos ramos formados para a renovação das plantas encontrados em outubro no cv. Sari, depois da poda de rebaixamento de julho. Tais elementos comprovariam um maior vigor vegetativo das plantas enxertadas. É evidente que somente as plantas enxertadas podem usufruir do mecanismo de formação de gemas a partir de tecidos não diferenciados da região de soldagem entre enxerto e portaenxerto, gemas que dão origem aos ramos chamados mergulhões ou ramos 
machos. Para as plantas propagadas por enraizamento das próprias estacas, em uma das duas variedades, ou seja no cv Anna, foram as gemas basais sobre o ramo principal da estaca que deram origem a esses tipos de ramos, passando a assumir o mesmo papel dos ramos denominados morfologica e funcionalmente de mergulhões. No cv Sari, tais mecanismos contrariamente ao cv anterior, não se manifestaram, resultando praticamente na ausência de ramos neste local.

A superioridade das plantas enxertadas em cultivo sem solo, com respeito às plantas de estacas, foi evidenciada por algumas pesquisas, e em outras não. Com base a algumas provas feitas na França, o cv Royal Red (planta microenxertada sobre a $R$. indica) cultivado sobre lã de rocha, forneceu no período de outubro/junho cerca $31 \%$ de produção a mais, quando comparada com plantas oriundas de enraizamento de estacas, com um aumento de $16,4 \%$ de produtos de primeira qualidade (Hoffmann, 1991). Os resultados de uma pesquisa feita por Bredmose \& Hansen (1995), relacionando a produção de 20 meses de cultivo sobre lã de rocha, demonstraram resultados superiores para as plantas de estacas do cv Frisco, enquanto o cv Gabriela, tanto de estacas ou microenxertadas, tenham apresentado resultados idênticos, principalmente dentro da classificação de primeira. Em ambos os casos, foram usados a $R$. canina (Inermis) como porta-enxerto. Halevy (1986) relata a superioridade produtiva em lã de rocha para muitas cultivares de rosa originadas de estacas em relação a plantas enxertadas. Contrariando estes dados, Van de Pol (1993) obteve dados de superioridade para plantas enxertadas. Estes dados contraditórios, no conjunto, levam-nos a uma visão pouco clara sobre eventual superioridade produtiva com o uso da enxertia, uma vez que os resultados se derivam de contradições, mas analogamente podem-se verificar os mesmos tipos de confrontos agronômicos, feitos para o uso ou não de plantas enxertadas para o cultivo tradicional, a nível de solo. Este tipo de discussão e contradições foram apresentadas por Picard (1968). 


\subsection{CONCLUSÃO}

Em relação aos resultados obtidos, parece totalmente favorável o uso de plantas enxertadas para os dois cultivares utilizados em hidroponia nesta pesquisa. Apesar disso, dado o pequeno número de cultivares empregados para o teste, não é absolutamente possível confirmar, em base genérica, o conceito da conveniência, do ponto de vista dos resultados produtivos. 


\section{EFEITO DA COBERTURA DO SUBSTRATO COM FILME PLÁSTICO EM CULTIVO SEM SOLO DA ROSEIRA}

\section{RESUMO}

Plantas das cultivares Anna e Sari foram conduzidas em cultivo sem solo em bancadas com e sem cobertura do substrato. O material usado para a cobertura foi o plástico preto de espessura de $0.18 \mathrm{~mm}$. Como substrato de cultivo, foi usada a mistura de areia:turfa $=4: 1 \mathrm{v} / \mathrm{v}$. Os transplantes foram feitos em novembro de 1995, dispostos em fila única com 7.5 plantas $/ \mathrm{m}^{2}$. Para o controle da fertirrigação, foi usado o método que se baseia no uso de um Lisímetro, colocado em cada bancada, o qual permite obter o percentual de drenado prefixado e também controlar o limite máximo de salinidade do percolado, a partir do qual é adicionada água para lavar o excesso de sais do substrato. O percentual de drenagem teórico foi fixado em $10 \%$ do volume irrigado, e a salinidade máxima a $4000 \mathrm{mmS} / \mathrm{cm}$ e as fertirrigações em duas por semana.

Como resultado do uso da cobertura do substrato, foi verificada redução do consumo hídrico de $35 \%$ e $16 \%$ correspondente as cultivares Anna e Sari e também menor salinização dos substratos. $O$ uso da cobertura do substrato permitiu uma melhoria de qualidade de flores e também ganho em produtividade, com menor consumo hídrico, resultando em maior eficiência de uso da água. A umidade no ambiente das raízes manteve-se mais estável 
principalmente na superfície do substrato, comprovando o uso da cobertura do substrato como uma técnica, a mais, para o controle da umidade e da salinidade do substrato, com redução da quantidade de drenagem e da quantidade de água e de fertilizantes administrados, com redução dos custos de produção e benefícios para o meio ambiente.

Palavras-chave: Rosa, cobertura do substrato, cultivo hidropônico

\section{EFFECT OF MULCHING IN SOILESS SYSTEMS ON THE ROSE CULTURE}

\section{SUMMURY}

Plants of rose cvs Anna and Sari grafted on Rosa indica rootstock were grown in close soilless systems with and without mulching of black polyethytene sheet $(0.18 \mathrm{~mm})$. The plants were grown in a greenhouse on raised benches filled with a mixture of sand:peat $(4: 1 \mathrm{v} / \mathrm{v})$. The plants in single row ( 7.5 plants / cultivated $\mathrm{m}^{2}$ ) were maintained in a greenhouse at a minimum temperature of $12^{\circ} \mathrm{C}$ in winter. The fertirrigation was carried out with a leaching fraction $10 \%$ controlled by lysimeters. According to a formerly tested method, substrate leaching by an increased volume of nutritive solution or water occurre in case of an electric conductivity level $=1>4000 \mathrm{mmS} / \mathrm{cm}$ in the leachate. There was a reduction in the water consumption of 35 and $16 \%$ corresponding respectively to cvs Anna and Sari in the case of mulching. The number of fertigations with increased volumes of nutritive solution or water for high leachate salinity decreased in the mulched cultivation. Salt accumulation near the subsbstrate surface of the control was very high in summer. A lower electrical conductivity and a higher water content of the mulched substrate was recorded both in fall and in spring/summer. The results showed significtive differences of flowers production and quality of mulched system. Higher 
efficiency of water use was caused by lower evaporation, and lower increase of the electrical conductivity of the substrate.

Key words: Rose, mulching, soilless culture

\subsection{INTRODUÇÃO}

O efeito da cobertura morta do solo, no sistema de cultivo tradicional em solo, é uma técnica com efeitos agronômicos bem definidos, sendo comprovado o melhoramento da produção e da qualidade da rosa com o uso da cobertura com filme de polietileno (Paskalev, 1983). Os efeitos desta cobertura sobre as características do substrato de cultivo são de natureza diversas. No cultivo de Angelica dahurica, a umidade do solo foi mantida em até $72 \%$ com a utilização desta técnica (Chung et al., 1991). Alguns efeitos da cobertura do substrato, sobre rosas de corte (Rosa Chinensis), foram obtidos no controle da salinidade, avaliado em diferentes profundidades, sobre o comprimento e diâmetro de hastes florais e rendimento na produção de flores (Wu GenLang \& Cai WeiGuo, 1996). Também foram verificados aumentos no número e rendimento na produção de hastes de rosas utilizadas na produção de óleos usados como essências, após uma poda drástica (Paskalev \& Tsacjev, 1982).

O cultivo da rosa sem solo, em bancadas ou mesmo em vasos, è conduzido usualmente sem essa proteção e sem controle da evaporação da água. Os substratos artificiais que normalmente são empregados para a cultura sem solo são caracterizados por elevada porosidade ou disponibilidade de ar. Normalmente, o mesmo não acontece com a disponibilidade de água, que na maioria dos casos é baixa. Nestas condições, os processos de evaporação podem assumir valores relativamente elevados, que conduzam a importantes alterações, tanto sobre a quantidade de água disponivel às plantas, quanto na composição química da solução nutritiva do substrato, fatores que podem influir 
na disponibilidade de todas as substâncias ou elementos fundamentais ao crescimento das plantas.

O problema da variação da salinidade no substrato via acumulação de sais e a sua renovação via fertirrigação tem sido avaliada nos sistemas de cultivo sobre lã de rocha (Van Noordwijk \& Raats, 1980), sistema em que o substrato vem protegido por um saco plástico com perfurações, fornecendo indicações sobre estratégias e parâmetros de fertirrigação a ser adotado para conter os efeitos desfavoráveis da evaporação. No sistema estudado, o substrato é envolvido por um plástico, podendo ser considerado como na presença da cobertura do substrato.

A manutenção da qualidade da solução nutritiva no substrato assume importância, tanto no sistema hidropônico no ciclo aberto quanto no ciclo fechado. Para o sistema a ciclo fechado, pode-se melhorar a qualidade do drenado em reciclo, uma vez que manteria os niveis dos elementos nutritivos em condições mais propícias as culturas por um período mais longo. Com base nestas ponderações, foi idealizado este experimento, com o objetivo de avaliar o efeito da cobertura do substrato com lona plástica, em sistema de cultivo sem solo, sobre o balanço hídrico/nutricional e sobre o crescimento e produtividade na cultura da roseira.

\subsection{MATERIAL E MÉTODOS}

Roseiras dos cultivares Sari e Anna microenxertadas, sobre $R$. indica, foram colocadas em cultivo hidropônico em bancadas suspensas, junto ao Istituto Sperimentale per la Floricoltura di Sanremo, Itália, adotando como variantes no sistema, plantas com cobertura do substrato e plantas sem cobertura. As coberturas do substrato nas bancadas foram feitas usando filme de plástico preto de espessura de 0,18 $\mathrm{mm}$. Como substrato, foi adotada uma mistura composta inicialmente de areia:turfa $=4: 1 \mathrm{v} / \mathrm{v}$. $O$ transplante foi feito no início de novembro de 1995, dispondo as plantas em linha única. A densidade 
final na superfície cultivada foi de 7.5 plantas/ $\mathrm{m}^{2}$ ( largura das bancadas de 0,7 $\mathrm{m}$ ). Em cada bancada foram conduzidas 7 parcelas (cada uma contendo 6 plantas), das quais apenas as 5 centrais foram utilizadas como unidades experimentais para a coleta dos dados de crescimento, e de produção. As plantas foram deixadas em crescimento livre, à temperatura mínima hibernal de $10^{\circ} \mathrm{C}$ até abril de 1996 , executando somente a retirada dos botões florais formados.

Foi utilizado o sistema hidropônico aberto com perda do drenado. Para o monitoramento e controle do estado hídrico das culturas, foi utilizado o método proposto por Farina et al. (1996), sobre o qual é calculado o volume de fertirrigação, baseando-se nos percentuais dos drenados e de sua salinidade prefixada. Neste ensaio, o percentual de drenagem teórica foi fixado em $10 \%$ do volume de solução fertirrigada. A salinidade máxima do drenado foi fixada em $4000 \mathrm{mmS} / \mathrm{cm}$. Toda vez que a salinidade atingisse o teto máximo fixado, a irrigação sucessiva era conduzida somente com água para lavar o substrato. Os intervalos entre irrigações foram fixados em dois interventos por semana. Caixas lisimétricas, dispostas na extremidade de cada bancada, permitiram o cálculo do balanço hídrico, a partir dos dados do volume irrigado e o volume drenado. Sistema igual foi colocado nas bancadas sem plantas para estimar a evaporação. O uso deste método prevê o uso de um software próprio "Fersan46" para os cálculos da quantidade da solução a ser irrigada, programa que armazena os dados de todas as soluções nutritivas administradas e seus respectivos drenados produzidos a cada intervento de fertirrigação.

As fertirrigações foram feitas com uma solução completa em macro e micro elementos, obtidas a partir de adubos minerais usuais, com as seguintes concentrações em mg/l; N-NO3 (150.9), N-NH4(23.4), P(41), K(220), Ca(96), $\mathrm{Mg}(33), \mathrm{Fe}(0.6), \quad \mathrm{Mn}(0.17), \mathrm{Cu}(0.17), \quad \mathrm{B}(0.03), \quad \mathrm{Zn}(0.03), \quad \mathrm{Mo}(0.03)$, $\mathrm{CE}(2.1 \mathrm{mS} / \mathrm{cm})$. A concentração foi reduzida a $2 / 3$ no período de verão. $O$ ferro foi distribuído alternando na solução irrigada na forma quelada (Sequestrene) e 
aquela ionica livre (sulfato ferroso). A distribuição da solução nutritiva (ou d'agua) foi feita uniformemente sobre toda superfície do substrato.

O ensaio foi conduzido em casa de vegetação climatizada, programada para manter o regime térmico mínimo do ar a $12{ }^{\circ} \mathrm{C}$ nos invernos de 96/97 e 97/98, e nos demais períodos do ano programada para a abertura de janelas laterais e posteriormente do teto a partir dos $25^{\circ} \mathrm{C}$ no ambiente interno da casa de vegetação.

Foi adotado o sistema de colheita contínua de flores. O materiais frescos colhidos; flores, descarte vegetal, ou materiais de poda, foram pesados. As flores colhidas foram divididas em classes comerciais caracterizadas por diferenças de comprimento de hastes: classe I, classe II, e classe III (descartes). Dados de temperatura, umidade e salinidade do substrato de $0-5 \mathrm{~cm}$ e de $6-10 \mathrm{~cm}$, foram coletados no quarto dia após a fertirrigação, seguindo a programação habitual de irrigação prevista. Os dados foram coletados durante duas semanas de novembro de 1997 e de junho de 1998, sendo cada período representado por seis repetições. Os dados de salinidade foram coletados a partir da adição de água destilada sobre a amostra do substrato previamente pesada, de acordo com o método utilizado por Chen et al. (1991) para alguns substratos minerais. $100 \mathrm{~g}$ do substrato foi pesado $\left(\mathrm{P}_{0}\right)$ acrescentado $100 \mathrm{ml}$ de água destilada e, após a decantação, foi medida a salinidade. Em seguida, o substrato foi colocado para secar a $110^{\circ} \mathrm{C}$ e novamente pesado $\left(P_{1}\right)$. Por Diferença de peso $\left(P_{0}-P_{1}\right)$ foi calculada a água inicial $\left(P_{2}\right)$. A partir do valor da água inicial, foi calculada a diluição $\left(P_{2}+100\right) / P_{2}$ empregada para estimar a salinidade real do substrato, usando uma curva, previamente calibrada, de diluição da solução nutritiva.

No final da pesquisa, o sistema radicular das plantas foi arrancado, secado e pesado. Todos os dados colhidos foram submetidos a análise de variância e sucessivamente aos testes de confronto de médias (Teste de Tukey, $P=0.01)$. 


\subsection{RESULTADOS}

Da análise do balanço hídrico dos 790 dias de cultivo sem solo com cobertura do substrato com filme plástico, foram verificadas reduções no consumo hídrico de $35 \%$ sobre o cultivar Anna e de $16 \%$ sobre o cultivar Sari e também, redução do total dos drenados de $29 \%$ nas bancadas cobertas, para a cv Anna e de $10 \%$ para a cv Sari. A necessidade de se fazer interventos somente com água para correção da salinidade foram reduzidas de 58.5 para 43,5 e de 51.5 para 42 interventos, respectivamente, sobre os cvs Anna e Sari com cobertura de plástico. Isto significa que a salinidade foi mantida por um período mais longo, sem alcançar a salinidade máxima fixada nos 4000 $\mathrm{mmS} / \mathrm{cm}$ (Tabela 1). É importante verificar que, somado à redução do volume total da solução drenada, foi ainda constatada aumento percentual do drenado em relação à quantidade administrada. Foi verificada, no caso, das bancadas vazias, a contribuição da evaporação sobre o consumo hídrico total. A cota de $1,41 \mathrm{Ll} / \mathrm{m}^{2} / \mathrm{dia}$, nas bancadas vazias, é bastante diferente de 1,89 e 1,88 $\mathrm{L} / \mathrm{m}^{2} /$ dia de consumo nas bancadas com os cultivares Anna e Sari, consumo que se deve à evaporação, transpiração e a água retida pelos tecidos. Entretanto, por observações já feitas anteriormente, por Farina e Cervelli (1994), as cotas de água retida pelos tecidos são tão pequenas que podem ser desprezadas em termos práticos.

A distribuição do consumo hídrico e da evaporação está representada nas Figuras 1 e 2 . Nos primeiros meses de cultivo, a evapotranspiração foi semelhante a evaporação nas bancadas sem o plástico para cobertura do substrato. À medida que as plantas foram crescendo, aumentou também o consumo de água por evapotranspiração, o mesmo acontecendo nas estações do ano mais quentes. No mês de abril, iniciaram-se as colheitas das flores, que continuaram nos meses sucessivos. O ritmo do consumo hídrico foi alterado ao iniciar as colheitas, a partir de abril, por causa da retirada da planta de material 
vegetal (flores e folhas), operação que interfere na superfície transpirante das mesmas. A cobertura do substrato explica uma ação complexa, agindo seja sobre evaporação do substrato, seja sobre a transpiração das plantas por meio dos efeitos sobre o seu próprio ritmo de crescimento. Portanto, para possibilitar o melhor entendimento deste processo, deve-se analisar o efeito da cobertura sobre o balanço hídrico em condições de produção. Assim, fez-se a análise dos componentes do balanço hídrico, juntamente com a produção exportada pelas plantas.

Tabela 1. Balanço hídrico de 790 dias de cultivo da roseira em sistema de cultivo sem solo, com e sem cobertura do substrato com filme plástico, e número de interventos com água para correção da salinidade

\begin{tabular}{llccccc}
\hline & substrato & $\begin{array}{c}\text { Irigação } \\
\mathrm{L} / \mathrm{m}^{2} / \mathrm{dia}\end{array}$ & $\begin{array}{c}\text { Drenado } \\
\mathrm{L} / \mathrm{m}^{2} / \mathrm{dia}\end{array}$ & $\begin{array}{c}\% \\
\text { percolado }\end{array}$ & $\begin{array}{c}\text { Ev+trans.+tecidos } \\
\mathrm{L} / \mathrm{m}^{2} / \mathrm{dia}\end{array}$ & Interv. c/ água \\
\hline Cv Anna & Coberto & 1.61 & 0.42 & 26.08 & 1.19 & \\
& Descoberto & 2.47 & 0.59 & 23.75 & 1.89 & 58.5 \\
\hline Cv Sari & Coberto & 2.05 & 0.52 & 25.22 & 1.53 & 42.0 \\
& Descoberto & 2.44 & 0.57 & 23.18 & 1.88 & 51.5 \\
\hline vazio & Descoberto & 1.83 & 0.43 & 23.27 & 1.41 & 65.5 \\
\hline
\end{tabular}

Da relação entre produção de matéria fresca e consumo hídrico, foi observada uma redução no consumo de água e incremento da eficiência no uso da água com o uso da cobertura do substrato, durante toda a condução do experimento (Figuras 3 e 4). Notáveis diferenças na eficiência e consumo de água foram demonstrados com a mudança das estações climáticas do ano. No verão, foi verificada redução na eficiência de uso da água para a produção de matéria fresca, ou seja, nesta estação foi gasta mais água para produzir uma 
unidade de peso de matéria seca, fato explicado em conseqüência da alta taxa de evaporação, e também, conforme Baille et al. (1994), o estresse hídrico e a alta temperatura durante este período, levariam a um déficit de vapor de pressão. Juntamente à alta temperatura do substrato, induzem o fechamento dos estômatos e, em conseqüência, reduzem a taxa de fotossíntese. Entretanto, mesmo neste período, as plantas com cobertura do substrato conseguiram maior eficiência de produção de matéria fresca por litro de água consumada.

Da análise agronômica dos dados de 27 meses de colheita contínua de rosa, foi verificado ganho tanto de qualidade quanto de produtividade, com o emprego da cobertura do substrato (Tabela 2), com aumento da produção de flores da classe I igual a 8.99 e 4,46 flores/planta respectivamente para a cV Sari e Anna, já para a classe II a produção foi significativamente superior somente para a cv Sari. O rendimento da produção comercial cresceu de 29.66 para 38.16 flores/planta (+29\%) para a cv Anna e de 33.52 para 52.43 flores/planta (+56\%) para a cv Sari.

A produção de matéria fresca proveniente das flores colhidas e também da exportação de flores de descartes e podas foi sempre a favor das plantas com cobertura do substrato. Quanto à massa média das flores, não foi verificada nenhuma diferença significativa com o uso da cobertura, isto significa que o aumento de matéria fresca corresponde simplesmente a um aumento no número de flores nas respectivas classes, mantendo a massa média das flores. Igualmente, na análise da distribuição de flores e comprimento em cada classe, verifica-se que o aumento na produção não vem acompanhado de aumento no comprimento das hastes, exceto na cv Sari classe II, Tabela 3 e 4. 


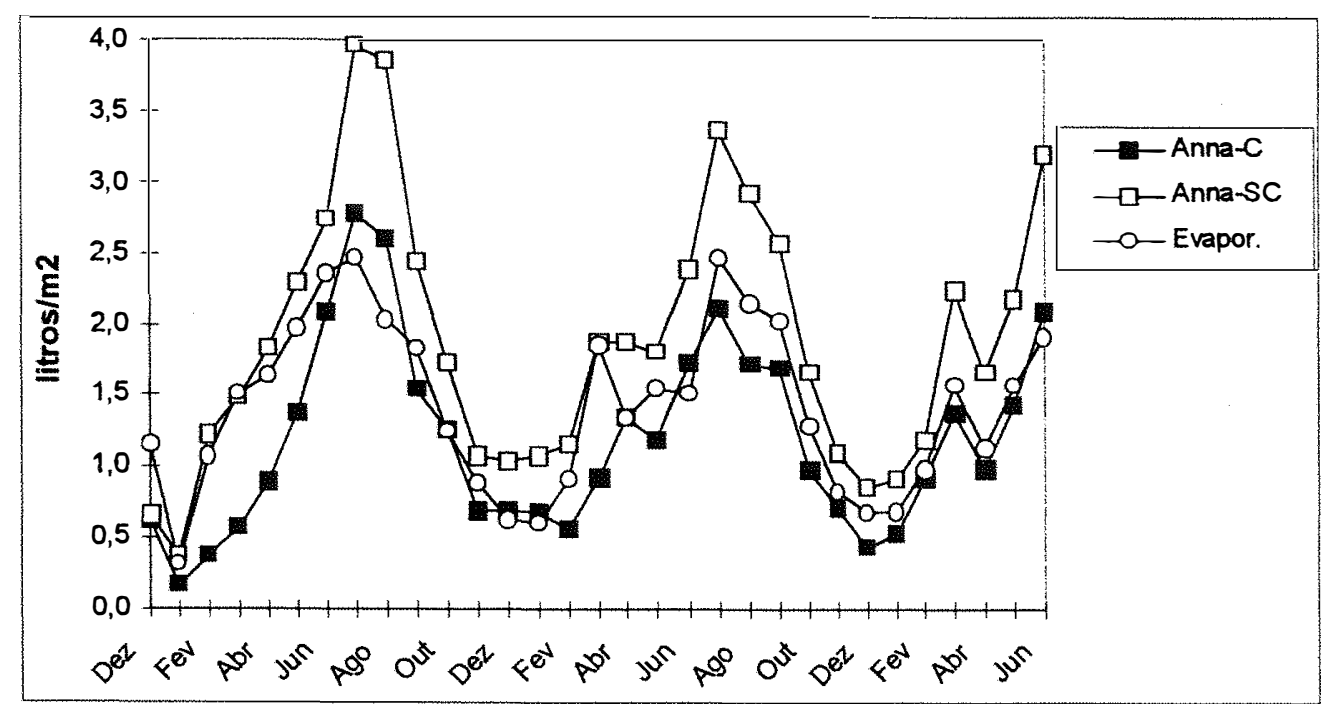

Figura 1 - Distribuição do consumo hídrico médio (cv Anna) e da evaporação por $\mathrm{m}^{2}$, com cobertura $C$ e sem cobertura SC do substrato

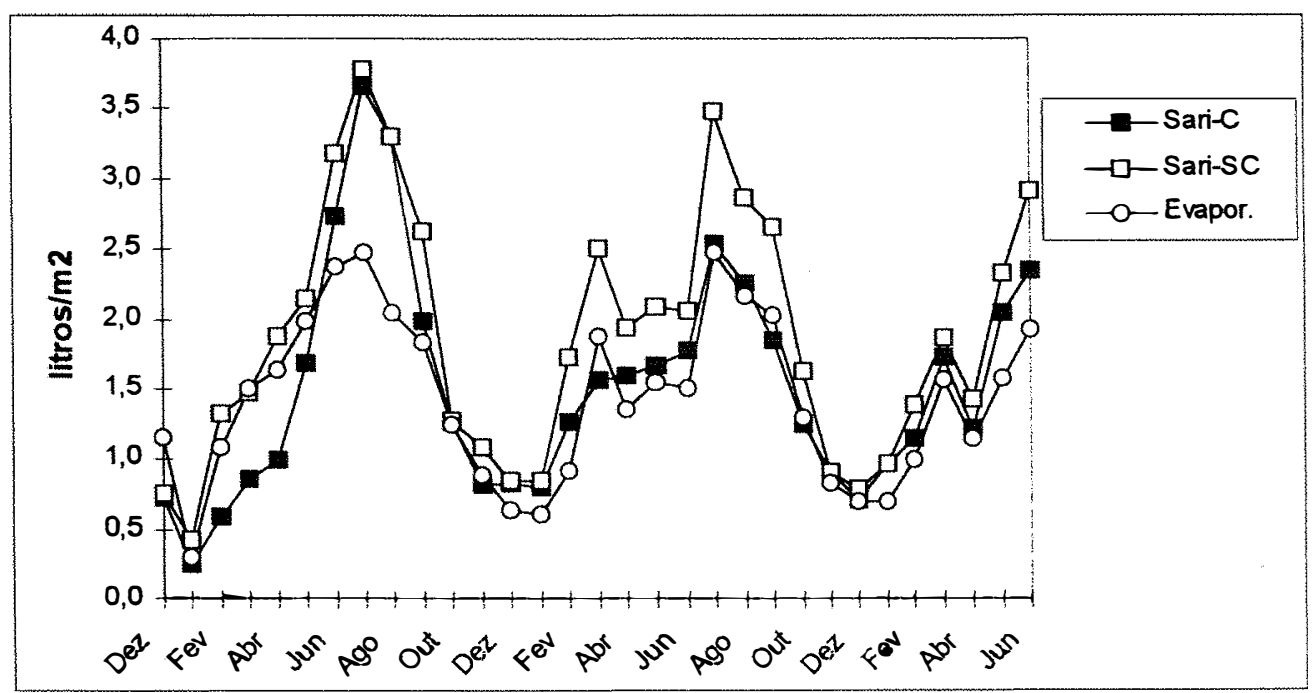

Figura 2 - Distribuição do consumo hídrico médio (cv Sari) e da evaporação por $\mathrm{m}^{2}$, com cobertura $C$ e sem cobertura SC do substrato 


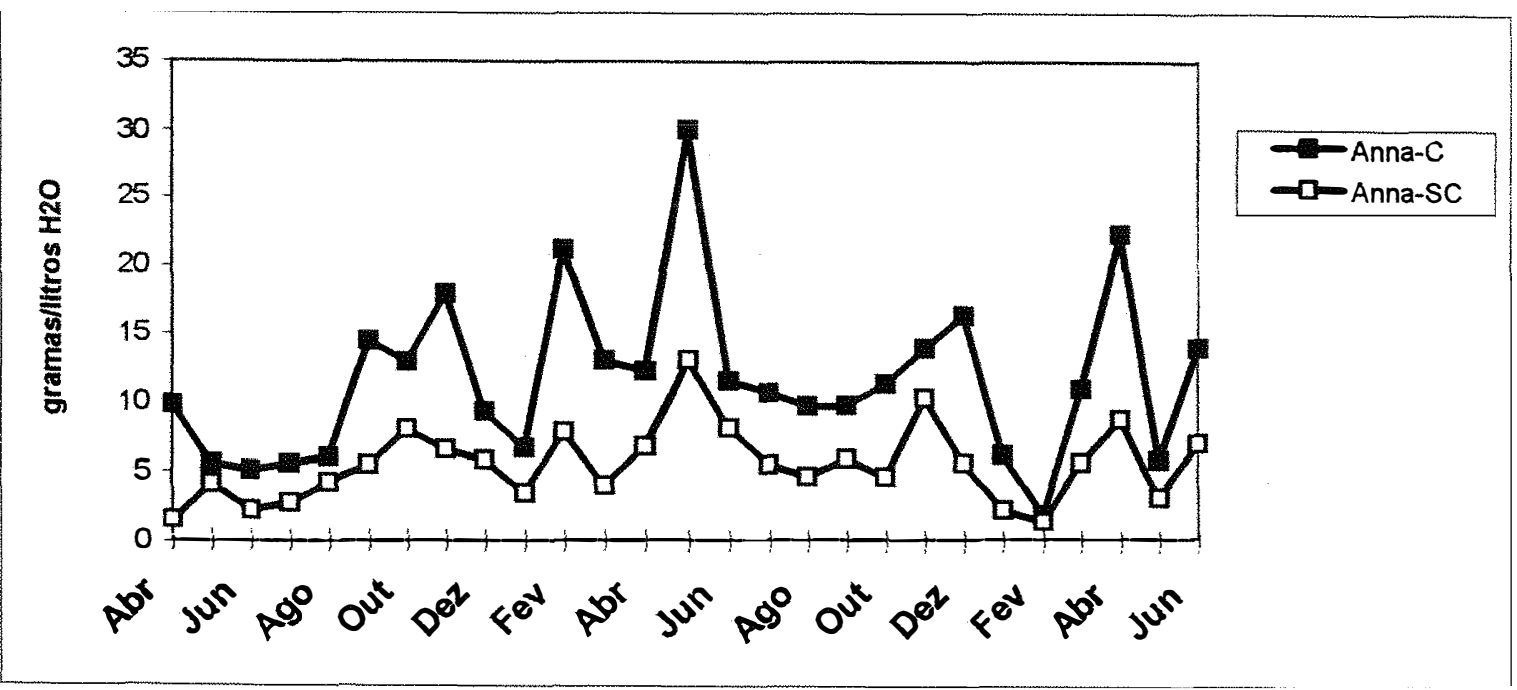

Figura 3 - Produção média mensal de matéria fresca por litro de água consumada com e sem cobertura com filme plástico do substrato, cv Anna, C-coberto e SC- sem cobertura

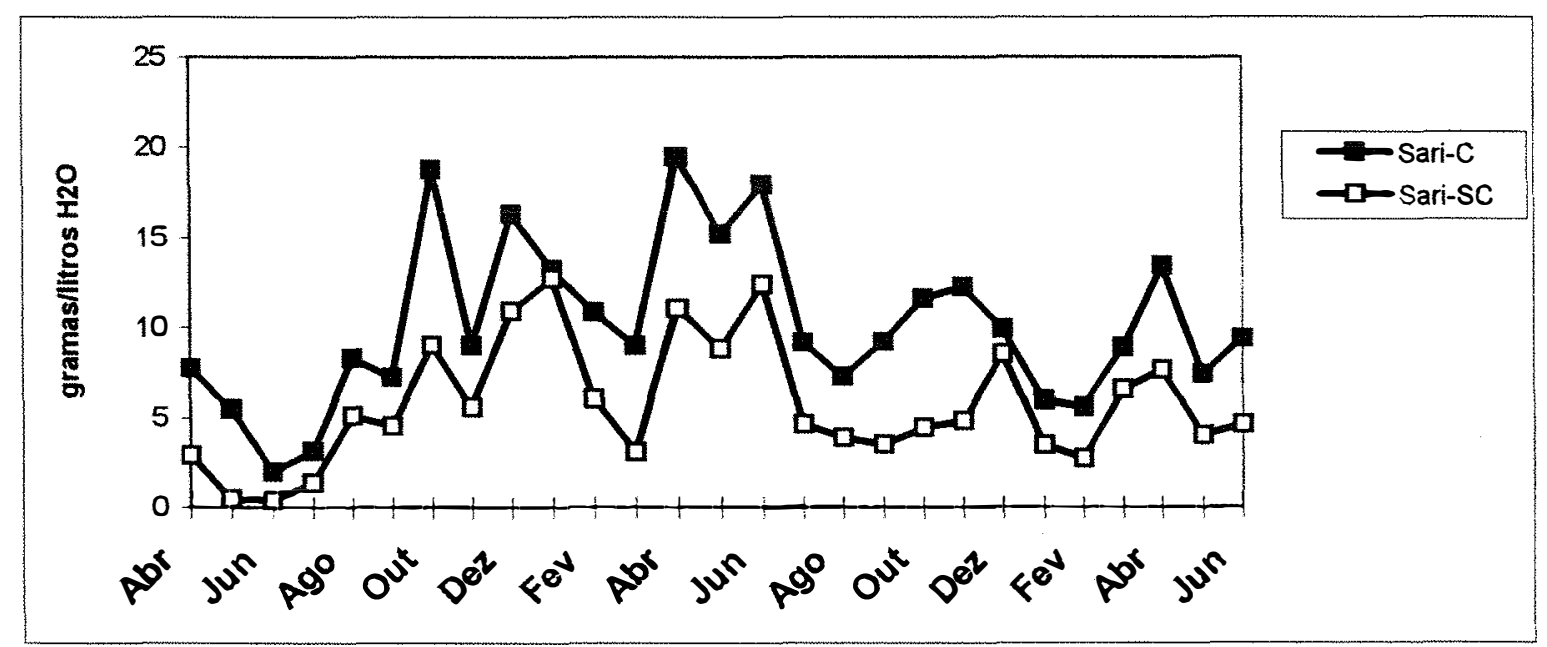

Figura 4 - Produção média mensal de matéria fresca por litro de água consumada com e sem Cobertura com filme plástico do substrato, cv Sari, C - coberto e SC- sem cobertura. 
Tabela 2. Produtção (número de flores por planta) de vinte sete meses de colheita

\begin{tabular}{lcccccc}
\hline & \multicolumn{2}{c}{ classe } & \multicolumn{2}{c}{ classe II } & \multicolumn{2}{c}{ comercial } \\
\cline { 2 - 7 } & Anna & Sari & Anna & Sari & Anna & Sari \\
\hline Coberto & $22.64 \mathrm{a}$ & $17.86 \mathrm{a}$ & $15.53 \mathrm{a}$ & $34.56 \mathrm{a}$ & $38.16 \mathrm{a}$ & $52.43 \mathrm{a}$ \\
Descoberto & $18.18 \mathrm{~b}$ & $8.87 \mathrm{~b}$ & $11.52 \mathrm{a}$ & $24.57 \mathrm{~b}$ & $29.66 \mathrm{~b}$ & $33.52 \mathrm{~b}$
\end{tabular}

As médias nas colunas seguidas da mesma letra nåo diferem significativamente entre elas (Teste de Tukey, $p=0.01$ )

Tabela 3. Peso fresco de flores por planta, peso médio por unidade de flor e matéria fresca total exportada das plantas de rosa com e sem cobertura do substrato

\begin{tabular}{lllllll}
\hline & \multicolumn{2}{c}{$\begin{array}{c}\text { Massa fresca de } \\
\text { flores } \\
(\mathrm{g})\end{array}$} & \multicolumn{2}{c}{$\begin{array}{c}\text { Massa média de } \\
\text { flores } \\
(\mathrm{g})\end{array}$} & \multicolumn{2}{c}{$\begin{array}{c}\text { Massa fresca total } \\
(\mathrm{g})\end{array}$} \\
\cline { 2 - 7 } & Anna & Sari & Anna & Sari & Anna & Sari \\
\hline Coberto & 1427.63 a & 1502.51 a & 37.41 a & 28.66 a & 1577.61 a & 1718.06 a \\
Descobert & 1096.07 b & 943.07 b & 36.95 a & 28.14 a & 1222.46 b & 1086.93 b \\
o & & & & & & \\
\hline
\end{tabular}

As médias nas colunas seguidas da mesma letra nåo diferem significativamente entre elas (Teste de Tukey, $P=0.01$ )

Tabela 4. Comprimento médio de flores dentro de suas respectivas classes

\begin{tabular}{lcccc}
\hline & \multicolumn{2}{c}{$\begin{array}{c}\text { Comprimento (classe } \\
(\mathrm{cm})\end{array}$} & $\begin{array}{c}\text { Comprimento (classe II) } \\
(\mathrm{cm})\end{array}$ \\
\cline { 2 - 5 } & Anna & Sari & Anna & Sari \\
\hline Coberto & $59.32 \mathrm{a}$ & $54.18 \mathrm{a}$ & $42.50 \mathrm{a}$ & $41.22 \mathrm{a}$ \\
S/ cobertura & $58.94 \mathrm{a}$ & $53.15 \mathrm{~b}$ & $42.63 \mathrm{a}$ & $39.21 \mathrm{~b}$
\end{tabular}

As médias nas colunas seguidas da mesma letra não diferem significativamente entre elas (Teste de Tukey, $P=0.01$ ) 
O efeito benéfico e progressivo (Figura 5 ) da cobertura do substrato foi evidenciado em todos os meses do ano. Entretanto, dentro da classe 1 este efeito foi menor para o período mais quente do ano, de julho a setembro, e também para o período mais frio, que foi em fevereiro (Figura 6 e 7).

Os efeitos da cobertura do substrato sobre a salinização, a retenção de umidade e a manutenção da temperatura, ao quarto dia da fertirrigação está representada na Tabela 5. A salinidade no substrato coberto foi sempre inferior a $50 \%$ àquela encontrada sobre o substrato não coberto. A salinidade no substrato apresentou variação com a profundidade. Para o substrato coberto, a salinidade de $0-5 \mathrm{~cm}$ foi menor do que a $6-10 \mathrm{~cm}$, enquanto que, no substrato não protegido com o plástico, ocorre exatamente o contrário, efeito que se torna ainda maior nos períodos mais quentes. Por exemplo, em junho, a salinidade chegou a $7062 \mathrm{mmS} / \mathrm{cm}$, fato decorrente da forte evaporação neste período. O uso da cobertura permitiu manter a umidade do substrato $21 \%$ superior no período mais fresco e em $10 \%$ no período mais quente nos primeiros $5 \mathrm{~cm}$ de profundidade, e de 15 e $12 \%$ superior para a profundidade de 6-10 cm ,respectivamente em novembro e em junho. Quanto à temperatura, esta se manteve praticamente a mesma em ambos os tratamentos, sendo um pouco menor no substrato protegido, no período mais fresco, talvez por causa da maior quantidade de água retida, sendo que, para o período mais quente, ela aumentou mais no substrato coberto, talvez pela maior incidência solar sobre o plástico preto que absorve calor, mas de grandeza pouco relevante quanto aos efeitos gerais da cobertura.

Ao final dos 27 meses de cultivo, foi verificado que as roseiras, mantidas sem a cobertura com o plástico, tiveram seus sistemas radiculares maiores, tanto no cv Anna quanto para o cv Sari (Tabela 6). As raízes no substrato coberto estavam distribuídas de tal maneira a formar uma espécie de bulbo partindo do colo da planta em direção ao fundo, sendo a distribuição das raízes uniforme no perfil do substrato, e com raízes finas; já no caso das plantas das bancadas sem cobertura, as raízes que se formavam próximas do 
coleto eram de diâmetros bastante diferentes, em geral, em reduzido número e predominando raizes grossas que se dirigiam para as partes mais profundas do substrato e lá se ramificavam (Figura 8).

Tabela 5. Dados da temperatura máxima, salinidade e umidade do substrato, em bancadas com e sem cobertura do substrato com plástico. Dados coletados no quarto dia da fertirrigação, às 15 horas

\begin{tabular}{|l|c|c|c|c|c|}
\hline & \multicolumn{2}{|c|}{ Não protegido } & \multicolumn{2}{c|}{ Protegido } & $\begin{array}{c}\text { Temp. da } \\
\text { Estufa }\end{array}$ \\
\hline & $0-5$ & $6-10$ & $0-5$ & $6-10$ & \\
\hline Salinidade média a novembro $(\mathrm{mmS} / \mathrm{cm})$ & $3567 \pm 188$ & $3179 \pm 148$ & $1518 \pm 111$ & $1683 \pm 93$ & \\
\hline Salinidade média a junho $(\mathrm{mmS/cm})$ & $7062 \pm 578$ & $5362 \pm 267$ & $2076 \pm 125$ & $2877 \pm 146$ & \\
\hline Umidade média a novembro $(\% \mathrm{v} / \mathrm{v})$ & $15.7 \pm 0.97$ & $18.7 \pm 073$ & $19.9 \pm 0.66$ & $22.0 \pm 0.53$ & \\
\hline Umidade média a junho $(\% \mathrm{v} / \mathrm{v})$ & $12.9 \pm 1.63$ & $14.3 \pm 0.89$ & $14.4 \pm 0.69$ & $16.2 \pm 0.64$ & \\
\hline Temperatura média a novembro $\left({ }^{\circ} \mathrm{C}\right)$ & $25.1 \pm 0.22$ & $24.1 \pm 0.14$ & $23.5 \pm 0.11$ & $22.6 \pm 0.09$ & 26.0 \\
\hline Temperatura média a junho $\left({ }^{\circ} \mathrm{C}\right)$ & $32.6 \pm 0.24$ & $30.1 \pm 0.22$ & $33.3 \pm 0.12$ & $30.5 \pm 0.15$ & 34.7 \\
\hline
\end{tabular}

Média \pm desv. pad.

Tabela 6. Peso seco de raízes após vinte sete meses de cultivo hidropônico com e sem cobertura do substrato

\begin{tabular}{lcc}
\hline & \multicolumn{2}{c}{ Peso seco de raízes } \\
\cline { 2 - 3 } & Cv Anna & Cv Sari \\
\hline Coberto & $12.34 \mathrm{a}$ & $11.77 \mathrm{a}$ \\
Descoberto & $16.60 \mathrm{~b}$ & $14.16 \mathrm{~b}$ \\
\hline As médias nas colunas seguidas da mesma letra não diferem \\
significativamente entre elas (Teste de Tukey, $P=0.01$ )
\end{tabular}




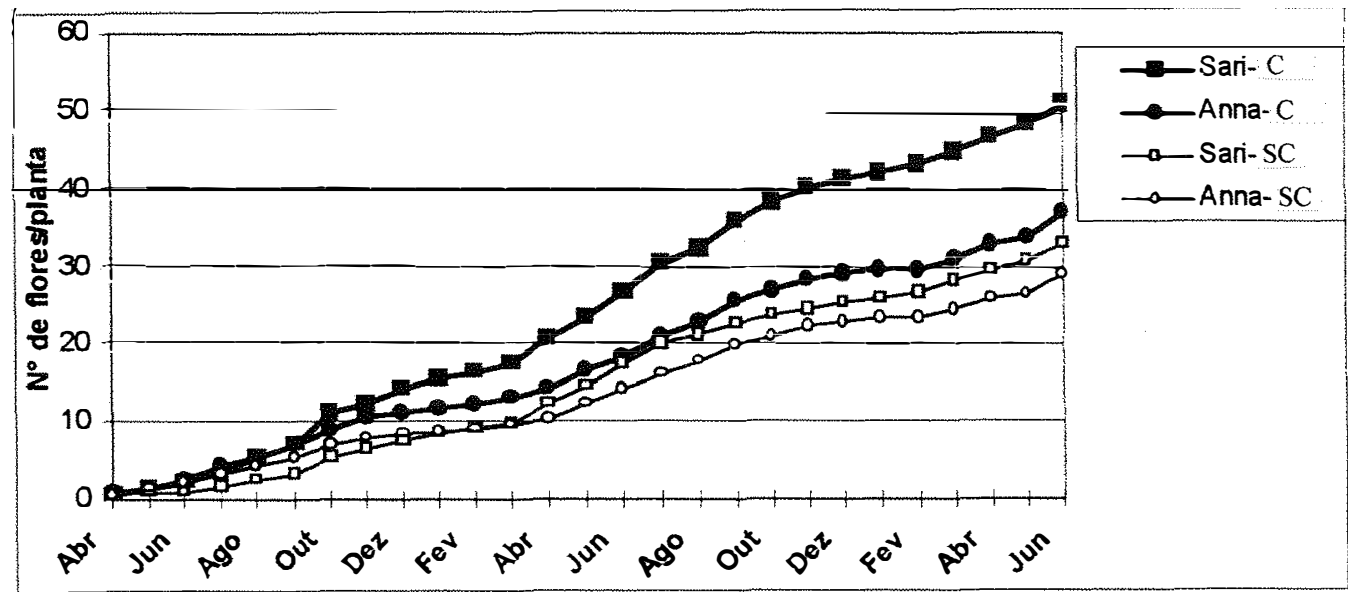

Figura 5 - Produção comercial acumulada ( ${ }^{\circ}$ de flores/planta), cvs Sari e Anna

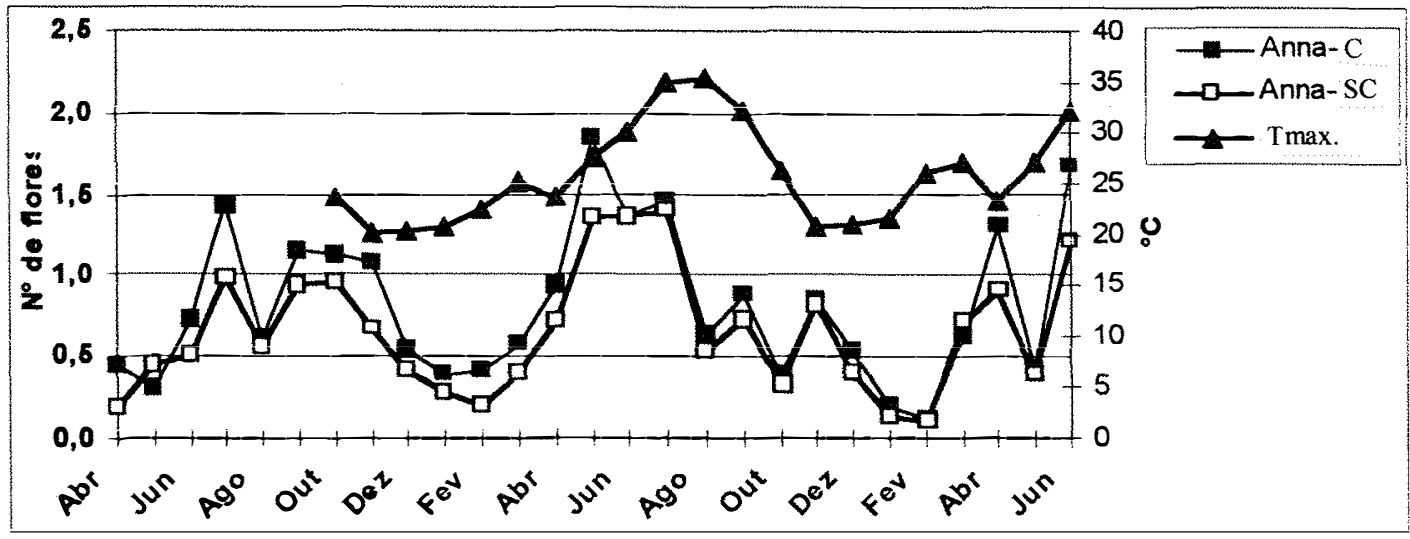

Figura 6 - Distribuição da produção de flores de 1 classe para a cv Anna com e sem cobertura e média da temperatura máxima, $C$ - coberto e $\mathrm{SC}$ - sem cobertura 


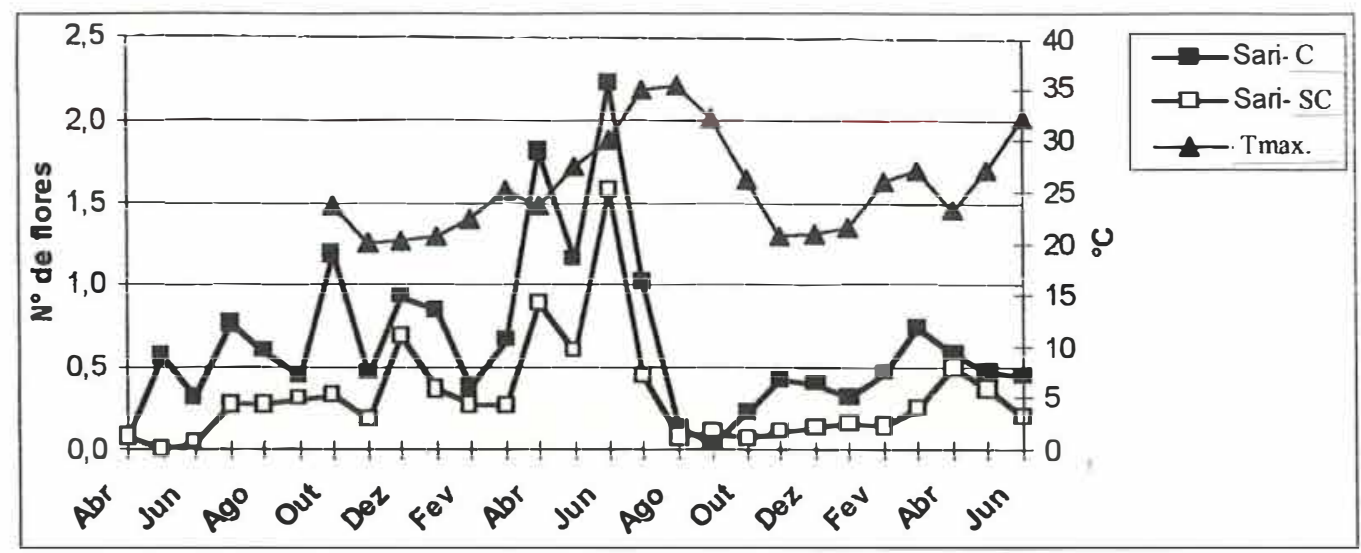

Figura 7 - Distribuição da produção de flores de I classe da cv Sari com e sem cobertura, e a média da temperatura máxima, C - coberto e SC sem cobertura

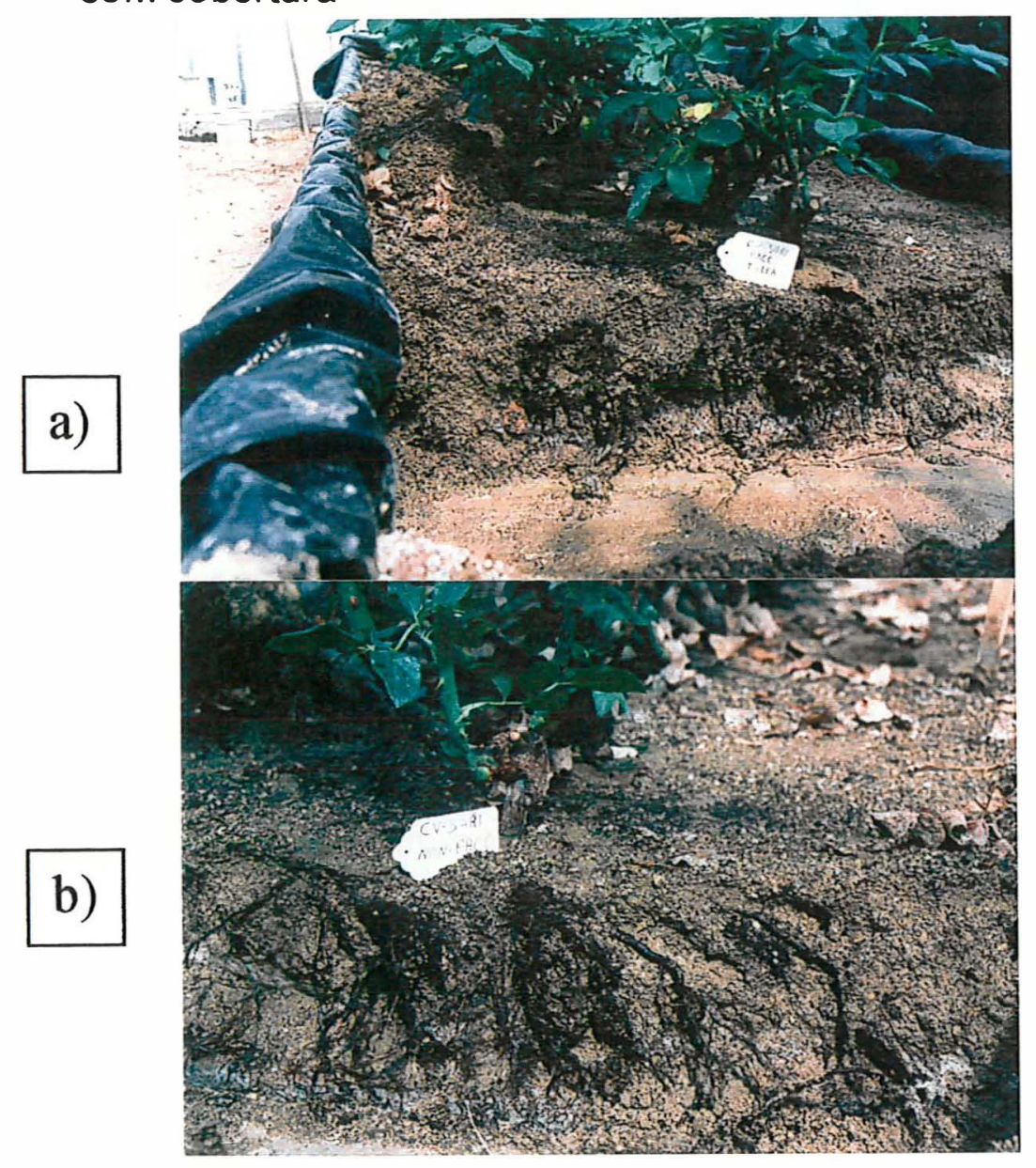

Figura 8 - Aspecto visual do sistema radicular com a) e sem b) cobertura do substrato 


\subsection{DISCUSSÃO}

Quando os elementos são retidos nos tecidos da planta ou se adiciona água, promove-se uma diluição e conseqüente redução da salinidade. Ao contrário, com a evaporação, concentra-se a solução e aumenta a salinidade. Este tipo de variação é mais acentuado no cultivo sem solo, em que a quantidade de água disponivel nos substratos artificiais normalmente é baixa. $O$ uso da cobertura do substrato permitiu uma redução das perdas de água por evaporação de até $35 \%$, perdas que acontecem sobre a superfície do substrato e elevam a salinidade a níveis não desejados para a cultura, freqüentemente.

Segundo De Kreij \& Van Den Berg (1990), a condutividade ideal estaria em torno de $1400 \mathrm{mmS} / \mathrm{cm}$ na solução fertirrigada, valores que correspondem a $2400 \mathrm{mmS} / \mathrm{cm}$ nos drenados. Segundo Brun \& Settembrino (1995), valores de salinidade da solução nutritiva superiores a $1800 \mathrm{mmS} / \mathrm{cm}$, para o cv Sonia, em lã de rocha, reduziram a produtividade. Por outro lado, Hughes \& Hanan (1978) verificaram perdas de produtividade do cv Forever Yours, a valores de salinidade da solução nutritiva de $1300 \mathrm{mmS} / \mathrm{cm}$, em condições da solução nutritiva desbalanceada. Ao contrário, Takeda \& Takahashi (1998) verificaram que para o cv Sonia, a produtividade era superior com soluções nutritivas de condutividade $2100 \mathrm{mmS} / \mathrm{cm}$, quando comparada a soluções mais diluídas. Sonneveld (1995) considera que os valores mais altos de salinidade para o tomate poderiam ser desejados para obter produtos de melhor qualidade, e que os valores máximos são variáveis com a cultura e também com o sistema de condução.

No presente experimento, foi adotada uma solução de $2100 \mathrm{mmS} / \mathrm{cm}$ nos períodos mais frios, e de $1400 \mathrm{mms} / \mathrm{cm}$ no verão e estipulada a salinidade máxima do drenado de $4000 \mathrm{mmS} / \mathrm{cm}$, método já comprovado por Farina et al. 
(1996), valores que podem corresponder a uma salinidade ainda mais alta no ambiente das raízes (Tabela 5), sendo observados valores de até 7000 $\mathrm{mmS} / \mathrm{cm}$, nas bancadas sem cobertura do substrato e valores inferiores a 3000 $\mathrm{mmS} / \mathrm{cm}$ para as bancadas com cobertura. O efeito da evaporação sobre a concentração da solução nutritiva é evidente nos meses de verão, mesmo porque, nos substratos não cobertos, a salinidade na parte superficial é maior por estar mais exposta a evaporação; já para o substrato coberto, o gradiente de concentração é o inverso. Portanto, o fato de se encontrar o sistema radicular mais desenvolvido no fundo da bancada é porque aí as condições são mais propícias ao seu desenvolvimento. Entretanto, não foram encontrados danos evidentes sobre as plantas, diferentemente de Bernsteins et al. (1972) que relatou desfolha e morte de roseiras, enxertadas sobre 'Dr. Huey', cultivado em solo irrigado com solução nutritiva com $4 \mathrm{~g} / \mathrm{L}$ de sais (salinidade no substrato saturado de $8500 \mathrm{mmS} / \mathrm{cm}$ ) e diferente de Hughes \& Hanan (1978) que verificaram sintomas de toxicidade como cloroses ou necroses folhiares $e$ também ramos mal formados. Isto pode ser explicado pela maior tolerância do porta-enxerto $R$. indica a salinidade.

$\mathrm{Da}$ análise do gradiente de salinidade no substrato $e$ do desenvolvimento relativo do sistema radicular, de tomate, sobre lã de rocha, com irrigação por gotejamento, foi verificado por Van Noordwjik \& Raats (1980) que nas zonas de maior salinidade não houve desenvolvimento de raízes. 0 gradiente de salinidade foi bastante acentuado tanto verticalmente quanto horizontalmente, não podendo ser confrontado com os obtidos neste trabalho que apresentou apenas um gradiente de salinidade vertical, visto que a distribuição da solução nutritiva foi mais homogênea sobre toda superfície com substrato.

Voltando, portanto, à situação que foi relatada, neste trabalho, em que as raizes se desenvolveram no sentido do fundo das bancadas, não cobertas com o filme plástico, pode-se dizer que este comportamento provavelmente tenha contribuído para diminuir o risco de toxicidade devido à alta salinidade, 
porque segundo Zeroni (1988), concentrações salinas, nos níveis obtidos neste trabalho, possuem efeitos potencialmente negativos sobre o crescimento das plantas, principalmente se somados à alta intensidade luminosa e baixa umidade relativa, condições semelhantes àquelas em que foram conduzidos neste experimento.

A composição química da solução no substrato resulta da diluição da solução contida no mesmo mais aquela da solução irrigada. Este resultado é variável segundo o volume administrado a cada intervento de fertirrigação. Portanto, nos períodos em que a evaporação está aumentando e a salinidade está chegando ao valor máximo estipulado, torna-se difícil baixar a salinidade utilizando este método de manejo, principalmente nas bancadas sem cobertura plástica que possuem maior taxa de evaporação. A diferença de evaporação encontrada nas bancadas cobertas é de grande importância, por resultar na manutenção da salinidade, em níveis próximos daqueles da solução irrigada, no ambiente das raizes, valores que corresponderam praticamente à metade da concentração salina encontrada nos substratos sem cobertura e, portanto, não permitindo efeitos danosos às plantas e mantêm a melhor qualidade e produtividade.

Os efeitos positivos da cobertura sobre a umidade do substrato estão demonstrados na Tabela 5. A cobertura do substrato possibilita melhores condições para o desenvolvimento e eficiência do sistema radicular das plantas e, consequentemente, para o crescimento e desenvolvimento da planta como um todo. É verdade que os níveis elevados de salinidade encontrados foram possibilitados pela baixa freqüência das fertirrigações, assim como é verdade, que para substratos mais permeáveis, como a pedra pome e a agriperlita, normalmente usados pelos floricultores, os processos de evaporação podem também assumir ritmos muito mais elevados que aqueles obtidos neste trabalho. Realmente, na prática, em tais substratos, a freqüência das fertirrigações, pode chegar a 10 interventos por dia, correspondendo à mesma realidade de estresse citada anteriormente, porém, conduzem a perdas 
importantíssimas de água e elementos nutritivos para o solo, com prejuízos ao nivel de custo e ainda problemas de impacto ambiental, no caso dos sistemas abertos.

No sistema aberto, é previsto um excesso na fertirrigação para permitir a renovação da solução contida no mesmo substrato, e também para abaixar a salinidade. Entretanto, nem sempre se conseguem os resultados esperados, isto acontece, segundo Van Noordwijk \& Raats (1980), porque a eficiência no reequilíbrio da solução no substrato depende tanto dos sistemas de distribuição de água sobre a superfície, como da distribuição dos orifícios para a drenagem, assim como da água contida inicialmente no mesmo substrato. Quanto mais uniforme a distribuição da água sobre a superfície do substrato, mais úmido estiver o substrato e também possuir os orifícios de dreno distribuídos fora das áreas de maior fluxo gravitacional da solução, maior eficiência e uniformidade serão obtidas no reequilíbrio da solução no substrato. No sistema usado nesta pesquisa, as fertirrigações foram feitas sobre a superfície total das arquibancadas, sistema que permitiria uma renovação por igual dos sais minerais. Portanto, as variações encontradas no substrato vem, seguramente, da retenção por parte das plantas e principalmente pela evaporação, que foi bastante alta (Tabela 1). Como nas bancadas com cobertura plástica a evaporação foi menor, pode haver dois sistemas interagindo, ajudando a manter a salinidade, seja a menor concentração de sais, pelo menor fornecimento de fertilizantes, assim como, a melhor eficiência no reequilíbrio da solução que permanece no substrato, fatores que refletiriam positivamente na eficiência de absorção dos elementos minerais, pelas raízes, e no desenvolvimento das plantas, reduzindo a quantidade de solução para reequilibrar a salinidade e, consequentemente, reduzindo o volume total do drenado. Como resultado, a menor distribuição de resíduos químicos poluentes ao meio ambiente. Portanto, a cobertura do substrato, em sistemas hidropônicos, deveria ser uma técnica adotada como prática agronômica para 
garantir as melhores condições nutricionais para a planta e racionalizar o uso de água e fertilizantes.

As formas para adotar a cobertura do substrato dependem essencialmente do tipo de sistema utilizado. De um lado, existem sistemas sobre os quais a cobertura já é prevista, como sobre a lã de rocha e NFT; por outro lado, há os sistemas com elevada densidade de plantas, sendo impossivel operacionalizar alguma coisa neste sentido. Fora esses dois casos extremos, existe uma infinidade de situações que podem ser pesquisadas soluções especificas. Uma solução particular foi, por exemplo, adotada para o sistema em canaleta a ciclo fechado (Farina et al., 1998).

Um outro efeito benéfico da cobertura do substrato com plástico preto sobre bancadas seria o aquecimento do substrato, em períodos frios e de baixa incidência de radiação. Segundo Zieslin \& Halevy (1975), algumas desordens fisiológicas que afetavam as plantas, como aborto de botões florais (hastes cegas) e flores mal formadas, resultam de insuficiente temperatura do ar e do solo. O uso da cobertura do solo com plástico pode ajudar na eficiência do crescimento da planta, em situações de baixa temperatura, com redução da variação térmica diária no substrato, já nos períodos mais quentes a temperatura do substrato poderá elevar-se acima de valores favoráveis as plantas.

A temperatura ideal no ambiente de raiz para a cultura da roseira, segundo Cooper (1979), é cerca de $19^{\circ} \mathrm{C}$, sendo que as temperaturas muito baixas nas raízes impedem a absorção dos elementos nutritivos e da própria água, provocando os fenômenos de amarelamento e envelhecimento das plantas, e no caso de temperaturas muito altas, superiores a $38^{\circ} \mathrm{C}$, no ambiente de raízes, provocam danos irremediáveis ao desenvolvimento do vegetal. Nesta linha de pesquisa, Ikeda \& Osawa (1980), pesquisando os efeitos da temperatura sobre a nutrição das plantas, verificaram que a concentração de $P$, $\mathrm{K}$, Ca e Mg, nas folhas de alface, aumentaram com o aumento da temperatura da solução nutritiva, em sistemas de cultivo NFT. Unger \& Danielson, (1967) 
foram quem comprovaram o aumento da absorção da água com o aumento da temperatura.

Mesmo que, no periodo de outono, o filme plástico tenha reduzido a temperatura do substrato, é importante observar que esta redução permitiu ainda manter a temperatura entre $22-23^{\circ} \mathrm{C}$, próximo aos $19^{\circ} \mathrm{C}$ que constitui a temperatura ideal para o sistema radicular da roseira. Entretanto, no verão, a cobertura com o plástico preto determinou aumentos de temperatura do substrato em relação ao controle. Tal aumento, mesmo que pequeno $\left(1.5^{\circ} \mathrm{C}\right)$, distancia-se ainda mais dos niveis ideais as culturais, os quais garantem as condições ótimas de crescimento em meios hidropônicos, como, por exemplo, $25^{\circ} \mathrm{C}$ para crisântemo (Moustafa \& Morgan, 1984), 25-30 $\mathrm{C}$ para alface (Mongeau \& Stewart, 1984), $<32^{\circ} \mathrm{C}$ per Cucumis sativus (Choi et al., 1995). Contudo, poderia ser levado em consideração a possibilidade de reduzir tal efeito de aquecimento com o uso de filmes de maior poder de reflexão da radiação, como, por exemplo, filmes plásticos de cor mais clara. Nos casos, em que se faz uso de sistemas fechados, com elevado número de fertirrigações durante 0 dia, a própria solução nutritiva pode ser suficiente para conter este aumento de temperatura.

\subsection{CONCLUSÃO}

Como resultado desta pesquisa, conclui-se que o uso da cobertura do substrato, no cultivo sem solo, promove melhoria na qualidade e produtividade de flores na cultura da rosa, com redução no consumo de água e também na quantidade de percolados, refletindo significativamente, ao nivel de custo de produção e mais importante ainda com ganhos para o meio ambiente, principalmente nos sistemas de cultivo abertos em que normalmente os percolados são dispersos sobre os terrenos. 


\section{REFERÊNCIAS BIBLIOGRÁFICAS}

ALT, D. Changes in the composition of the nutrient solution during plant growth - na important factor in soilless culture. In: INTERNATIONAL SOCIETY ON SOILESS CULTURE, 5, Wageningen, 1980. Proceedings. Wageningen: ISOSC, 1980. p. $97-109$.

ARNON, D.I. The investigation of plant nutrition by artificial cultur methods. Biology Review, v. 19, p. 55-67, 1944.

BAILLE, M.; BAILLE, A. DELMON, D. Microlimate and transpiration of greenhouse rose crop. Agricultural Forestry and Meterereology, v. 71, p. 83-97, 1994.

BARBOSA, J. G. Cultivo hidropônico de crisântemo 'yellow polares' em argila expandida para flor-de-corte. Porto Alegre, 1996. 102p. Tese (Doutorado) Faculdade de Agronomia, Universidade Federal do Rio Grande do Sul.

BELLIARD, J.L. Impianto di una coltura fuori suolo di rose. In: ATTI DEL CONVEGNO DI SANREMO SU ROSA FUORI SUOLO, Floriviera, 1996. Sanremo: Associazione Produttori Florovivaisti della Liguria, 1996. p. 11-19.

BERNSTEIN, L.; FRANCOIS, L.E.; CKARJ R.A. Salt tolerance of ornamental shrubs and ground clovers. Journal of the American Society for Horticultural Science, v. 97, n. 4 , p. $550-556,1972$. 
BLOEMHARD, C.M.J.; VAN MOOLENBROEK, J. Management of mineral elemnents of roses grown in closed rockwool systems. Acta Horticulturae, n. 401, p. 481-490, 1995.

BREDMOSE, N.; HANSEN, J. Influence of propagation material and method on regeneration, growth and flowering of cut rose cv. Frisco and Gabriella. Acta Horticulturae, v. 424, p. 23-28, 1995

BRUN, R.; SETTEMBRINO, A. Production and quality of rosa hybida cv. Sonia in rockwool at three levels of electrical conductivity conbined with two levels of relative humidity. Acta Horticulturae, n. 424, p. 115-117, 1995.

CABRERA, R.I.; EVANS, R.Y.; PAUL, J.L. Cyclic nitrogen uptake by greenhouse roses. Scientia Horticulturae, n. 63, p. 57-66, 1995 a.

CABRERA, R.I.; EVANS, R.Y.; PAUL, J.L. Nitrogen partitioning in rose plants over a flowering cycle. Scientia Horticulturae, n. 63, p. 67-76, 1995 b.

CHEN, Y.; GOTTESMAN, A.; AVIAD,T.; INBAR,Y. The use of bottom-ash-coalcinder amended with comost as a container medium in horticulture. Acta Horticulturae, n. 294, p. 173-181, 1991.

CHOI, K.J.; CHUNG, G.C.; CHOI, W.Y.; HAN, K.P. Effect of root zone temperature on the mineral composition of xylem sap, photosynthetic activity and transpiration in cucunber plants. Acta Horticulturae, n. 396, p. 161-166, 1995.

CHUNG, S. H.; SUIH, D.H.; HWANG, H.B.; KWON, J.R.; LEE, S.B.; CHOI, D.U. The effect of mulching materials and plant density on growth characteristics and yield of Angelica dahurica Benth. Upland \& Industrial Crops, v. 33, n.1, p. 71-76, 1991. 
COOPER, A.J. Crop production in recirculating nutrient solution. Scientia Horticulturae, n. 3, p. 251-258, 1979.

DE KREIJ, C.; VAN DEN BERG, TH. J. M. Nutrient uptake, production and quality of rose hybrida in rockwool as affected by electrical conductivity of the nutrient solution. Plant nutrition: physiology and applications. Kluwer: Kluwer Academic Publisers, 1990. p. 519-523.

DUCHEIN, M.; BAILLE, M.; BAILLE, A. Water use efficiency and nutrient consumption of a greenhouse rose crop grown in rockwool. Acta Horticulturae, n.408, p. 129-135, 1995.

FARINA, E.; CERVELLI,C. Growth and water requirements of carnation cultivated in raised benches. Acta Horticulturae, n. 361, p. 478-485, 1994.

FARINA, E.; PATERNIANI T.; PALAGI, M. Risultati nella gestione idrica in sistemi fuori suolo mediante il metodo di controllo della frazione di percolato. Floricoltura, v. 3, p. $17-19,1997$ b.

FARINA, E.; PATERNIANI, T.; PALAGI, M. Controllo della fertirrigazione su ornamentali fuori suolo. Colture Protette ,v. 1, p. 77-86, 1996.

FARINA, E.; PATERNIANI, T.; PALAGI, M. Un sistema a ricircolo per ornamentali fuori suolo. Colture Protette, v. 9, p. 67-72, 1997 a.

FARINA, E.; PERGOLA, G. Criteri pel la gestione della nutrizione in sistemi aperti di coltivazione fuori suolo e risultati su alcune specie floricole. Flortecnica, n. 6, p. 7277, 1995. 
FARINA, E.; RODRIGUES, E.J.R.; PATERNIANI, T.; PALAGI, M. Ricircolo prolungato in rosa fuori suolo a basso impiego di tecnologia. Colture Protette, n. 9, p....93-100, 1998.

FISCHER, P. Stability of various forms of chelated iron in nutrient solutions of different pH-values. In: INTERNATIONAL SOCIETY ON SOILESS CULTURE, 6, Lunteren, 1984. Proceedings. Lunteren: ISOSC, 1984. p. 225-233.

GABRIELS, R. E MENEVE, I. Nutritional requirements of roses grown in peat. Scientia Horticulturae. n. 1, p. 341-349, 1973.

GANMORE-NEUMANN, R. e KAFKAFI, U. The effect of root temperature and $\mathrm{NO}_{3}^{-}$/ $\mathrm{NH}_{4}{ }^{+}$ratio on strauberry plants. I. growth, flowering, and root development. Agronomy Journal, v. 75, p. 941-947. 1983.

GERICKE, W.F. The complete guide to soilless gardening. New York: Prentice-Hall. 1940. snp.

GRAAF, R. Influence of moisture deficit leaf-air and cultural practices on transpiration of glasshouse roses. Acta Horticulturae, n. 401, p. 545-552, 1995.

GUERIN, V.; LEMAIRE，F.; RIVIERE，L.M.; SINTES，G.; CHARPENTIER, S.; CHASSERIAUX, G. Gestion des apports hydriques et mineraux sur les cultures en conteneurs. PHM Revue Horticole, v. 356, p. 39-46, 1995.

HALEVY, A.H. Rose research: current situation and future needs. Acta Horticulturae, n. 189, p. 11-20, 1986.

HOFFMANN, M. Bullettin d' Information de l' Horticulture et de la Pepiniere Mediterraneennes. La France Horticole, v. 4, p. 12-17, 1991. 
HUGHES ED HANAN. Effect of salinity in qater supplies on greenhouse rose production. Journal of the American Society for Horticultural Science, v. 103, n. 5, p. 694-699, 1978.

IKEDA, H.; OSAWA T. Lettuce growth as influenced by $\mathrm{N}$ source and temperature of the nutrient solution. In: INTERNATIONAL SOCIETY ON SOILESS CULTURE, 5., Wageningen, 1980. Proceedings. Wageningen: ISOSC, 1980. p. 273-284.

JEANNEQUIN, B.; FABRE, R. Procede de culture hors-sol a circuit fermé. Etudes et perspectives. PHM Revue Horticole, v. 338, p. 21 -26, 1993.

KOOL, M.T.N; VAN DE POL, P.A. Long-term flower production of a rose crop.I. The influence of planting system and rootstock clone. Journal of Horticultural Science, v.71, n. 3, p. 435-443, 1996.

MATITSCHKA, G.; ERNST, M. Effect of mulch material on N-content in soil, N-uptke and growth and growth of lettuce. Gartenbauwissenschaft, v. 60, n. 6, p. 280-286, 1995.

MENGEL, K.; KIRKBY, E.A. Principles of plant nutrition. 4.ed. Bern: International Potash Institute, 1987. 687p.

MONGEAU, R.; STEWART, K.A. Effect of solution temperature on the growth and development of lettuce cv. Ostinata. . In: INTERNATIONAL SOCIETY ON SOILESS CULTURE, 6., Lunteren, 1984. Proceedings. Lunteren: ISOSC, 1984. p. 387-392.

MORISOT, A. La pelote ou conduite japonaise du risuer: moins de rendement, plus de qualité. PHM Revue Horticole, v. 386, p. 22-25, 1997. 
MOUSTAFA, A.T.; MORGAN, J.V. The effect of root zone warming and air temperature on dry matter accumulation, nutrient uptake and nutrient composition of spray chrysanthemum in NFT. In: INTERNATIONAL SOCIETY ON SOILESS CULTURE, 6., Lunteren, 1984. Proceedings. Lunteren: ISOSC, 1984. p. 401-420.

NIELSEN, P.E. Crop production in recirculanting nutrient solution according to the principles of regeneratiol. In: INTERNATIONAL CONGRESS ON SOLILESS CULTURE, 6., Lunteren, 1984. Proceedings. Lunteren: ISOSC, 1984. p. 421-446.

NOORDEGRAAF, C.V. Production and marketing of high quality plants. Acta Horticulturae, n. 353, p. 134-147, 1994.

PASKALEV, G. Studies on the effect of a conbined mulchin method on the establisment an growth of Kazanluk rose. Rasteniev" dni Nauki, v. 20, n. 2, p. 67-71, 1983.

PASKALEV, G.; TSACHEV, S. Investigations on rejuvenation of rose plantations mulched with polyethylene film. Rasteniev" dni Nauki, v. 19, n. 7, p. 36-39, 1982.

PICARD, M. Comparaison entre rosiers de boutures et rosiers greffes en culture de serres puor la production de fleurs coupees. La France Horticole, v. 213, p. 13-23, 1968.

RAVIV, M.; REUVENI, R.; KRASNOVSKY, A. E.; MEDINA, S.H. Recirculation of rose drainage water under semi-arid conditions. Acta Horticulturae, n. 401, p. 427433, 1995.

SCHUBERT, M. Manual práctico de hidrocultivo. Baracelon: Omega, 1981. 225p. 
SINGH, B. P.; CHITKARA, S. D. Effect of different levels of sodicity on chloropphyll content $(\mathrm{mg} / \mathrm{g})$ in leaves of various rose rootstocks. Haryana Journal of Horticultural Sciences, v.13, n.3/4, p. 91-94, 1984.

SONNEVELD, C. Fertirrigation in the greenhouse industy. $\mathbb{N}$ : DAHLIA GREIDINGER INTERNATIONAL SYMPOSIUM ON FERTIGATION, Technion, 1995. Procedings. Haifa: Israel Institute of Tecnology, 1995. p. 121-140.

SONNEVELD, C. A method for calculating the composition of nutrient solutions for soilless cultures. Naaldwijk: Glasshouse Crops Research Station, 1989. 70p (Voedingsopossingen glastuinbouw, 10).

SONNEVELD, C.; WELLES, G.W.H.. Yield and quality of rockwool-grown tomatoes as affected by variations in EC-value and climatic conditions. Plant and Soil, v. 111, p. 37-42. 1988.

STEINER, A. A. The history of mineral planta nutrition til about 1860 as sorce of tre origin of soilles culture methods. Soilless Culture, v. 1, n. 1, p. 7-23. 1985.

STEINER, A. The universal nutrient solution. In: INTERNATIONAL SOCIETY ON SOILESS CULTURE, 6., Lunteren, 1984. Lunteren: ISOSC, 1984. p. 633-649.

TAIZ, L.; ZAIZER, E. Plant physiology. Redwood:The Benjamin / Cummings Publ. 1991. 559p.

TAKEDA, T.; TAKAHASHI, K. Seasonal changes of macroelemtent absorption in solution cultured rose. Journal of the Japanese Society for Horticultural Science, v..67, n. 1, p. 116-122, 1998. 
UNGER, P.W.; DANIELSON, R.E. Water relation and growth of beans (Phaseolus vulgaris L.) as influenced by nutrient solution temperatures. Agronomy Journal, v. 59 , p. 143-146, 1967.

URBAN, I.; BRUN, R.; URBAN, L. Influencie of electrical conductivity, relative humidity and seasonal variations on the behaviour of cut roses produced in soilless culture. Acta Horticulturae, n. 408, p. 101-107, 1995a.

URBAN, I.; JAFFRIN, A.; BRUN,R. control of salinity in the rhizoaphere of plants grown in solilless media. Acta Horticulturae. n. 408 p. 73-81, 1995b.

VAN DE POL, P.A. Landbow universiteit ontwikkelt variant op stenten van rozen. Vakblad voor de Bloemisterij, v. 18, p. 35, 1993.

VAN NOORDWIJK, M.; RAATS, P.A.C. Drip and drainage systems for rockwool cultures in relation to accumulation an leaching of salts. IN: INTERNATIONAL SOCIETY ON SOILESS CULTURE, 5., Wageningen, 1980. Proceedings. Wageningen: ISOSC, 1980. p. 279-287.

VINCENZONI, A. Coltivazione senza terra, idroponiche e aeroponiche. 2.ed. Bologna: Agricole, 1989, 238p.

WILLUMSEN, J. Nutritional requirements of lettuce in water culture. In: INTERNATIONAL SOCIETY ON SOILESS CULTURE, 6., Lunteren, 1984. Proceedings. Lunteren: ISOSC, 1984. p. 777-791.

WITHROW, R.B.; BIEBEL, J.P. Nutrient solution methods of grenhouse crop produtction. Purdue: Purdue University Agricultural Experiment Station., 1943. (Circular 232) 
WU GENLANG; CAI WEIGUO. effects of mulching and irrigation on the salt movement in solil used for plantinga cut flower rose in greenhouse. Acta Agriculturae Zhejiangensis, v. 8, n. 1, p. 62-64, 1996.

ZERONI, M. Plant tolerance of salinity in greenhouses: physiologiacal and paractica considerations. Acta Horticulturae, n. 229, p. 55-71, 1988.

ZIESLIN, N.; HALEVY, A.H. Flower bud atrophy in Bacara roses: II. The effect of environmental factors. Scientia Horticulturae, v. 3, n. 4, p. 55-67, 1975. 